\title{
Towards restraint-free care for psychogeriatric nursing home residents
}

Citation for published version (APA):

Huizing, A. R. (2008). Towards restraint-free care for psychogeriatric nursing home residents. [Doctoral Thesis, Maastricht University]. Universiteit Maastricht. https://doi.org/10.26481/dis.20080314ah

Document status and date:

Published: 01/01/2008

DOI:

10.26481/dis.20080314ah

Document Version:

Publisher's PDF, also known as Version of record

\section{Please check the document version of this publication:}

- A submitted manuscript is the version of the article upon submission and before peer-review. There can be important differences between the submitted version and the official published version of record.

People interested in the research are advised to contact the author for the final version of the publication, or visit the DOI to the publisher's website.

- The final author version and the galley proof are versions of the publication after peer review.

- The final published version features the final layout of the paper including the volume, issue and page numbers.

Link to publication

\footnotetext{
General rights rights.

- You may freely distribute the URL identifying the publication in the public portal. please follow below link for the End User Agreement:

www.umlib.nl/taverne-license

Take down policy

If you believe that this document breaches copyright please contact us at:

repository@maastrichtuniversity.nl

providing details and we will investigate your claim.
}

Copyright and moral rights for the publications made accessible in the public portal are retained by the authors and/or other copyright owners and it is a condition of accessing publications that users recognise and abide by the legal requirements associated with these

- Users may download and print one copy of any publication from the public portal for the purpose of private study or research.

- You may not further distribute the material or use it for any profit-making activity or commercial gain

If the publication is distributed under the terms of Article $25 \mathrm{fa}$ of the Dutch Copyright Act, indicated by the "Taverne" license above, 


\section{Towards restraint-free care for psychogeriatric nursing home residents}


ISBN 978-90-9022540-1

(C) copyright A.R. Huizing, Maastricht 2008

Cover drawing by Frederika Scheuneman (inspired by a photograph made by Theo Giizen)

Lay-out and cover design by Hans en Inge Duimel

Printed by Drukkerij Duplica 


\title{
Towards restraint-free care for psychogeriatric nursing home residents
}

\author{
PROEFSCHRIFT
}

ter verkrijging van de graad van doctor

aan de Universiteit Maastricht,

op gezag van de Rector Magnificus,

Prof. mr. G.P.M.F. Mols,

volgens het besluit van het College van Decanen,

in het openbaar te verdedigen op

vrijdag 14 maart 2008 om 12.00 uur

door

Anna Rensche Huizing 


\section{Promotoren}

Prof. dr. J.P.H. Hamers

Prof. dr. M.P.F. Berger

\section{Beoordelingscommissie}

Prof. dr. G.I.J.M. Kempen (voorzitter)

Prof. dr. T. van Achterberg (UMC St. Radboud, Nijmegen)

Prof. dr. G. Meyer (Universität Bremen, Bremen)

Prof. dr. J.M.G.A. Schols

Prof. dr. G.A.M. Widdershoven

The studies presented in this thesis have been supported by grants from the MeanderGroep Zuid-Limburg, the Province of Limburg, the SWBV and the School for Public Health and Primary Care (CAPHRI), Maastricht University.

The printing of this thesis was financially supported by Pidebo Facilitair Project Partner, the Internationale Stichting Alzheimer Onderzoek and the section Nursing Science (Maastricht University). 


\section{Contents}

$\begin{array}{lll}\text { Chapter } 1 \quad \text { General Introduction } & 7\end{array}$

Chapter 2 Why do we use physical restraints in the elderly? 23

Chapter 3 Organisational determinants of the use of physical 37 restraints: a multilevel approach

Chapter 4 Short-term effects of an educational intervention on 55 physical restraint use: a cluster randomized trial

Chapter 5 A cluster-randomized trial of an educational 75 intervention to reduce the use of physical restraints with psychogeriatric nursing home residents

Chapter 6 Preventing the use of physical restraints with 95 residents newly admitted to psychogeriatric nursing home wards: a cluster-randomized trial

Chapter 7 General Discussion

Appendix Observational tool

Summary

Samenvatting

Dankwoord 



\section{Chapter 1}

\section{General Introduction}

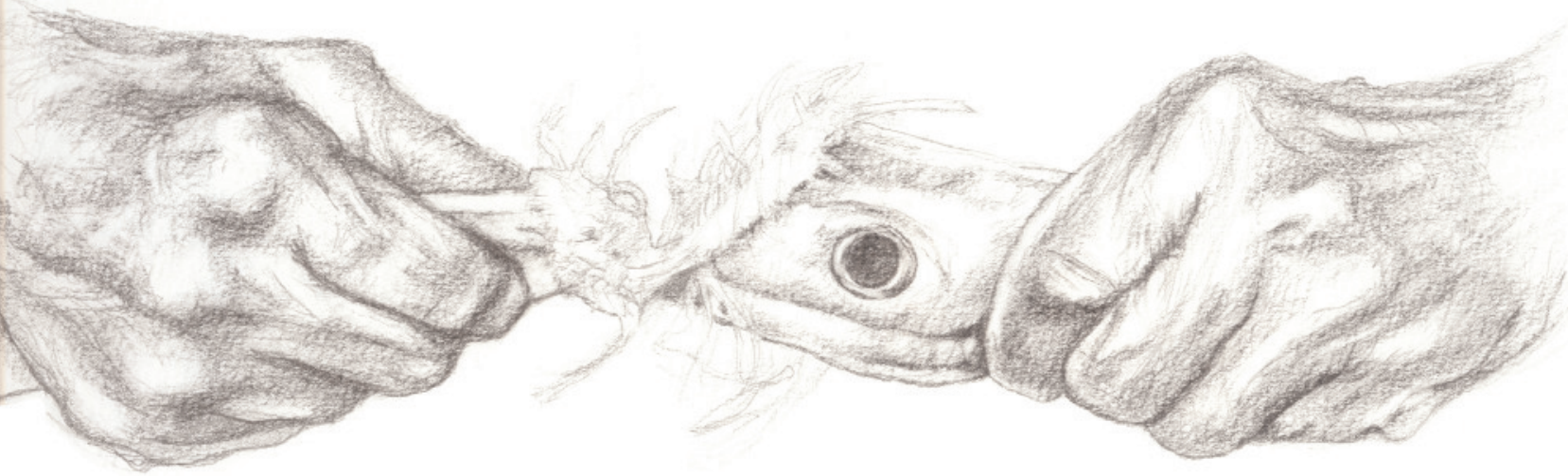




\section{Introduction}

The use of physical restraints is a common procedure in the care of psychogeriatric nursing home residents, with international prevalence values varying between $15 \%$ and $66 \% .^{1.3}$ The main determinants of the use of physical restraints are the characteristics of the nursing home residents, such as mobility and cognitive status. The relationship between the use of physical restraints and organizational characteristics still remains unclear. The most important reason for using physical restraints on nursing home residents is the prevention of falls and fall-related injuries. ${ }^{4,5}$ However, the effectiveness of physical restraint use for the prevention of falls and fall-related injuries has not been proven and restraint use has negative physical, psychological and social consequences for the residents. ${ }^{6.8}$ In recent years, the use of physical restraints in nursing homes has, therefore, often been under discussion in the research literature and in practice. Providing restraint-free care in nursing homes has often been strongly recommended in the literature. ${ }^{\text {e.g. } 9}$ The primary aim of this thesis is, therefore, to contribute to restraint-free care in psychogeriatric nursing home residents by answering the following three research questions:

- What is the current knowledge of the use of physical restraints on elderly people?

- What is the relationship between organizational characteristics (i.e., job and ward characteristics) and the use of physical restraints on psychogeriatric nursing home residents?

- What is the effectiveness of an educational intervention aimed at achieving restraint-free care for psychogeriatric nursing home residents?

In this chapter, a brief introduction to nursing home care in the Netherlands will be provided, followed by information about the use of physical restraints in psychogeriatric nursing home residents. Additionally, information about restraint-free care, including the development of the educational intervention, will be given. Finally, this chapter will end with the outline of this thesis.

\section{Nursing home care in the Netherlands}

In the Netherlands, about 2.2 million people (14\% of the total population) are aged 65 years or older. ${ }^{10}$ The number of elderly people is still on the increase, and in 2040 an estimated $25 \%$ of the total population will be aged 65 years or older. ${ }^{10}$ Of the current population aged 65 or older, approximately 50,000 persons live in nursing homes." In 2004, a total of 342 nursing homes with a capacity of 63,027 beds and 6,100 day-care facilities were counted in the 
Netherlands. ${ }^{12}$ Nursing homes are providing long-term care to very frail (mainly) elderly people with physical and/or psychogeriatric disorders. ${ }^{13}$ Although most of the nursing homes have both somatic wards and psychogeriatric wards, some only have one of these two types of wards. ${ }^{14}$ In 2004 , there were approximately 27,392 beds in somatic wards and 35,635 beds in psychogeriatric wards. ${ }^{15}$ The population of psychogeriatric residents mainly consists of residents with dementia $(85 \%) .{ }^{14}$

In nursing homes the care is provided by multidisciplinary teams, consisting of, for example, nursing home physicians, nurses, physiotherapists and psychologists. ${ }^{13}$ Within the nursing profession several qualification levels can be distinguished: registered nurses, care workers, care helpers and care assistants. ${ }^{16}$ The qualifications within the nursing profession decrease in complexity from registered nurses performing the most complex activities to care helpers and care assistants doing mainly routine and standard procedural work. ${ }^{16}$ In nursing homes most of the nurses are qualified as care workers. ${ }^{17}$ In this thesis the terms 'nurses', as well as 'nursing staff', are both used for the nursing profession.

\section{The use of physical restraints on psychogeriatric nursing home residents}

In this section information concerning the use of physical restraints on psychogeriatric nursing home residents will be reported. For a detailed overview concerning this topic, the reader is also referred to Chapter 2.

\section{Definition of physical restraints}

Based on the most typical definitions used in the literature ${ }^{\text {se }} 18$, physical restraints are defined in this thesis as 'any limitation on an individual's freedom of movement by using measures or equipments such as belts tied to a chair or bed, bilateral bedrails, chairs with tables, deep or overturned chairs, chairs on a board (a chair with chair legs fixed to a board), special sheets (a fitted sheet including a coat enclosing a mattress), sleep suits, tight sheets (a sheet over belly and upper legs that is tightened at both sides of a bed), sensor mats (including sensor strips in beds) and infrared systems'. This definition includes a wide variety of restraint types.

In the literature on physical restraints, the definitions of physical restraints include and exclude a heterogeneity in devices. ${ }^{19}$ For example, bedrails are not always categorized as a restraint type. Furthermore, some of the literature ${ }^{19,20}$ stresses that the reason for the use of a device is important in classifying a device as a restraint type. A broad definition of physical restraints was used in this thesis so as to emphasize that any limitation of an individual's freedom of movement can be harmful for psychogeriatric nursing home residents and must be considered thoroughly. 


\section{Legislation concerning the use of physical restraints in the Netherlands}

In the Netherlands the legal framework for the use of physical restraints in psychogeriatric nursing home wards consist of different legal acts, of which the Psychiatric Hospitals (Compulsory Admission) Act and the Medical Treatment Contracts Act are important ones. ${ }^{21,22}$ The use of restraints is only justified when specific conditions are met, such as the lack of suitable alternatives to restraint use and the presence or expectancy of danger. ${ }^{21}$ In the Netherlands the formal responsibility for the use of physical restraints in nursing homes lies with the nursing home physicians. ${ }^{21}$ However, the decision-making process in the use of physical restraints is a multidisciplinary matter ${ }^{21}$ in which nursing staff also play an important role both in the Netherlands ${ }^{23}$ and in other countries. ${ }^{24,25}$

\section{Prevalence of physical restraint use in nursing homes}

The prevalence of physical restraint use is high, varying between $15 \%$ and $66 \% .^{1.3}$ This implies that restraint use is common in nursing home care and that residents are confronted daily with the use of physical restraints on themselves and/or on their co-residents. In addition, physical restraints are often used for a long period of time, as is emphasized in a study of Hamers et al. ${ }^{2}$, where $90 \%$ of the restrained nursing home residents were restrained for more than three months and where these restraints were used as a routine measure.

\section{Determinants of the use of physical restraints}

The most important reason for using physical restraints on nursing home residents is for the prevention of falls and fall-related injuries among residents. ${ }^{4,5}$ The prevention of wandering, managing agitation and aggression, and the promotion of positional support are also reasons for the use of physical restraints. ${ }^{4,18}$

Many characteristics of elderly people, such as impairments in cognitive status and mobility, were found to be related to the use of physical restraints in the literature. e.9. 3,26 Furthermore, there were also indications that nurses' attitudes towards restraint use influenced the actual restraint use. ${ }^{25,27,28}$ However, the relationship between restraint use and organizational characteristics, such as the job characteristics of the nursing staff and ward characteristics, has been found to be less consistent in the research. In the opinion of different health care professionals, including nursing staff ${ }^{18}$, the use of restraints increases with an insufficient number of nursing staff. However, this relationship is not clearly described in the literature. . $6,27,29,30^{2}$

Thus, more insight into the determinants of restraint use is required to contribute to restraint-free care. In this respect it appears to be clear that the characteristics of elderly residents are important determinants for the use of 
physical restraints, and they therefore are considered to be important factors to bring into focus when providing restraint-free care. With regard to the relationship between restraint use and organizational characteristics, the research findings are less consistent. This being the case, it is not yet clear whether a focus on these factors will prove worthwhile in the effort to provide restraint-free care. The second research question in this thesis, therefore, will address the relationship between organizational characteristics and the use of physical restraints on psychogeriatric nursing home residents.

\section{Ineffectiveness and consequences of the use of physical restraints}

Several studies have shown that the use of physical restraints is ineffective and has several negative consequences.

Firstly, the use of physical restraints is based mainly on the assumption that restraints prevent falls and fall-related injuries. ${ }^{2,4,5}$ However, various studies conclude that the use of physical restraints is ineffective in preventing falls and fall-related injuries. ${ }^{1,8}$ The use of physical restraints does not lower the risk of falls or injuries in those residents likely to be restrained. ${ }^{7}$ In fact, several studies have shown that a decrease in restraint use did not result in an increase in fall incidence and serious fall-related injuries. . $^{6,31,32}$

Secondly, both prolonged and short periods of restraint use have negative physical, psychological and social consequences for nursing home residents. ${ }^{33,34}$ The use of restraints may cause immobility, incontinence, pressure ulcers, depression, agitation and aggression, and even may increase the risk of serious injury and death. ${ }^{34,35}$ In addition, physical restraints are in contradiction to the residents' right of freedom, autonomy and respect. ${ }^{9,36}$

Thirdly, the use of physical restraints also has consequences for nursing staff. Most nurses seem to have negative feelings about the use of physical restraints, although some of the nurses express no feelings or express feelings of security when using restraints. ${ }^{37}$ Furthermore, nursing staff experience conflicts between the desire to preserve residents' autonomy and the duty to ensure the safety of the residents. ${ }^{36}$

Finally, the use of physical restraints also has financial consequences. Phillips et al. ${ }^{38}$ have indicated that residents who are restrained require more nursing care than other residents, which implies that restrained residents are more costly to care for than unrestrained residents.

For a long time the use of physical restraints in the care of elderly people was regarded as useful. This is, however, paradoxical in view of the existing knowledge about the lack of effectiveness and the consequences for residents of restraint use. ${ }^{39}$ However, several entrenched beliefs, referred to as myths by Evans et al. ${ }^{5}$, still form the basis of the use of physical restraints in elderly 
people. Professionals rarely use the findings from research to determine or guide their actions, which is a factor also commonly described in the literature concerning evidence-based practice. ${ }^{40}$ Professionals seem to rely on less reliable indicators, such as prejudice and opinion, rather than on reliable research findings. ${ }^{40}$ Therefore, it is important to educate professional staff about the lack of effectiveness and about the consequences of the use of physical restraints. To this end, the educational intervention developed and tested in the studies presented in this thesis consisted of an educational programme for nursing staff, combined with the consultation of a nurse specialist (see Table 1). In view of the limited number of randomized clinical trials (RCT), and the lack of any RCT conducted in the Netherlands, an RCT was performed to examine the effectiveness of this educational intervention for Dutch psychogeriatric nursing home residents. The third research question in this thesis, therefore, will address the effectiveness of this educational intervention aimed at achieving restraint-free care for psychogeriatric nursing home residents.

\section{Restraint-free care}

\section{The transition to restraint-free care}

With the number of elderly people substantially increasing in the near future ${ }^{10}$, and consequently a growing number of elderly people with dementia as well, the use of physical restraints in psychogeriatric nursing homes becomes a major issue in health care. In recent years, the use of physical restraints in nursing homes, coupled with the quality of care in nursing homes, has been an important topic discussed in the research literature, in practice, and also in the Dutch media and political circles. Given the ineffectiveness and negative consequences of physical restraint use, restraint-free care for psychogeriatric nursing home residents is strongly recommended. At the same time reducing the use of physical restraints in nursing homes is a complex process. Strumpf et al. ${ }^{9}$ stated that the transition to restraint-free care involves a 'paradigm shift'. The view that behaviour is a problem that can be controlled with physical restraints has to be changed in a view that behaviour is a communication of health-state change or unmet needs. ${ }^{9}$ This process of change is and will be complex and slow $^{9}$, just like other processes of change in healthcare. ${ }^{42,43}$

\section{Initiatives to achieve restraint-free care}

Recently, restraint reduction programmes have been initiated in various kinds of health care settings. e.g. $32,44,45$ The review of Evans et al. ${ }^{46}$ on restraint reduction programmes in acute- and residential-care settings showed that these programmes mostly consisted of multiple activities in which restraint education was often the main component. 


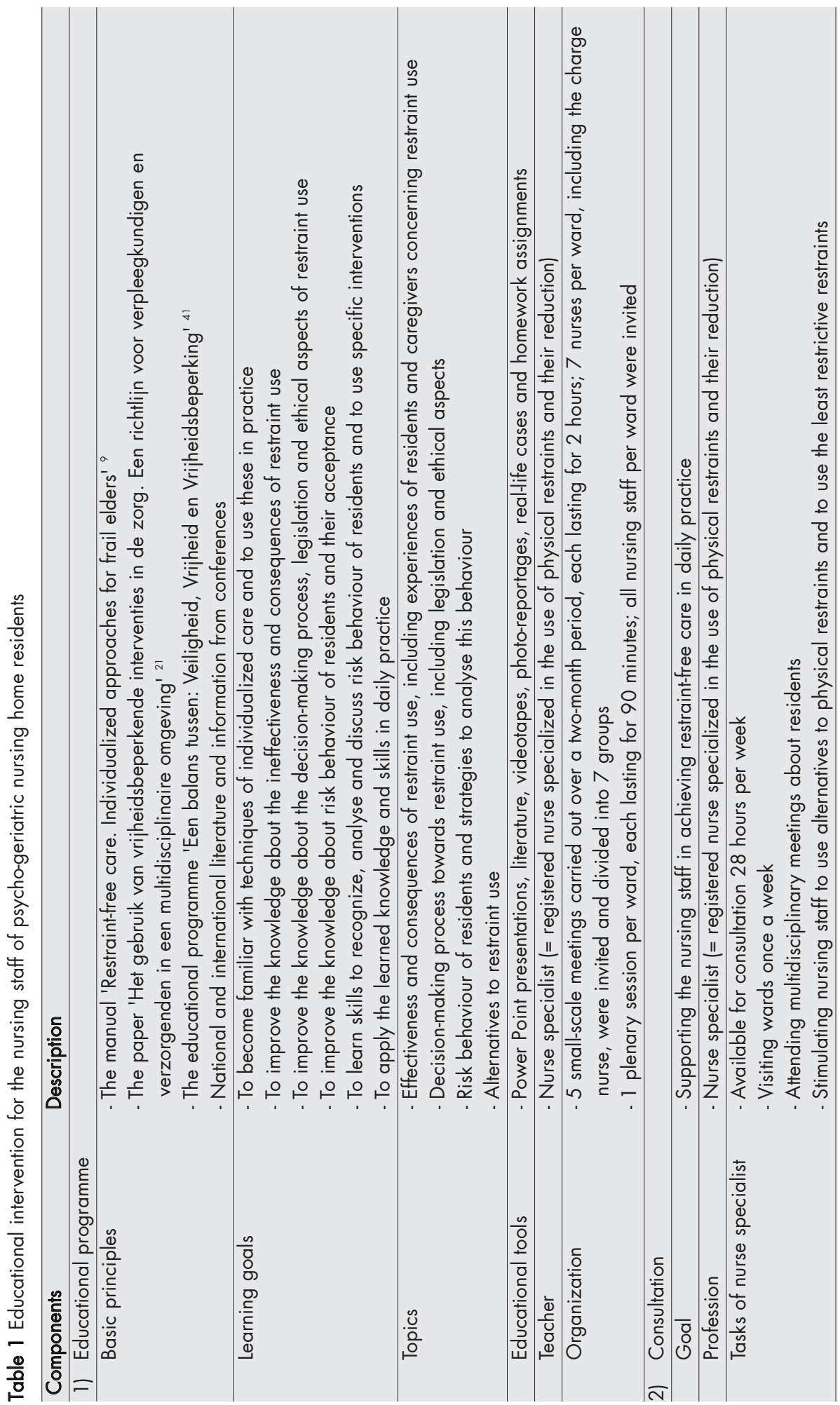


These restraint reduction programmes have been evaluated in several studies. Results have shown that these programmes were effective in reducing the use of physical restraints. ${ }^{\text {see review }}{ }^{46}$ Nevertheless, the effectiveness of these programmes was hardly ever tested by RCTs. At the beginning of the present study (2002) only one RCT had been performed to investigate the effectiveness of a restraint reduction programme in nursing homes. ${ }^{32}$ This trial concluded that a six-month educational programme combined with unit-based, residentcentred consultation reduced the use of physical restraints in US nursing homes effectively and safely. ${ }^{32}$

\section{Development of the educational intervention used in the present study}

The initiatives for research focusing on the use of physical restraints on psychogeriatric nursing home residents, as described in this thesis, were taken by a multidisciplinary group. This group consisted of health care professionals, including a registered nurse, a nursing home physician, management staff and other professions, from the MeanderGroep Zuid-Limburg, and researchers at Maastricht University, the Netherlands.

The educational intervention developed for this study consisted of 1) an educational programme for nursing staff and 2) consultation with a nurse specialist (see Table 1). The aim of the educational intervention was to reduce and prevent the use of physical restraints on psychogeriatric nursing home residents and was designed to encourage nursing staff in psychogeriatric nursing home wards to adopt a philosophy of restraint-free care and to familiarize themselves with the techniques of individualized care. ${ }^{\text {see } 9}$ As can be seen from Table 1, the educational programme was taught by the nurse specialist and carried out over a two-month period. Several topics concerning physical restraints were discussed in five small-scale meetings, each lasting two hours. Seven nurses per experimental ward, including the charge nurse, were invited to attend the meetings. A ninety-minute plenary session was organized for all the nursing staff of each experimental ward after the five small-scale meetings. During the trial period, the nurse specialist was available for consultation 28 hours per week, visited the wards once a week, attended multidisciplinary meetings about residents and stimulated nursing staff to use alternatives to physical restraints.

\section{Outline of the thesis}

Chapter 2 describes the results of a literature review on the use of physical restraints on elderly people. The literature review has been undertaken so as to present a clear overview of the current knowledge on the use of physical restraints on elderly people. 
Chapter 3 reports on a study that investigated the relationship between the use of physical restraints and organizational characteristics (i.e., perceived job characteristics of nursing staff and characteristics of nursing home wards). It was hypothesized that the use of physical restraints would be associated with impairments in residents, as well as with the perceived job characteristics of nursing staff and characteristics of the nursing home wards. A cross-sectional study design was used to gain insight into these hypothesized determinants for restraint use. Data from the baseline measurement of the cluster-randomized trial were used for this study.

Chapter 4, Chapter 5 and Chapter 6 report on the evaluation of the effectiveness of the educational intervention aimed at achieving restraint-free care with psychogeriatric nursing home residents. In a cluster-randomized trial applied to psycho-geriatric nursing home wards (the trial identification number is ISRCTN10117742), the effectiveness of the educational intervention on reducing and preventing restraint use was evaluated by comparing the educational intervention with usual care. A cluster-randomized trial is an RCT where the intervention is randomized to the clusters (in this study the wards). Data were collected at baseline and one, four and eight months postintervention. The study design is shown in Figure 1. The purpose of the study, described in Chapter 4, was to investigate the short-term effects of the educational intervention on the use of physical restraints on psychogeriatric nursing home residents. The effectiveness of this intervention on restraint reduction was then evaluated. Chapter 5 also presents the results of the effect evaluation of this educational intervention. It describes the effectiveness of the educational intervention in reducing the use of physical restraints at one, four and eight months postintervention. Chapter 6 describes the effectiveness of the educational intervention in preventing the use of physical restraints on residents newly admitted to psychogeriatric nursing home wards.

Chapter 7 contains a general discussion of the thesis on the main conclusions of this thesis, as well as some theoretical and methodological reflections. In addition, the implications of this study for research and practice will be presented here.

The Chapters 2 through 6 of this thesis have been published in or were submitted for publication to international journals. Therefore, there may be some overlap between the chapters regarding the description of the background and the design of the study. 


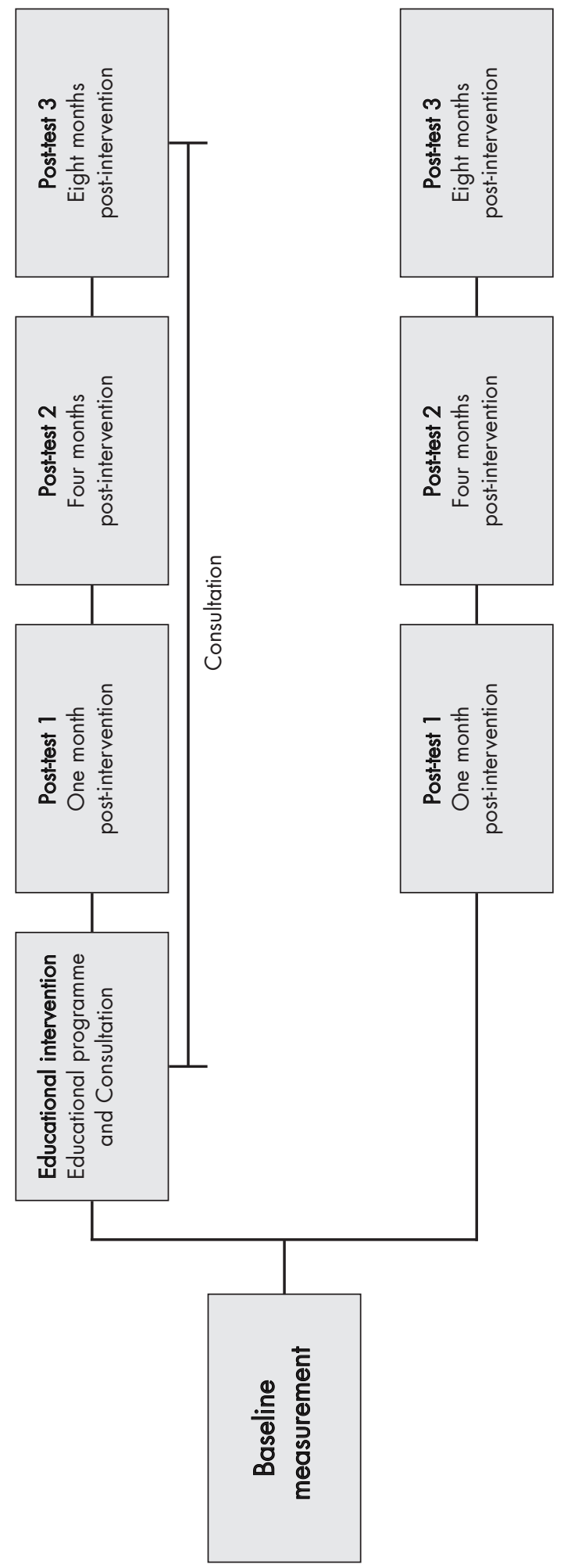

ํํㅇำ

즌즘

๖ํํㅇำ

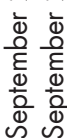

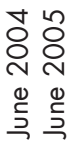

๖ั ญ

⿳ㅡㄴ

或

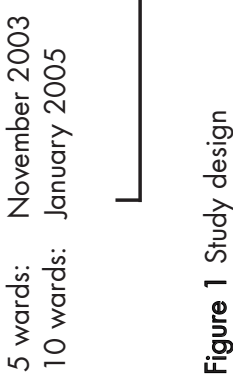




\section{References}

1. Capezuti E, Wagner LM, Brush BL, Boltz M, Renz S, Talerico KA.Consequences of an intervention to reduce restrictive side rail use in nursing homes. J Am Geriatr Soc 2007; 55:334-341.

2. Hamers JPH, Gulpers MM, Strik W. Use of physical restraints with cognitively impaired nursing home residents. Journal of Advanced Nursing 2004;45(3):246-251.

3. Karlsson S, Bucht G, Eriksson S, Sandman PO. Physical restraints in geriatric care in Sweden: prevalence and patient characteristics. J Am Geriatr Soc 1996;44(1 1):1348-1354.

4. Evans D, FitzGerald B. Reasons for physically restraining patients and residents: a systematic review and content analysis. Int J Nurs Stud 2002;39:735-743.

5. Evans LK, Strumpf NE. Myths about elder restraint. Image J Nurs Sch 1990;22(2):124-8.

6. Neufeld RR, Libow LS, Foley WJ, Dunbar JM, Cohen C, Breuer B. Restraint reduction reduces serious injuries among nursing home residents. J Am Geriatr Soc 1999;47(10):1202-1207.

7. Capezuti E, Evans L, Strumpf N, Maislin G. Physical restraint use and falls in nursing home residents. J Am Geriatr Soc 1996;44(6):627-633.

8. Evans D, Wood J, Lambert L. Patient injury and physical restraint devices: a systematic review. Journal of Advanced Nursing 2003;41 (3):274-282.

9. Strumpf NE, Robinson JP, Wagner JS, Evans LK. Restraint-free care; Individualized approaches for frail elders. New York: Springer Publishing Company, Inc, 1998.

10. Centraal Bureau voor de Statistiek. Gezondheid en zorg in cijfers 2006 (Health and health care in figures 2006). Voorburg / Heerlen: Statistics Netherlands (CBS), 2006.

11. De Klerk M. Ouderen in instellingen. Landelijk overzicht van de leefsituatie van oudere tehuisbewoners (Elderly people in residential care. A national overview of the living conditions of older residents). Den Haag: Social and Cultural Planning Office of the Netherlands (SCP), 2005.

12. Giesbers H. Aantal verpleeghuizen per gemeente 2004 (The number of nursing homes per municipality 2004). Volksgezondheid Toekomst Verkenning, Nationale Atlas Volksgezondheid (www.zorgatlas.nl). Bilthoven: RIVM, 2005.

13. Schols JMGA, Van der Schriek - Van Meel C. Day care for demented elderly in a dairy farm setting: positive first impressions. J Am Med Dir Assoc 2006;7:456-459.

14. Schols JMGA, Crebolder HFJM, Van Weel C. Nursing home and nursing home physician: the Dutch experience. J Am Med Dir Assoc 2004;5:207-212.

15. Mathijssen SW. Beschikbare capaciteit in materiaal en kapitaal (Available capacity in material and capital). Brancherapporten VWS (www.brancherapporten.minvws.nl). Den Haag:VWS, 2005.

16. MinVWS. Qualified for the Future. Coherent training system for nursing and patient care in the Netherlands: a summary. Zoetermeer: Ministry of Health, Welfare and Sport, 1997.

17. Van der Windt W, Calsbeek H, Talma H, Hingstman L. Feiten over verpleegkundige en verzorgende beroepen in Nederland 2003 (Facts about nursing professions in the Netherlands 2003). Utrecht: The Netherlands Centre for Excellence in Nursing (LEVV), 2003. 
18. Hantikainen V. Physical restraint: a descriptive study in Swiss nursing homes. Nursing Ethics 1998;5(4):330-346.

19. Dielis-van Houts AM, Lendemeijer BHGM, Hamers JPH. Op zoek naar een balans tussen: Veiligheid, Vrijheid en Vrijheidsbeperking. Een literatuuronderzoek naar het gebruik van vrijheidsbeperkende interventies in de zorg voor ouderen in zieken-huizen en verpleeghuizen (Finding the balance between safety, freedom and restraint use. A state-of-the-art study on the use of restraints on elderly people in hospitals and nursing homes). In: Jongerden I, HeijenKaales Y, eds. State of the Art Studie verpleging \& verzorging. Utrecht: LEVV, 2003:29-62.

20. Cohen C, Neufeld R, Dunbar J, Pflug L, Breuer B. Old problem, different approach: alternatives to physical restraints. J Gerontol Nurs 1996;22(2):23-29.

21. $C B O, V W R$. Het gebruik van vrijheidsbeperkende interventies in de zorg. Een richtlijn voor verpleegkundigen en verzorgenden in een multidisciplinaire omgeving (The use of restraints in care situations. A guideline for nurses in a multidisciplinary environment). Utrecht: Dutch Institute for Healthcare Improvement (CBO), 2001.

22. Arends LAP. Psychogeriatrische patiënt en recht. Zorg voor vrijheidsbeperking (Psychogeriatric patients and law. Care and restraining). Den Haag: Sdu vitgevers, 2005.

23. Hamers JPH, Van Wijmen FCB. Vrijheidsbeperking in de zorg: een verpleegkundige beslissing (The use of restraints in health care: a nursing decision). TvZ Tijdschrift voor Verpleegkundigen 2003(3):30-33.

24. Sullivan-Marx EM. Restraint-free care: how does a nurse decide? J Gerontol Nurs 1996;22(9):7-14.

25. Werner $P$, Mendelsson $G$. Nursing staff members' intentions to use physical restraints with older people: testing the theory of reasoned action. Journal of Advanced Nursing 2001;35(5):784-791.

26. Sullivan-Marx EM, Strumpf NE, Evans LK, Baumgarten M, Maislin G. Predictors of continued physical restraint use in nursing home residents following restraint reduction efforts. J Am Geriatr Soc 1999;47(3):342-348.

27. Karlsson S, Bucht G, Eriksson S, Sandman PO. Factors relating to the use of physical restraints in geriatric care settings. J Am Geriatr Soc 2001;49(12):1722-1728.

28. Weiner C, Tabak N, Bergman R. The use of physical restraints for patients suffering from dementia. Nurs Ethics 2003;10(5):512-525.

29. Castle NG, Fogel B, Mor V. Risk factors for physical restraint use in nursing homes: pre- and post-implementation of the nursing home reform act. Gerontologist 1997;37(6):737-747.

30. Phillips CD, Hawes C, Mor V, Fries BE, Morris JN, Nennstiel ME. Facility and area variation affecting the use of physical restraints in nursing homes. Medical Care 1996;34(11):114962.

31. Capezuti E, Strumpf NE, Evans LK, Grisso JA, Maislin G. The relationship between physical restraint removal and falls and inju-ries among nursing home residents. Journal of Gerontology: MEDICAL SCIENCES 1998;53A(1):M47-M52.

32. Evans LK, Strumpf NE, Allen-Taylor SL, Capezuti E, Maislin G, Jacobsen B. A clinical trial to reduce restraints in nursing homes. J Am Geriatr Soc 1997;45(6):675-681. 
33. Burton LC, German PS, Rovner BW, Brant L. Physical restraint use and cognitive decline among nursing home residents. J Am Geriatr Soc 1992;40(8):81 1-6.

34. Castle NG, Mor V. Physical restraints in nursing homes: a review of the literature since the nursing home reform act of 1987. Medical Care Research and Review 1998;55(2):139-170.

35. Miles SH, Irvine P. Deaths caused by physical restraints. The Gerontologist 1992;32(6):762766.

36. Weiner C, Tabak N, Bergman R. Use of restraints on dementia patients: an ethical dilemma of a nursing staff in Israel. JONA's Healthcare Law, Ethics, and Regulation 2003;5(4):87-93.

37. Chuang Y-H, Huang H-T. Nurses' feelings and thoughts about using physical restraints on hospitalized older patients. Journal of Clinical Nursing 2007; 16:486-494.

38. Phillips $C D$, Hawes $C$, Fries $B E$. Reducing the use of physical restraints in nursing homes: will it increase costs? American Journal of Public Health 1993;83(3):342-348.

39. Evans LK, Strumpf NE. Tying down the elderly. A review of the literature on physical restraint. JAGS 1989;37(1):65-74.

40. Trinder L. Introduction: the context of evidence-based practice. In: Trinder L, Reynolds S, eds. Evidence-based practice. A critical appraisal. Oxford: Blackwell Publishing, 2000.

41. Dielis-van Houts A, Schuurmans M. Een balans tussen: Veiligheid, Vrijheid en Vrijheidsbeperking (The balance between safety, freedom of movement and use of restraints). Utrecht, 2004.

42. Grol R, Wensing M, Eccles M. Improving Patient Care. The implementation of change in clinical practice. London: Elsevier, 2005.

43. Rogers EM. Diffusion of innovations. Fifth ed. New York: Free Press, 2003.

44. Mion LC, Fogel J, Sandhu S, et al. Outcomes following physical restraint reduction programs in two acute care hospitals. Jt Comm J Qual Improv 2001;27(1 1):605-618.

45. Testad I, Aasland AM, Aarsland D. The effect of staff training on the use of restraint in dementia: a single-blind randomised con-trolled trial. Int J Geriatr Psychiatry 2005;20(6):58790.

46. Evans D, Wood J, Lambert L. A review of physical restraint minimization in the acute and residential care settings. Journal of Advanced Nursing 2002;40(6):616-25. 
General Introduction 


\section{Chapter 2}

\section{Why do we use physical restraints in the elderly?}

Jan PH Hamers, Anna R Huizing

Published in Zeitschrift für Gerontologie und Geriatrie 2005;38(1):19-25

Reprinted with kind permission of Springer Science and Business Media. 


\section{Summary}

The use of physical restraints in the elderly is a common practice in many countries. This paper summarizes the current knowledge on the use of restraints in home care, hospitals and nursing homes. Between 1999-2004 reported prevalence numbers range from $41-64 \%$ in nursing homes and $33-68 \%$ in hospitals; numbers of restraint use in home care are unknown. Bedrails and belts have been reported as the most frequently used restraints in bed; chairs with a table and belts are the most frequently reported restraints in a chair.

It is evident that physical restraints in most cases are used as safety measures; the main reason is the prevention of falls. In the hospital setting, the safe use of medical devices is also an important reason for restraint use. Predictors for the use of physical restraints are poor mobility, impaired cognitive status and high dependency of the elderly patient and the falls risk in the nurses' opinion. Furthermore, there are indications that restraint use is related to organizational characteristics. Finally, many adverse effects of restraint use have been reported in the literature, like falls, pressure sores, depression, aggression, and death.

Because of the adverse effects of restraints and the growing evidence that physical restraints are no adequate measure for the prevention of falls, measures for the reduction of physical restraint are discussed and recommendations are made for future research. 


\section{Introduction}

Physical restraint can be defined as any limitation on an individual's freedom of movement using devices such as a geriatric chair with table, belts tied to a chair or a bed and bedrails.' The use of physical restraints in elderly during admission to acute and residential care facilities is a common practice in many countries like Australia, Ireland, Korea, the Netherlands, Sweden and the USA. ${ }^{1.8}$ There are also indications that restraints are used in home care ${ }^{9,10}$; however systematic research on the prevalence of restraint use in home care is lacking.

The use of physical restraint has received increasingly more attention from researchers, institutions and governments in the last few years. Questions have been raised about the reasons and effectiveness of the use of physical restraint, and the consequences for patients. In a qualitative study by Gallinagh and colleagues ${ }^{11}$, the majority of elderly patients who experienced restraints in an acute care hospital reported negative feelings about physical restraints, like discomfort and indifference. The question is: 'why do we use physical restraints in the elderly?' The relevance of this question is further stressed by the knowledge that the use of physical restraints may increase the risk of death, falls and serious injury. ${ }^{12,13}$

The purpose of this paper is to answer this question by summarizing the current knowledge on the use of restraints in the elderly. Therefore, the following research questions will be successively answered:

- What is the prevalence of restraint use in the elderly in home care, hospital and nursing home?

- Which factors are related to the use of physical restraints in the elderly?

- What are the consequences of the use of physical restraints in the elderly?

Finally, based on the results of the review of the literature we will discuss possibilities for the reduction of restraints in clinical practice.

\section{Methods}

To answer the research questions we reviewed relevant publications on the use of restraints in the elderly from 1990 until 2004, using Medline, CINAHL and PubMed using restraint(s), physical restraint(s) and mechanical restraint(s), as key words. The search was limited to nursing homes, hospitals, home care and elderly (and synonyms of these words). Furthermore, additional references were collected using reference lists. 


\section{Results}

\section{Prevalence}

The prevalence of restraint use reported in the literature, ranges between $15 \%{ }^{14}$ and $66 \%{ }^{15}$ in nursing homes and between $8 \%{ }^{16}$ and $68 \%{ }^{4}$ in hospital settings. Looking at the studies published most recently (from 1999 until 2004), the prevalence numbers range from $41-64 \% 8,17$ in nursing homes and $33-68 \%$ in hospitals. ${ }^{4,18}$ As far as we know, prevalence values of restraint use in home care situations are not available. However, a study by Bakker et al. ${ }^{9}$ in the Netherlands indicated that bedrails and belts are commonly used in home care. This finding has recently been confirmed in a qualitative study. ${ }^{10}$

Although the use of various modalities of physical restraints has been reported in the literature, bilateral and unilateral bedrails and belts have been reported as the most used restraints in bed. Chairs with a table and belts have been reported as the most frequently used restraints in a chair. e. $4,5,12$ Other measures reported are, for example, tipping chairs, blankets or sheets, vests, wrist and elbow restraints, and manipulation of furniture. e.9. 3,4,19

A study in Dutch nursing homes showed that $90 \%$ of the restrained elderly patients have been restraint for at least 3 months and that restraints were used as a routine measure. ${ }^{5}$ In other countries, especially the use of bedrails has been reported as a routine measure that translates to safe patient care ${ }^{20}$ These findings raise the question whether the use of restraints is irreversible and safe.

\section{Factors relating to the use of physical restraints}

Factors that are related to the use of restraints can be classified as reasons for the use of restraints, characteristics of the elderly, characteristics of health care organizations, nurses' attitudes en legislation. They will be discussed in succession.

\section{Reasons for the use of restraints}

Without doubt, the main reason to use physical restraints in health care is the prevention of falls. ${ }^{\text {e.g. } 2,5,21}$ Furthermore, it has been found that patients' falls-risk in the opinion of the nurse is a predictor of restraint use. ${ }^{5,22}$

In the hospital setting the protection of medical devices or the safe use of medical devices is also an important reason for restraint use. ${ }^{3,23}$ Other reasons are the prevention of wandering, the control of behaviours like aggression and restlessness, and the promotion of positional support. ${ }^{1-4,24}$

\section{Characteristics of the elderly}

In the literature e.9. 3.6,22,24 numerous characteristics of elderly patients have been related to the use of physical restraints, like gender, age, mobility, ADL 
performance, medical diagnoses, medical devices, psychosocial performance, care dependency, cognitive status, incidence of falls, psychoactive drug use and continence. Restrained elderly patients sometimes differed on these characteristics compared to unrestrained elderly. To illustrate, Choi \& Song ${ }^{3}$ found differences between the type of medical device and the use of restraints in the hospital setting (ICU); restraints were used more often in patients with a nasogastric tube. However, these results often are not replicated in other studies. Nevertheless, there is growing evidence that poor mobility, high dependency and impaired cognitive status are predictors for the use of physical restraints. ${ }^{2,4,5,22,25}$

\section{Characteristics of health care organizations}

With regard to the relationship between organizational characteristics and the use of physical restraints research findings are less consistent. It has been suggested that there is a relation between staff mix and the use of restraints; residents who received care from more experienced nurses had a lower risk to be restrained. ${ }^{22,26,27}$ Furthermore, Bourbonniere et al. ${ }^{26}$ found an increased likelihood of restraint use in weekend days. Finally, Castle and colleagues ${ }^{28}$ found that the number of FTE registered nurses (RN) per resident and occupancy rate were predictors for restraint use; nursing homes with high FTE RN's per resident and those with average occupancy were less likely to use restraints.

\section{Nurses' attitudes}

Different researchers ${ }^{\text {e.g. } 29,30}$ assume that nurses' attitudes have an influence on the use of physical restraints in clinical practice. Werner and Mendelsson ${ }^{31}$ concluded in a study among nurses working in an elder care hospital in Israel that attitudes were associated with the intention of nurses to use physical restraints. However, this finding was not confirmed in an Australian study; nurses' attitudes did not predict their self-reported use of restraints.

In a Swedish study ${ }^{29}$ on 33 nursing home ward and 12 group living units for older people with dementia, it was found that the nursing staff attitudes on the use of physical restraints were strongly associated towards their use in practice. Nurses working on 'restraint-free' wards were having more negative attitudes (were least prone to use restraints) towards restraint use than nurses working on 'high-use' wards.

\section{Legislation}

It is evident that legislation has a clear impact on the use of restraints in clinical practice. In some countries, like Denmark and Scotland, the use of restraints in 
the elderly is prohibited. As a result, these measures are hardly used in these countries. Furthermore, it is known from the USA that the introduction of new legislation (the Omnibus Budget Reconciliation Act (OBRA) in 1987 resulted in a strong decrease in the use of physical restraints to prevent falls in nursing homes. e.9. 27,32.34

Recently, in the USA, the Joint Commission on Accreditation of Healthcare Organizations (JCAHO) introduced standards for long-term care which: prohibit the use of restraints for purpose of discipline, staff convenience, or to prevent wandering; prohibit the use of restraints except to treat medical symptoms; and allow residents to refuse restraints. ${ }^{35}$ According to these standards (JCAHO standards for restraint and seclusion, as well as FDA alerts and guidelines based on the OBRA'87 regulation for nursing homes) ${ }^{36}$, restraints are used only if alternatives are ineffective or if absolutely required to ensure the safety of the resident, other residents or staff. ${ }^{35}$ Furthermore, these standards redefined restrictive bedrails use as restraints and are expected to lead to further decreases in bedrail use. ${ }^{2}$ However, new prevalence figures are not yet available.

\section{Consequences of the use of restraints}

The use of physical restraints has negative physical, psychological and social consequences for the elderly. Both prolonged and short period of physical restraint use had linked to poor physical, psychological and social functioning. . $^{513,25,33}$ In the literature $e^{\text {e.g. } 2,23,33}$ in addition to mortality, many physical and psychological consequences have been reported like falls, pressure sores, loss of muscle strength and endurance, joint contractures, problems with balance and coordination, incontinence, demoralization, humiliation feelings of low self worth, depression, aggression and impaired social functioning. Evans and colleagues ${ }^{12}$ conducted a systematic review on patient injury and physical restraint devices. The review highlighted the potential danger of using physical restraint in acute and residential health care facilities. The use of physical restraints, especially the use of vest restraints and bedrails, may increase the risk of death, serious injury and increased duration of hospitalization. However, the magnitude of the problem remains unclear. ${ }^{12}$ Although physical restraint often are used as a measure to prevent falls, Kron et al. ${ }^{37}$ found that the use of trunk restraints is a predictor of falls. Some studies investigated the experiences of restrained elderly. Minnick et al. ${ }^{38}$ concluded in a qualitative study that most of the patients $(n=15)$ in an ICU did not remember great distress specifically related to the use of restraints. However, in a qualitative study by Gallinagh and colleagues ${ }^{11}$ among 17 elderly patients who experienced restraints in an acute care hospital, the majority reported negative 
feelings about physical restraints, like discomfort and indifference. These findings are confirmed in a Dutch 'experiment ${ }^{15}$, in which four caregivers were voluntary restrained for 24 hours. These caregivers reported very unpleasant experiences, like the complete absence of privacy, freedom of movement and independency.

\section{Discussion}

Physical restraints are still highly prevalent in health care settings in many countries. Between 1999 and 2004 reported prevalence numbers range from $41-64 \%$ in nursing homes and $33-68 \%$ in hospitals. $2,4,8,18,23$ The variance in the prevalence numbers can be explained by the definition of physical restraints used by different researchers; in some studies, bedrails were excluded as a measure of physical restraints. Furthermore, different data collection methods (observation versus questionnaires) and different sample sizes undoubtedly add to the level of variance. Prevalence numbers of restraint use in home care are unknown and as a result, future research in home care is strongly recommended. In nursing homes and hospitals the most used restraints are belts (bed and chair), table (chair), and bedrails (bed). e.g. 4,5,12

It is evident that physical restraints in most cases are used as safety measures. $^{\text {e.g. } 2,5,21,39}$ In the hospital setting, the protection of medical devices and the safe use of medical devices, seem to be 'acute care-specific reasons.' However, overall (in acute and long term care) the main reason to use physical restraints is the prevention of falls and falls-related injuries. Clearly related to the main reason are the predictors for the use of restraints: the patient's poor mobility, impaired cognitive status and high dependency ${ }^{2,4,5,22,25}$, and the falls risk in the nurses' opinion. ${ }^{52}$

The last predictor suggests a key role of nurses in decision-making regarding the use of restraints, which has partly been confirmed in studies on nurses' attitudes and decision-making. ${ }^{39.42}$ It is therefore remarkable that, in a recent study on attitudes among 83 registered nurses who use physical restraints, only $18 \%$ of the nurses agreed with the proposition 'when I'm old and admitted to a nursing home, hopefully the nurse will decide to apply physical restraints when he/she thinks that this is appropriate' (Hamers and Huizing, in preparation). Knowing that decisionmaking is mainly based on individual's experiences ${ }^{39}$ and often is ambiguous ${ }^{43,44}$, the development of evidence-based guidelines to support decision-making regarding the (non)-use of physical restraints is highly recommended. These guidelines especially should focus on elderly 'at risk' for restraint use (e.g., elderly with poor mobility and impaired cognitive status).

Furthermore, there are indications that the use of restraints is related to 
organizational characteristics, like the number of nursing staff. ${ }^{22,26,28}$ However, more research is needed to investigate the influence of organizational characteristics on physical restraints.

Finally, it should be stressed that the use of physical restraints in the elderly

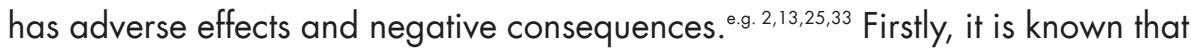
the use of restraints may increase the risk of death and serious injuries. Secondly, restraints often lead to a lot of negative physical and psychological consequences. It is remarkable that among reported negative consequences are 'falls' and 'problems with balance and coordination'. e.9. 2,37 Knowing that most restraints are used to prevent falls, a vicious circle has been created. Therefore it is questionable whether the use of physical restraint is an adequate measure to prevent falls.

There is growing evidence that reducing the number of physical restraints does not lead to an increased number of falls or fall-related injuries. ${ }^{8,33,45-48}$ This holds also true for the use of bedrails. ${ }^{17,20,49}$ Knowing that the use of physical restraints has been shown to be ineffective and sometimes even hazardous, the question is how to reduce the use of restraints?

\section{Reducing physical restraint use}

Reducing the use of physical restraint in health care is a complex process. According to Strumpf and colleagues ${ }^{36}$ a 'paradigm shift' in clinical practice regarding the interpretation and response to behaviour is necessary. Change in this standard of practice depends on breaking established myths and assumptions on the use of restraints. ${ }^{50} \mathrm{~A}$ philosophy of an individualized care approach for frail elders could be the key to understanding older adults and to providing restraint-free care. ${ }^{36}$ From this point of view, the use of restraints symbolizes a poor quality of care because of failure to address real needs of the person. ${ }^{36}$

To make the transition to restraint-free care, staff education on the use of restraints, consultation and alternative interventions should be offered. $2,8,36,47,51$ For instance, consultation by an Advanced Practice Nurse (APN) has been found to be important for changing practice and maintain change in nursing homes. ${ }^{52}$ Several studies ${ }^{17,47,53.55}$ demonstrated that restraint-reduction programs resulted in a decrease in the number of restraints in nursing homes in the USA. Evans and colleagues ${ }^{47}$ showed, for example, a decrease in restraints use without increased falls, falls-related injuries, and the use of psychoactive drugs. Currently, comparable studies on the effects of education and consultation by specialized nurses are ongoing in the Netherlands ${ }^{56}$ and Germany (C. Becker, personal communication, July 2004). The Dutch study employs a randomized clinical trial (400 elderly, 15 nursing home units) to examine the effect of an 
education program for nurses and a nurse specialist on the use of physical restraints in cognitively impaired nursing home residents.

Measures for falls prevention play an important role in restraint reduction programs. With regard to prevention of falls, numerous interventions have been suggested in the literature e.9. 20,49,57-60, like floor mats, hip protectors, position alarms, motion devices, anti-slip mats, height adjustable beds, bed next to wall and multi-factorial falls risk assessment and management programs. However, as Capezuti ${ }^{2}$ indicated, more research on the effects of alternative interventions for physical restraints is needed.

Finally, legislation seems an important measure in the reduction of restraints. When law prohibits the use of physical restraint to prevent falls, the prevalence of restraints will decrease. As already mentioned, this was demonstrated in the USA with the introduction of OBRA in 1987. e.9. 28,33 However, more than legislation is necessary to ensure good patient care. ${ }^{41}$ The challenge of clinicians and researchers still remains to find the ideal mix of interventions to expel the use of physical restraints from clinical practice.

\section{References}

1. Hantikainen V. Physical restraint: a descriptive study in Swiss nursing homes. Nursing Ethics 1998;5(4):330-346.

2. Capezuti E. Minimizing the use of restrictive devices in dementia patients at risk for falling. Nurs Clin N Am 2004;39:625-647.

3. Choi E, Song M. Physical restraint use in a Korean ICU. J Clin Nurs 2003;12(5):651-659.

4. Gallinagh $R$, Nevin R, Mc Iroy $D$, et al. The use of physical restraints as a safety measure in the care of older people in four rehabilitation wards: findings from an exploratory study. Int J Nurs Stud 2002;39(2):147-156.

5. Hamers JPH, Gulpers MM, Strik W. Use of physical restraints with cognitively impaired nursing home residents. Journal of Ad-vanced Nursing 2004;45(3):246-251.

6. Karlsson S, Bucht G, Eriksson S, Sandman PO. Physical restraints in geriatric care in Sweden: prevalence and patient characteristics. J Am Geriatr Soc 1996;44(1 1):1348-1354.

7. Meyers $H$, Nikoletti S, Hill A. Nurses' use of restraints and their attitudes toward restraint use and the elderly in an acute care set-ing. Nurs Health Sci 2001;3(1):29-34.

8. Neufeld RR, Libow LS, Foley WJ, Dunbar JM, Cohen C, Breuer B. Restraint reduction reduces serious injuries among nursing home residents. J Am Geriatr Soc 1999;47(10):1202-1207.

9. Bakker RH, Tiesinga L, Gassman P, Dassen TWN. Vrijheidsbeperkende maatregelen in niet BOPZ aangemerkte instellingen (Methods of restraint in health care settings and institutions in the Netherlands that do not fall under the law BOPZ). TSG 2002;80(7):455-462.

10. Huiberts $E M H$. Vrijheidsbeperking bij psychogeriatrische zorgvragers in de thuissituatie (The use of restraints on psychogeriatric patients in home care). Maastricht (unpublished master thesis): Universiteit Maastricht, 2004. 
11. Gallinagh R, Nevin R, McAleese L, Campbell L. Perceptions of older people who have experienced physical restraint. Br J Nurs 2001;10(13):852-859.

12. Evans $D$, Wood J, Lambert L. Patient injury and physical restraint devices: a systematic review. Journal of Advanced Nursing 2003;41 (3):274-282.

13. Miles SH, Irvine P. Deaths caused by physical restraints. The Gerontologist 1992;32(6):762766.

14. Retsas AP, Crabbe H. Use of physical restraints in nursing homes in New South Wales, Australia. Int J Nurs Stud 1998;35(3):177-183.

15. Tinetti ME, Lui WL, Marottoli MD, Ginter SF. Mechanical restraint use among residents of skilled nursing facilities. Prevalence, patterns and predictors. JAMA 1991;265(4):468-471.

16. Minnick AF, Mion LC, Leipzig R, Lamb K, Palmer RM. Prevalence and patterns of physical restraint use in the acute care setting. J Nurs Adm 1998;28(1 1):19-24.

17. Capezuti E, Maislin G, Strumpf N, Evans LK. Side rail use and bed-related fall outcomes among nursing home residents. J Am Geriatr Soc 2002;50(1):90-96.

18. Sullivan-Marx EM. Achieving restraint-free care of acutely confused older adults. Journal of Gerontological Nursing 2001;27(4):56-61.

19. Maccioli GA, Dorman T, Brown BR, et al. Clinical practice guidelines for the maintenance of patient physical safety in the intensive care unit: use of restraining therapies-American College of Critical Care Medicine Task Force 2001-2002. Crit Care Med 2003;31 (26652676).

20. Hoffman SB, Powell-Cope G, MacClellan L, Bero K. BedSAFE. A bed safety project for frail older adults. J Gerontol Nurs 2003;29(1 1):34-42.

21. Werner P. Perceptions regarding the use of physical restraints with elderly persons: comparison of Israeli health care nurses and social workers. Journal of Interprofessional Care 2002;16(1):59-68.

22. Sullivan-Marx EM, Strumpf NE, Evans LK, Baumgarten M, Maislin G. Predictors of continued physical restraint use in nursing home residents following restraint reduction efforts. J Am Geriatr Soc 1999;47(3):342-348.

23. Dielis-van Houts AM, Lendemeijer BHGM, Hamers JPH. Op zoek naar een balans tussen: Veiligheid, Vrijheid en Vrijheidsbeperking. Een literatuuronderzoek naar het gebruik van vrijheidsbeperkende interventies in de zorg voor ouderen in ziekenhuizen en verpleeghuizen (Finding the balance between safety, freedom and restraint use. A state-of-the-art study on the use of restraints with elderly people in hospitals and nursing homes). In: Jongerden I, HeijenKaales Y, eds. State of the Art Studie verpleging \& verzorging. Utrecht: LEVV, 2003: 29-62.

24. Ryden $M B$, Feldt $\mathrm{KS}, \mathrm{Oh} \mathrm{HL}$, et al. Relationships between aggressive behavior in cognitively impaired nursing home residents and use of restraints, psychoactive drugs, and secured units. Archives of Psychiatric Nursing 1999;13(4):170-178.

25. Burton LC, German PS, Rovner BW, Brant L, Clark RD. Mental illness and the use of restraints in nursing homes. The Gerontologist 1992;32(2):164-170.

26. Bourbonniere M, Strumpf NE, Evans LK, Maislin G. Organizational characteristics and 
restraint use for hospitalized nursing home residents. J Am Geriatr Soc 2003;51(8):10791084.

27. Castle NG. Nursing homes with persistent deficiency citations for physical restraint use. Med Care 2002;40(10):868-878.

28. Castle NG, Fogel B, Mor V. Risk factors for physical restraint use in nursing homes: pre- and post-implementation of the nursing home reform act. Gerontologist 1997;37(6):737-747.

29. Karlsson S, Bucht G, Eriksson S, Sandman PO. Factors relating to the use of physical restraints in geriatric care settings. J Am Geriatr Soc 2001;49(12):1722-1728.

30. Weiner C, Tabak N, Bergman R. The use of physical restraints for patients suffering from dementia. Nurs Ethics 2003;10(5):512-525.

31. Werner $P$, Mendelsson $G$. Nursing staff members' intentions to use physical restraints with older people: testing the theory of reasoned action. Journal of Advanced Nursing 2001;35(5):784-791.

32. Bower FL, McCullough CS, Timmons ME. A synthesis of what we know about the use of physical restraints and seclusion with patients in psychiatric and acute care settings: 2003 update. Online J Know Synth Nurs 2003;10(1):1-46.

33. Castle NG, Mor V. Physical restraints in nursing homes: a review of the literature since the nursing home reform act of 1987. Medical Care Research and Review 1998;55(2):139-170.

34. Dunn KS. The effect of physical restraints on fall rates in older adults who are institutionalized. J Gerontol Nurs $2001 ; 27(10): 40-48$.

35. Dimant J. Avoiding physical restraints in long-term care facilities. J Am Med Dir Assoc 2003;4(4):207-215.

36. Strumpf NE, Robinson JP, Wagner JS, Evans LK. Restraint-free care; Individualized approaches for frail elders. New York: Springer Publishing Company, Inc, 1998.

37. Kron M, Loy S, Sturm E, Nikolaus T, Becker C. Risk indicators for falls in institutionalized frail elderly. Am J Epidemiol 2003;158(7):645-653.

38. Minnick A, Leipzig RM, Johnson ME. Elderly patients' reports of physical restraint experiences in intensive care units. Am J Crit Care 2001;10(3):168-171.

39. Ludwick R, O'Toole AW. The confused patient: nurses' knowledge and interventions. Journal of Gerontological Nursing 1996;22(1):44-49.

40. Hamers JPH, Van Wijmen FCB. Vrijheidsbeperking in de zorg: een verpleegkundige beslissing (The use of restraints in health care: a nursing decision). TvZ Tijdschrift voor Verpleegkundigen 2003(3):30-33.

41. Ludwick R, O'Toole R, O'Toole AW, Webster S. Measuring judgments of professionals: using vignettes in a social survey about patient confusion. J Clin Geropsych 1999;5:177-189.

42. Sullivan-Marx EM. Restraint-free care: how does a nurse decide? J Gerontol Nurs 1996;22(9):7-14.

43. Hamers JPH, Huijer Abu Saad H, Halfens RJG. Diagnostic process and decision making in nursing: a literature review. Journal of Professional Nursing 1994;10(3):154-163.

44. Hamers JPH, Huijer Abu Saad H, Van den Hout MA, Halfens RJG. The influence of childrens' 
vocal expressions, age, medical diagnosis and information obtained from parents, on nurses' pain assessments and interventions. Pain 1996;65(1):53-61.

45. Capezuti E, Evans L, Strumpf N, Maislin G. Physical restraint use and falls in nursing home residents. J Am Geriatr Soc 1996;44(6):627-633.

46. Capezuti E, Strumpf NE, Evans LK, Grisso JA, Maislin G. The relationship between physical restraint removal and falls and injuries among nursing home residents. Journal of Gerontology: MEDICAL SCIENCES 1998;53A(1):M47-M52.

47. Evans LK, Strumpf NE, Allen-Taylor SL, Capezuti E, Maislin G, Jacobsen B. A clinical trial to reduce restraints in nursing homes. J Am Geriatr Soc 1997;45(6):675-681.

48. Ejaz FK, Jones JA, Rose MS. Falls among nursing home residents: an examination of incident reports before and after restraint reduction programs. J Am Geriatr Soc 1994;42(9):960-964.

49. Capezuti E, Talerico KA, Cochran I, Becker H, Strumpf N, Evans L. Individualized interventions to prevent bed-related falls and reduce siderail use. J Gerontol Nurs 1999;25(1 1):26-34; quiz 52-53.

50. Blakeslee JA, Goldman BD, Papougenis D, Torell CA. Making the transition to restraint-free care. J Gerontol Nurs 1991;17(2):4-8.

51. Koch S, Lyon C, Lyon KS. Case study approach to removing physical restraint. Int J Nurs Pract 2001;7(3):156-161.

52. Patterson JE, Strumpf NE, Evans LK. Nursing consultation to reduce restraints in a nursing home. Clin Nurse Spec 1995;9(4):231-235.

53. Mion LC, Fogel J, Sandhu S, et al. Outcomes following physical restraint reduction programs in two acute care hospitals. Jt Comm J Qual Improv 2001;27(1 1):605-618.

54. Smith NH, Timms J, Parker VG, Reimels EM, Hamlin A. The impact of education on the use of physical restraints in the acute care setting. J Contin Educ Nurs 2003;34(1):26-33; quiz 4647.

55. Sundel M, Garrett RM, Horn RD. Restraint reduction in a nursing home and its impact on employee attitudes. J Am Geriatr Soc 1994;42(4):381-387.

56. Huizing AR, Hamers JPH, Berger MPF, et al. Het verminderen van fixaties bij psychogeriatrische verpleeghuisbewoners (The reduction of physical restraints on psychogeriatric nursing home residents). Verpleegkunde 2003;18(4):244-245.

57. Becker $C$, Kron $M$, Lindemann $U$, et al. Effectiveness of a multifaceted intervention on falls in nursing home residents. J Am Geriatr Soc 2003;51(3):306-313.

58. Chang JT, Morton SC, Rubenstein LZ, et al. Interventions for the prevention of falls in older adults: systematic review and meta-analysis of randomised clinical trials. BMJ 2004;328(7441):680.

59. Freeman MA. Motion device: an alternative to physical restraints. Geriatr Nurs 2004;25(3): 175 .

60. Talerico KA, Capezuti E. Myths and facts about side rails. Am J Nurs 2001;101 (7):43-48. 
A review of the literature 


\section{Chapter 3}

\section{Organisational determinants of the use of physical restraints: a multilevel approach}

Anna R Huizing, Jan PH Hamers, Jan de Jonge, Math Candel and Martijn PF Berger

Published in Social Science \& Medicine 2007;65(5):924-933

Reprinted with kind permission from Elsevier. 


\section{Abstract}

This paper reports a study of the relationship between the use of physical restraints with psychogeriatric nursing home residents and the characteristics of organisations and residents. It is hypothesized that impairment in residents and organisational characteristics, such as a high workload of nursing staff and a low full-time equivalent (FTE) ratio on the wards, are associated with increased restraint use.

In a cross-sectional study involving 15 Dutch psychogeriatric nursing home wards, 432 residents were selected for participation, of which 371 actually participated. Restraint status was measured using observations. Other resident characteristics, such as cognitive status, were determined using the Minimum Data Set (MDS). Job characteristics, such as workload, were determined by different self-reported measures. Characteristics of the wards, such as the FTE ratio, were derived from the registration system of the wards.

Physical restraints were used with $56 \%$ of the psychogeriatric nursing home residents. Bivariate analysis showed that job and ward characteristics were not associated with restraint use. Bivariate and multilevel analysis showed that residents' characteristics, such as mobility and cognitive status were significantly associated with restraint use. Furthermore, multilevel analysis showed that higher job autonomy experienced by nursing staff and a higher FTE ratio on the wards were also associated with increased restraint use.

In conclusion, job and ward characteristics were not as strongly associated as residents' characteristics with restraint use. Impairments in residents, such as immobility, were strongly related to the use of restraints. Therefore, education and support of nursing staff in caring for psychogeriatric nursing home residents with poor mobility is recommended to reduce the use of physical restraints in nursing homes. 


\section{Introduction}

The use of physical restraints in nursing homes has often been under discussion in recent years. Physical restraints are frequently used with nursing home residents although the effectiveness of these methods has not been proved. ${ }^{1.3}$ Restraint use also has negative physical, psychological and social consequences for nursing home residents. ${ }^{46}$ Restraint reduction programmes have been initiated recently to reduce the use of physical restraints in different kinds of health care settings. ${ }^{7.9}$ Insight into predictors of restraint use is necessary to engage the discussions and to improve programmes for restraint reduction. ${ }^{10,11}$ Residents' characteristics, such as impairment in cognitive status, self-performance in activities of daily living (ADL status) and mobility, are highly associated with re-straint use with nursing home residents. ${ }^{12,13}$ There are also indications that nurses' attitude influence the use of physical restraints. ${ }^{14.16}$ However, consistent associations between restraint use and organisational characteristics, such as job characteristics and characteristics of nursing home wards, have not been found yet.

Perceived job characteristics, such as workload, job autonomy and social support, are key variables in prominent theoretical frameworks about work stress.cf. ${ }^{17}$ Theoretical frameworks, such as the Demand-Control (DC) model ${ }^{18}$ and its extension, the Demand-Control-Support (DCS) model ${ }^{19}$, provide insight into the relations between these job characteristics and employees' health and well-being. These associations have been proven by numerous empirical studies.cf. ${ }^{20,21}$ More specifically, results showed that high workload, low job autonomy and low social support are related to poor health and well-being. However, the relation of these job characteristics with employees' work activities, such as the use of physical restraints, have been scarcely reported in research.

In the opinion of different health care professions, the use of restraints increases with an insufficient number of nursing staff. This especially concerns to nursing staff. ${ }^{22}$ However, the relations between ward characteristics and restraint use described in the literature are less consistent. ${ }^{5,10-12,14}$ Castle et al. ${ }^{10}$ showed that institutions with high full-time equivalent (FTE) registered nurses (RNs) per resident and those with high average occupancy were less likely to use restraints. However, Sullivan-Marx et al. ${ }^{12}$ reported no associations between institutional factors, such as nursing hours and staff mix, and restraint use.

It is important to study the relation between job and ward characteristics and the use of physical restraints with psychogeriatric nursing home residents. Reason for this is that the number of elderly people with dementia will increase substantially in the near future, while the number of nursing staff is not likely to 
increase or may even decrease as a result of a decreasing working population. ${ }^{23}$ Furthermore, insight into the relation between restraint use and characteristics of residents, job and wards, will significantly contribute to restraint reduction by improving the development of restraint reduction programmes. Restraint reduction programmes will, therefore, be more efficient by focussing on the important themes for restraint reduction.

The aim of this study is to investigate the relation between organisational characteristics (i.e., job and ward characteristics) and the use of physical restraints with psychogeriatric nursing home residents. All determinants included in this research are shown in Table 1. As can be seen in this table, impairment in residents, as well as job and ward characteristics are all determinants of restraint use. More specifically, the following three hypotheses are derived:

Hypothesis 1: Restraint use is positively associated with impairment in cognitive status, ADL status and mobility.

Hypothesis 2: Restraint use is positively related to high workload, low job autonomy and low social support experienced by nursing staff.

Hypothesis 3: Restraint use is positively associated with a low FTE ratio, a low percentage of RNs and a high rate of sickness absence on the wards.

Table 1 List of determinants of the use of physical restraints

\section{Characteristics of psychogeriatric nursing home residents}

- Age (in years)

- Gender (male or female)

- Cognitive status (based on the Cognitive Performance Scale)

- ADL status (based on the MDS ADL Self-performance Hierarchy)

- Mobility (based on seven Minimum Data Set items)

\section{Job characteristics of nursing staff}

- Workload (the extent to which nursing staff per ward experienced workload)

- Job autonomy (the extent to which nursing staff per ward had opportunities to determine a variety of task elements)

- Social support (the extent to which nursing staff per ward experienced instrumental and/or emotional support from colleagues and supervisors)

\section{Characteristics of psychogeriatric nursing home wards}

- FTE ratio (the number of nursing staff FTE per resident per ward during one month)

- Percentage of registered nurse (the percentage of registered nurses per ward for one month as a portion of the total ward nursing staff in that month)

- Sickness absence (the percentage of sickness of nursing staff per ward during one month) 


\section{Methods}

\section{Design and sample}

Data were obtained in a cross-sectional design involving 15 Dutch psychogeriatric nursing home wards, with a total of 432 psychogeriatric nursing home residents. This sample did not include residents suffering from Korsakov's disease and psychiatric diseases residing in special Korsakov's or psychiatric wards. A total of 306 nursing staff (including full-time and part-time workers) worked on the 15 wards. In this study nursing staff is defined as RNs, care workers, care helpers and care assistants. ${ }^{24}$ The qualifications within the nursing staff decrease in complexity from RNs doing the most complex activities to care helpers and care assistants doing mainly routine and standard procedural work. ${ }^{24}$ Data were collected using observers, survey questionnaires and registration systems of the nursing home wards. For five wards, data were collected in November 2003, whereas for 10 wards data were collected in January 2005.

\section{Measures}

\section{Residents' characteristics}

Restraint use with residents was measured by independent, trained observers (three RNs, one care worker, one charge nurse, two occupational therapists, one physiotherapist) on four separate occasions during a $24 \mathrm{~h}$ period (see Appendix). All three shifts were included in the observations and the day of visit to each ward was unannounced to discourage any artificial removal of restraints by staff. ${ }^{7}$ Restraint use indicates residents observed under restraint at any time during the $24 \mathrm{~h}$ period. Any limitation on an individual's freedom of movement was regarded as a restraint. Examples of restraint types are belts tied to a chair or bed, bilateral bedrails, chairs with tables, deep or overturned chairs, chairs with a board, special sheets, sleep suits, sensor mats and infrared systems. In the Netherlands, the use of physical restraints in psychogeriatric nursing homes is regulated by the Psychiatric Hospitals (Compulsory Admission) Act. The use of restraints is only justified under certain conditions, such as there are no alternatives available and there is the presence or expectancy of danger. ${ }^{25}$ Two of the eight observers were selected to measure the inter-rater reliability. These two observers scored the same residents with restraints (Kappa=1.0).

The Minimum Data Set (MDS) version 2.1, which is part of the Resident Assessment Instrument (RAI) ${ }^{26}$, was used to collect data about age, gender, cognitive status, $A D L$ status and mobility of the residents. The MDS was completed by trained nurses who worked on the wards. The nurses completed the questionnaires for residents in their care. Different scales based on MDS 
items were used to determine the characteristics of residents. The Cognitive Performance Scale $(C P S)^{27}$ was used to determine the cognitive status of residents. This scale consists of five MDS items (comatose, short-term memory, cognitive skills for daily decision making, understood by others, ADL selfperformance in eating). The scores range from 0 (intact) to 6 (very severe impairment). Cronbach's alpha was 0.64 for this sample. The $A D L$ status was measured with the MDS ADL Self-performance Hierarchy. This scale is based on four MDS items (personal hygiene, toilet use, locomotion on ward, eating) and the scores range from 0 (independent) to 6 (total dependency). ${ }^{28}$ The internal consistency of the scale was good (Cronbach's alpha=0.86). A mobility scale was developed from seven MDS items (movement in bed, transfer in and out of bed, transfer to standing up, walking in the room, walking in the corridor, locomotion on ward, locomotion outside the ward) to determine mobility in residents. The scores of the mobility scale range from 0 (independent) to 28 (total dependency). Cronbach's alpha was 0.97. The reliability and validity of the MDS and related scales have been tested and found to be sufficient in other studies. ${ }^{27-29}$

\section{Job characteristics}

Self-reported measures were used to determine the job characteristics workload, job autonomy and social support. These measures were completed anonymously by nursing staff who worked on the wards. Workload of the nursing staff per ward was measured using an eight-item scale. ${ }^{30}$ Responses to these items were rated on a five-point scale $(1=$ never, $2=$ seldom, $3=$ sometimes, $4=$ often, 5=always). The scale includes a wide range of qualitative and quantitative demanding aspects of the job, such as working under time pressure, strenuous work and job complexity. ${ }^{30}$ An example item is 'in the ward where I work, work is carried out under pressure of time'. .ee also 31 The internal consistency of the scale was high (Cronbach's alpha $=0.88$ ). Job autonomy of the nursing staff per ward was measured by the Maastricht Autonomy Questionnaire (MAQ). ${ }^{30}$ The questionnaire consists of 10 Likert items, with a five-point response scale ( 1 =very little, 2 =little, $3=$ any, $4=$ much, $5=$ =very much). The questionnaire measures the worker's opportunities to determine a variety of task elements, such as the method of working, the pace of work and the work goals. ${ }^{31}$ An example item is 'to what extent does the work offer you the opportunity to choose your own method of working?'. Cronbach's alpha was 0.88 . The reliability and validity of both scales has been profoundly tested and found to be sufficient in other studies. for an overview, se 30 Workplace social support was measured using a well-validated Dutch translation of the social support scale from Karasek's ${ }^{32}$ Job Content Questionnaire. ${ }^{33}$ Workplace social support 
indicates the extent to which nursing staff per ward experienced instrumental and/or emotional support from colleagues and supervisors. The scale consists of eight items with a four-point response scale ranging from 1 'totally disagree' to 4 'totally agree'. An example item is 'my colleagues help to get the job done'. Cronbach's alpha was 0.81 .

\section{Ward characteristics}

Data from the registration systems of the nursing home wards was provided by the nursing home organisation and examined by the researcher in order to determine the full-time equivalent (FTE) ratio, the percentage of $R N s$ and the sickness absence per ward in a 1-month period. The FTE ratio was defined as the number of nursing staff FTE per resident per ward during one month. The percentage of $R N s$ was defined as the percentage of registered nurses per ward for one month as a portion of the total ward nursing staff in that month. Sickness absence indicates the percentage of sickness of nursing staff per ward during one month. The sickness absence percentage was determined by dividing the sickness days per ward per month (sickness days during 1 month multiplied by FTE) by the occupancy per ward per month (number of days of 1 month multiplied by FTE) and multiplying by $100 \%{ }^{34}$

\section{Ethical considerations}

Approval for the study was obtained from the Medical Ethical Committee of the university hospital Maastricht and the Maastricht university. Representatives of the residents received written information about the study from the nursing homes and the university. Based on this information the representatives were asked to give their written consent for the use of personal data of the residents in the main study. The nursing staff and other employees of the nursing homes were informed about the study by presentations and written information.

\section{Data analysis}

Descriptive statistics were computed for the residents, job and ward characteristics. The normality of these characteristics was checked by frequencies and distribution tables. Based on these results the variable mobility was categorised into five groups (range: 0 'independent' to 4 'total dependency'). To determine whether restraint use was related to residents, job and ward characteristics, bivariate relations between the independent variables and dependent variable were examined. Therefore, the differences between restrained and unrestrained residents for these characteristics were investigated using the $\chi^{2}$ test for variables at a dichotomous level (gender) and the t-test for variables at an ordinal, interval and ratio level. Job and ward 
characteristics were assigned to each resident according to the ward in which the resident lived for this analysis. With residents being nested within nursing home wards multilevel analysis, using MLwiN 2.02, was carried out to examine which characteristics determined the use of restraints with psychogeriatric nursing home residents. ${ }^{35}$ Data were, therefore, organized into two levels - the nursing home ward level and the resident level. Resident, job and ward characteristics were entered in the analysis as predictor variables. The random slopes and random intercept were statistically tested first in accordance with the top-down procedure, followed by testing the fixed effects with a significance level of $\alpha=0.10$ for backward deletion. All available data were used in the multilevel analysis.

\section{Results}

\section{Sample}

A total of 432 residents were selected for participation in this study and informed consent was obtained for 404 of them. Unfortunately, 31 residents died before the measurement started. Furthermore, two residents were discharged from the nursing home ward before the measurement. A total of 371 residents were included in the study. Mean age of the residents was 83 years $(S D=6.9)$ and the sample consisted of $75(20 \%)$ men and $296(80 \%)$ women. Mean cognitive status of the residents was 3.9 ( $S D=1.7)$ and mean $\mathrm{ADL}$ status was $3.6(\mathrm{SD}=1.9)$. Furthermore, mean mobility status was 1.9 (SD=1.7) and physical restraints were used with 206 (56\%) residents.

The self-reported measures for the job characteristics of workload, job autonomy and social support on the wards were completed by 193 of the 306 nursing staff (response rate=63\%). The sample consisted of 181 (94.8\%) women. Mean age of the nursing staff was 36.9 years (SD=10.1). Most of the respondents (69.4\%) were qualified as care workers, only 20 (10.4\%) respondents were RNs, 31 (16.1\%) of the respondents were qualified as care helpers and $8(4.1 \%)$ respondents were qualified as care assistants. Mean workload of the nursing staff was $3.14(S D=0.58)$. With regard to job autonomy of the nursing staff, the mean score was 2.93 (SD=0.62). Furthermore, mean social support experienced by the nursing staff on the wards was 3.06 (SD=0.37).

A total of 15 nursing home wards were included in the current study. The restraint prevalence on each nursing home ward varied between $28.6 \%$ and $78.6 \%$. In this respect, no statistically significant difference between the different nursing home wards was found $(p=0.115)$. The FTE ratio on the 15 wards varied between 0.40 and 0.76 FTE nursing staff per resident $M=0.58$, $S D=0.12$ ). The percentage of $R N s$ on the ward as a portion of the total ward 
nursing staff varied from $0 \%$ to $15 \%(M=7.42 \%, S D=4.94)$. The average sickness absence per month of the total nursing staff on the 15 wards was $4.21 \%(S D=2.39)$.

Relation between restraint use and resident, job and ward characteristics.

Bivariate relations between restraint use and resident, job and ward characteristics are shown in Table 2. The association between restraint use and the residents' characteristics of age, cognitive status, ADL status and mobility were statistically significant. Restrained residents were older compared to unrestrained residents $(p=0.032)$. The cognitive status of restrained residents was more impaired $(p<0.001)$ than the cognitive status of unrestrained residents. Furthermore, the restrained residents were more dependent in $A D L$ $(p<0.001)$ and were more dependent in mobility $(p<0.001)$ compared to the unrestrained residents. Job and ward characteristics did not differ significantly between restrained and unrestrained residents (Table 2).

Table 2 Bivariate relations between the use of physical restraints and characteristics of psychogeriatric nursing home residents ( $n=371)$, nursing staff $(n=193)$ and nursing home wards $(n=15)$

\begin{tabular}{|c|c|c|c|c|}
\hline Variables & $\begin{array}{l}\text { Missing } \\
\text { values }\end{array}$ & $\begin{array}{l}\text { Restrained } \\
(n=206)\end{array}$ & $\begin{array}{l}\text { Unrestrained } \\
(n=165)\end{array}$ & p-value \\
\hline \multicolumn{5}{|l|}{ Resident characteristics } \\
\hline Age in years $(M, S D)$ & 0 & $84.0(6.8)$ & $82.5(6.9)$ & 0.032 \\
\hline Gender & 0 & & & \\
\hline Male & & $44(21.4 \%)$ & $31(18.8 \%)$ & 0.540 \\
\hline Female & & $162(78.6 \%)$ & $134(81.2 \%)$ & \\
\hline Cognitive status $(M, S D)$ & 3 & $4.5(1.5)$ & $3.1(1.6)$ & $<0.001$ \\
\hline ADL status $(M, S D)$ & 22 & $4.6(1.4)$ & $2.2(1.5)$ & $<0.001$ \\
\hline Mobility ${ }^{a}(M, S D)$ & 6 & $3.0(1.3)$ & $0.47(0.9)$ & $<0.001$ \\
\hline \multicolumn{5}{|l|}{ Job characteristics } \\
\hline $\begin{array}{l}\text { Workload of nursing staff per ward } \\
(M, S D)\end{array}$ & 0 & $3.1(0.3)$ & $3.1(0.3)$ & 0.997 \\
\hline $\begin{array}{l}\text { Autonomy of nursing staff per ward } \\
(M, S D)\end{array}$ & 0 & $3.0(0.3)$ & $2.9(0.3)$ & 0.458 \\
\hline $\begin{array}{l}\text { Social support of nursing staff per ward } \\
(M, S D)\end{array}$ & 0 & $3.1(0.2)$ & $3.1(0.2)$ & 0.484 \\
\hline \multicolumn{5}{|l|}{ Ward characteristics } \\
\hline FTE ratio per ward $(M, S D)$ & 0 & $0.58(0.12)$ & $0.57(0.12)$ & 0.323 \\
\hline $\begin{array}{l}\text { Percentage of registered nurses per ward } \\
(M, S D)\end{array}$ & 0 & $7.9(4.4)$ & $7.6(4.8)$ & 0.474 \\
\hline Sickness absence $(\%)$ per ward $(M, S D)$ & 0 & $4.1(2.1)$ & $4.3(2.3)$ & 0.547 \\
\hline
\end{tabular}

${ }^{\circ}$ The variable mobility was categorised into five groups, range 0 (independent)- 4 (total dependency) 
After examining the bivariate relations, all variables were entered in a multilevel analysis to examine which characteristics were associated with restraint use (Table 3; Model 1). The multilevel model also included a random intercept and a random slope for age. Since the variances of the random slopes for gender, cognitive status, ADL status and mobility were extremely small, these random slopes were not included in the multilevel model. The analysis showed that restraint use was significantly associated with the mobility status of residents. The chance of restraint use was higher $(O R=2.487)$ for immobile residents than for mobile residents. Furthermore, a weak association $(p<0.10)$ was found for gender. Female residents had a lower chance of restraint use than male residents $(O R=0.519)$.

The results of a top-down procedure, with a significance level of $\alpha=0.10$ for backward deletion of variables, are also shown in Table 3 (Model 2). This multilevel model confirms that residents' mobility and gender are associated with restraint use. A significant association was also found with the cognitive status of residents. It shows that more impairment in cognitive status is associated with a higher chance for restraint (OR=1.247). In contrast with the bivariate relations and the multilevel model including all independent variables, this model also demonstrated that job autonomy experienced by the nursing staff is significantly associated with restraint use. A higher job autonomy experienced by the nursing staff is associated with a higher chance for the use of restraint with residents (OR=5.307). Furthermore, a weak association $(p<0.10)$ was found with the FTE ratio per ward. The chance for restraint use was higher $(O R=28.446)$ for residents who lived on wards with a high FTE ratio compared to wards with a low FTE ratio. A standard backward logistic regression analysis $(\alpha=0.10)$ was also performed because the random intercept and slope were not statistically significant in the multilevel analysis. The results of this analysis were similar to the results of the multilevel analysis and will, therefore, not be reported separately. 
Table 3 Determinants of restraint use in psychogeriatric nursing home residents based on a logistic multilevel analysis ( $\mathrm{n}=371$ )

\begin{tabular}{|c|c|c|c|c|c|}
\hline Variables & Estimate & SE & p-value & $\begin{array}{l}\text { Odds } \\
\text { Ratio }\end{array}$ & $95 \% \mathrm{Cl}$ \\
\hline \multicolumn{6}{|l|}{ Model 1: complete multilevel model } \\
\hline \multicolumn{6}{|l|}{ Fixed effects } \\
\hline \multicolumn{6}{|l|}{ Resident characteristics } \\
\hline Gender $(0=$ male $; 1=$ female $)$ & -0.656 & 0.397 & 0.099 & 0.519 & $0.24-1.13$ \\
\hline Age & 0.023 & 0.026 & 0.373 & 1.023 & $0.97-1.08$ \\
\hline Cognitive status & 0.175 & 0.113 & 0.121 & 1.191 & $0.96-1.49$ \\
\hline ADL status & 0.151 & 0.166 & 0.363 & 1.163 & $0.84-1.61$ \\
\hline Mobility & 0.911 & 0.198 & $<0.001$ & 2.487 & $1.69-3.67$ \\
\hline \multicolumn{6}{|l|}{ Job characteristics } \\
\hline Workload of nursing staff per ward & -0.357 & 0.647 & 0.582 & 0.700 & $0.20-2.49$ \\
\hline Job autonomy of nursing staff per ward & 1.586 & 1.068 & 0.136 & 4.884 & $0.60-39.62$ \\
\hline Social support of nursing staff per ward & -0.775 & 1.364 & 0.569 & 0.461 & $0.03-6.68$ \\
\hline \multicolumn{6}{|l|}{ Ward characteristics } \\
\hline FTE ratio per ward & 1.780 & 1.462 & 0.222 & 5.930 & $0.34-104.12$ \\
\hline Percentage of registered nurses per ward & 0.054 & 0.040 & 0.177 & 1.056 & $0.98-1.14$ \\
\hline Sickness absence per ward & -0.034 & 0.080 & 0.667 & 0.967 & $0.83-1.13$ \\
\hline \multicolumn{6}{|l|}{ Random effects } \\
\hline Variance of the random intercept & 12.526 & 20.417 & $0.271^{\mathrm{b}}$ & & \\
\hline Variance of the random slope (age) & 0.002 & 0.003 & $0.251^{\mathrm{b}}$ & & \\
\hline \multicolumn{6}{|c|}{ Model 2: final multilevel model by top-down procedure $(\alpha=0.10)$} \\
\hline \multicolumn{6}{|l|}{ Fixed effects } \\
\hline \multicolumn{6}{|l|}{ Resident characteristics } \\
\hline Gender $(0=$ male $; 1=$ female $)$ & -0.839 & 0.416 & 0.043 & 0.432 & $0.19-0.98$ \\
\hline Cognitive status & 0.221 & 0.110 & 0.044 & 1.247 & $1.01-1.55$ \\
\hline Mobility & 1.327 & 0.135 & $<0.001$ & 3.770 & $2.89-4.91$ \\
\hline \multicolumn{6}{|l|}{ Job characteristics } \\
\hline Job autonomy of nursing staff per ward & 1.669 & 0.757 & 0.027 & 5.307 & $1.20-23.40$ \\
\hline \multicolumn{6}{|l|}{ Ward characteristics } \\
\hline FTE ratio per ward & 3.348 & 1.853 & 0.070 & 28.446 & $0.75-1074.79$ \\
\hline \multicolumn{6}{|l|}{ Random effects } \\
\hline Variance of the random intercept & 0.116 & 0.193 & $0.274^{\mathrm{b}}$ & & \\
\hline
\end{tabular}

The ratios of the odds of being restrained were calculated for two groups differing in one unit on the independent variable

'These $p$-values correspond to a one-sided test, the other $p$-values correspond to a two sided test 


\section{Discussion}

This study has shown that characteristics of the job and nursing home wards were less important in relation to the use of physical restraints compared to residents' characteristics. The use of physical restraints with psychogeriatric nursing home residents is most strongly related to impairment in mobility.

The hypothesis that the use of physical restraints is positively associated with residents' characteristics was confirmed, except for impairment in ADL status. The use of restraints was shown to be most strongly related to impairment in mobility. Furthermore, residents with a poor cognitive status had a higher risk for restraint use, and gender was also shown to be associated. These results about the relation between resident characteristics and restraint use are in accordance with other studies. ${ }^{12.14}$ The strong association between restraint use and impairment in mobility is also related to the main reason for using restraints - fall prevention. Some studies showed that the fall risk in the opinion of nurses is associated with restraint use. ${ }^{12,13}$ Therefore, restraint reduction programmes focussing on impairment in mobility and the prevention of falls are recommended.

The hypothesis regarding the association between the use of physical restraints and high workload and low social support experienced by nursing staff was not confirmed. In other words, restraint use was not associated with workload and social support experienced by the nursing staff. Although many empirical work stress studies proved that workload and social support are related to employees' health and well-being ${ }^{20}$, these job characteristics were in this study not found to be associated with this particular work activity. This could be explained by the fact that residents' characteristics were found to be the most important factors in relation to the use of physical restraints with psychogeriatric nursing home residents. Apparently, residents' characteristics are more important factors in the decision-making process toward restraint use than these job characteristics. On the other hand, this study showed that job autonomy experienced by nursing staff on the wards was positively associated with restraint use. A higher job autonomy experienced by nursing staff is associated with a higher chance for the use of restraints with residents. However, this association may seem to be contradictory. A possible explanation for this result might be that nursing staff with more job autonomy have more persuasiveness and have more control in the decision-making process toward restraint use. Knowledge and experience are important in decision making in nursing. ${ }^{36,37}$ Knowing that knowledge about physical restraints is inadequate ${ }^{38,39}$, this can lead to the use of more restraints. Research about the knowledge and attitude of nurses toward restraint use in relation to job characteristics is, therefore, recommended. In addition, this finding 
underlines the need for educational interventions to improve knowledge of nurses about restraint use. Given the limited number of studies examining the associations between restraint use and job characteristics, more research is needed. This is also supported by a recent study about nursing working conditions in relation to physical restraints which did find an association between job demands and the use of restraints in units with low job control. ${ }^{40}$ In further studies, the association between restraint use and job characteristics for the different qualification levels within the nursing staff also needs to be examined.

The hypothesis that restraint use is associated with a low percentage of RNs and a high rate of sickness absence on the ward was not confirmed in this study. This could be explained by the fact that residents' characteristics were found to be the most important factors in relation to the use of restraints with psychogeriatric nursing home residents. The multilevel analysis has shown a moderate relation between restraint use and a high FTE ratio on the wards. This finding suggests that increasing the number of nursing staff will not lead to a decrease in the use of physical restraints. This finding is in contrast with the common opinion of nurses that the use of restraints increases with an insufficient number of nursing staff. ${ }^{22}$ Research with more nursing home wards included is recommended in order to further investigate the relation between restraint use and ward characteristics. Different types of definitions and data collection methods have been used to determine ward characteristics in other studies about these relations. ${ }^{10,12}$ These differences probably explain the differences in results between the studies. However, based on the results of the present study, the conclusion is that ward characteristics are less important in relation to restraint use compared to resident characteristics.

Physical restraints were used with $56 \%$ of the residents. This high prevalence value is in line with other studies showing that physical restraints are frequently used with nursing home residents. ${ }^{3,41}$ Furthermore, this finding strengthens the need, also reported in other studies, to reduce the use of physical restraints with psychogeriatric nursing home residents. ${ }^{13,42}$ Since this study has shown that characteristics of residents seem to be the most important factors associated with restraint use, restraint reduction programmes should focus predominantly on resident characteristics. Nursing staff should be educated and supported in caring for psychogeriatric nursing home residents with poor mobility. Therefore, the availability of alternative interventions for physical restraints is needed. Sullivan-Marx et al. ${ }^{12}$ also pointed out that education in the assessment and analysis of fall risk in cognitive-impaired residents, along with targeted interventions, is important in reducing restraint use. Further research to explore alternative interventions for restraint use 
focusing on caring for persons with poor cognitive status and poor mobility in relation to a higher fall risk is recommended.

This study has some limitations. In the first place, a cross-sectional study was conducted to investigate the relation between organisational characteristics and the use of physical restraints. Conclusions regarding causal effects are, therefore, not possible. Secondly, the sample consisted of nursing home residents from 15 nursing home wards that belonged to one coordinating organisation for the care for older people in the southern part of the Netherlands, which may limit the generalization of the results. Besides, a total of 15 wards also might be considered as relatively small given that one is interested in establishing the relation between restraint use and ward characteristics. Research including more nursing home wards in different regions is highly recommended to further investigate the relation between job and ward characteristics and the use of restraints. In addition, comparison of characteristics of nursing home wards with wards from other health care organisations might contribute to a better understanding of these relations. Thirdly, not all possible determinants of the use of physical restraints, such as the use of psychoactive medication, were included in this study. Fourthly, the ward characteristics were determined during a 1-month period compared to restraint use measured during a $24 \mathrm{~h}$ period. Therefore, precise insight into the number of nursing staff per resident and the percentage of RNs during the observations is not available. Although ward characteristics probably will not be static within a 1-month period, the present study has gained an appropriate insight into the associations between restraints use and resident, job and ward characteristics. Finally, collection of data about sickness absence was difficult, due to changes in the registration systems of the coordinating organisation. The accuracy of the data about sickness absence may, therefore, have been affected and must be interpreted with caution.

\section{Conclusions}

The use of physical restraints with psychogeriatric nursing home residents is mainly associated with impairment in the mobility of residents. Job and ward characteristics were not as strongly associated with restraint use as residents' characteristics. The hypothesized associations between job characteristics (e.g., high workload) and ward characteristics (e.g., low percentage of RNs) with a higher chance for restraint use were not found to be statistically significant. The study results underline the importance of reducing the use of restraints with psychogeriatric nursing home residents and contribute to the discussions about restraint reduction. Since characteristics of the job and nursing home wards are less important in relation to restraint use compared to 
residents' characteristics, it is recommended that initiatives to reduce restraint use with psychogeriatric nursing home residents should focus on the education and support of nursing staff in caring for psychogeriatric nursing home residents with poor mobility. Further research in this particular area is badly needed.

\section{References}

1. Capezuti E, Evans L, Strumpf N, Maislin G. Physical restraint use and falls in nursing home residents. J Am Geriatr Soc 1996;44(6):627-633.

2. Ejaz FK, Jones JA, Rose MS. Falls among nursing home residents: an examination of incident reports before and after restraint reduction programs. J Am Geriatr Soc 1994;42(9):960-964.

3. Neufeld RR, Libow LS, Foley WJ, Dunbar JM, Cohen C, Breuer B. Restraint reduction reduces serious injuries among nursing home residents. J Am Geriatr Soc 1999;47(10):1202-1207.

4. Castle NG, Mor V. Physical restraints in nursing homes: a review of the literature since the nursing home reform act of 1987. Medical Care Research and Review 1998;55(2):139-170.

5. Hamers JPH, Huizing AR. Why do we use physical restraints in the elderly? Z Gerontol Geriat 2005;38:19-25.

6. Miles SH, Irvine P. Deaths caused by physical restraints. The Gerontologist 1992;32(6):762766.

7. Evans LK, Strumpf NE, Allen-Taylor SL, Capezuti E, Maislin G, Jacobsen B. A clinical trial to reduce restraints in nursing homes. J Am Geriatr Soc 1997;45(6):675-681.

8. Testad I, Aasland AM, Aarsland D. The effect of staff training on the use of restraint in dementia: a single-blind randomised controlled trial. Int J Geriatr Psychiatry 2005;20(6):587-90.

9. Mion LC, Fogel J, Sandhu S, et al. Outcomes following physical restraint reduction programs in two acute care hospitals. Jt Comm J Qual Improv 2001 ;27(1 1):605-618.

10. Castle NG, Fogel B, Mor V. Risk factors for physical restraint use in nursing homes: pre- and post-implementation of the nursing home reform act. Gerontologist 1997;37(6):737-747.

11. Phillips CD, Hawes C, Mor V, Fries BE, Morris JN, Nennstiel ME. Facility and area variation affecting the use of physical restraints in nursing homes. Medical Care 1996;34(1 1):1 149-62.

12. Sullivan-Marx EM, Strumpf NE, Evans LK, Baumgarten M, Maislin G. Predictors of continued physical restraint use in nursing home residents following restraint reduction efforts. J Am Geriatr Soc 1999;47(3):342-348.

13. Hamers JPH, Gulpers MM, Strik W. Use of physical restraints with cognitively impaired nursing home residents. Journal of Advanced Nursing 2004;45(3):246-251.

14. Karlsson S, Bucht G, Eriksson S, Sandman PO. Factors relating to the use of physical restraints in geriatric care settings. J Am Geriatr Soc 2001;49(12):1722-1728.

15. Werner $P$, Mendelsson $G$. Nursing staff members' intentions to use physical restraints with older people: testing the theory of reasoned action. Journal of Advanced Nursing $2001 ; 35(5): 784-791$.

16. Suen LKP, Lai CKY, Wong TKS, et al. Use of physical restraints in rehabilitation settings: staff 
knowledge, attitudes and predictors. Journal of Advanced Nursing 2006;55(1):20-28.

17. Cooper CL, Dewe PJ, O'Driscoll MP. Organizational stress: A review and critique of theory, research, and applications. Thousand Oaks, CA: Sage Publications, 2001.

18. Karasek RAJ. Job Demands, Job Decision, Latitude, and Mental Strain: Implications for Job Redesign. Administrative Science Quarterly 1979;24(2):285-308.

19. Johnson JV, Hall EM. Job Strain, Work Place Social Support, and Cardiovascular Disease: A Cross-Sectional Study of a Random Sample of the Swedish Working Population. American Journal of Public Health 1988;78(10):1336-1342.

20. Van der Doef M, Maes S. The job demand-control (-support) model and psychological wellbeing: A review of 20 years of empirical research. Work \& Stress 1999;13:87-1 14.

21. De Lange AH, Taris TW, Kompier MAJ, Houtman ILD, Bongers PM. "The very best of the Millennium": longitudinal research and the Demand-Control-(Support) model. Journal of Occupational Health Psychology 2003;8(4):282-305.

22. Hantikainen V. Physical restraint: a descriptive study in Swiss nursing homes. Nursing Ethics 1998;5(4):330-346.

23. Eurostat. The social situation in the European Union 2004. http://epp.eurostat.ec.europa.eu 2005 .

24. MinVWS. Qualified for the Future. Coherent training system for nursing and patient care in the Netherlands: a summary. Zoetermeer: Ministery of Health, Welfare and Sport, 1997.

25. $\mathrm{CBO}, \mathrm{VWR}$. Het gebruik van vrijheidsbeperkende interventies in de zorg. Een richtlijn voor verpleegkundigen en verzorgenden in een multidisciplinaire omgeving (The use of restraints in care situations. A guideline for nurses in a multidisciplinary environment). Utrecht: Kwaliteitsinstituut voor de Gezondheidszorg CBO, 2001.

26. interRAI. RAI for Nursing Home Care (RAI 2.1). Utrecht: interRAl Corporation, 2002.

27. Morris JN, Fries BE, Mehr DR, et al. MDS Cognitive Performance Scale. Journal of Gerontology: MEDICAL SCIENCES 1994;49(4):M174-82.

28. Morris JN, Fries BE, Morris SA. Scaling ADLs within the MDS. Journal of Gerontology: MEDICAL SCIENCES 1999;54A(1 1):M546-53.

29. Holtkamp CCM. Effects of the Resident Assessment Instrument on Quality of Care and Quality of Life in Nursing Homes. Utrecht: NIVEL, 2003.

30. De Jonge J. Job autonomy, well-being, and health. Maastricht: Rijksuniversiteit Limburg, 1995.

31. De Jonge J, Mulder MGP, Nijhuis FJN. The incorporation of different demand concepts in the job demand-control model: effects on health care professionals. Social Science \& Medicine 1999;48:1149-1160.

32. Karasek RA. Job Content Instrument: Questionnaire and user's guide. Los Angeles: Department of Industrial and Systems Engineering, University of Southern California, 1985.

33. De Jonge J, Reuvers MMEN, Houtman ILD, Bongers PM, Kompier MAJ. Linear and nonlinear relations between psychosocial job characteristics, subjective outcomes, and sickness absence: Baseline results from SMASH. Journal of Occupational Health Psychology 2000;5(2):256-268. 
34. WCC. Berekening van ziekteverzuim. Standaard voor verzuimregistratie (Calculation of sickness absence. Standard for the registration of absence). Amsterdam, 1996.

35. Snijders TAB, Bosker RJ. Multilevel analysis: An introduction to basic and advanced multilevel modeling. London: Sage, 1999.

36. Hamers JPH, Huijer Abu Saad H, Halfens RJG. Diagnostic process and decision making in nursing: a literature review. Journal of Professional Nursing 1994;10(3):154-163.

37. Ludwick R, O'Toole AW. The confused patient: nurses' knowledge and interventions. Journal of Gerontological Nursing 1996;22(1):44-49.

38. Evans LK, Strumpf NE. Myths about elder restraint. Image J Nurs Sch 1990;22(2):124-8.

39. Karlsson S, Bucht G, Sandman PO. Physical restraints in geriatric care. Knowledge, attitudes and use. Scand J Caring Sci 1998;12(1):48-56.

40. Pekkarinen L, Elovainio M, Sinervo T, Finne-Soveri H, Noro A. Nursing working conditions in relation to restraint practices in long-term care units. Medical Care 2006;44(12):1 11 14-1 120.

41. Capezuti E, Maislin G, Strumpf N, Evans LK. Side rail use and bed-related fall outcomes among nursing home residents. J Am Geriatr Soc 2002;50(1):90-96.

42. Strumpf NE, Robinson JP, Wagner JS, Evans LK. Restraint-free care; Individualized approaches for frail elders. New York: Springer Publishing Company, Inc, 1998. 


\section{Chapter 4}

$\left|\begin{array}{r}\text { Shortterm effects of an educational } \\ \text { intervention on physical restraint use: } \\ \text { a cluster randomized trial }\end{array}\right|$

Anna R Huizing, Jan PH Hamers, Math JM Gulpers, Martijn PF Berger

Published in BMC Geriatrics 2006;6:17 


\section{Abstract}

Physical restraints are still frequently used on nursing home residents despite growing evidence for the ineffectiveness and negative consequences of these methods. Therefore, reduction in the use of physical restraints on psychogeriatric nursing home residents is very important. The aim of this study was to investigate the short-term effects of an educational intervention on the use of physical restraints on psychogeriatric nursing home residents.

A cluster randomized trial was applied to 5 psychogeriatric nursing home wards ( $n=167$ residents with dementia). The wards were assigned at random to either educational intervention ( 3 wards) or control status ( 2 wards). The restraint status was observed and residents' characteristics, such as cognitive status, were determined by using the Minimum Data Set (MDS) at baseline and 1 month after intervention.

Restraint use did not change significantly over time in the experimental group $(55 \%-56 \%)$, compared to a significant increased use $(p<0.05)$ in the control group (56\%-70\%). The mean restraint intensity and mean multiple restraint use in residents increased in the control group but no changes were shown in the experimental group. Logistic regression analysis showed that residents in the control group were more likely to experience increased restraint use than residents in the experimental group.

An educational programme for nurses combined with consultation with a nurse specialist did not decrease the use of physical restraints on psychogeriatric nursing home residents in the short term. However, the residents in the control group experienced more restraint use during the study period compared to the residents in the experimental group. Whether the intervention will reduce restraint use in the long term could not be inferred from these results. Further research is necessary to gain insight into the long-term effects of this educational intervention. 


\section{Background}

The use of physical restraints on psychogeriatric nursing home residents is a common procedure in Dutch nursing homes. The prevalences reported in the literature range from 49 to 61 percent. ${ }^{1.3}$ International prevalence values range from $15 \%$ to $66 \%$ in nursing homes. ${ }^{4}$ A physical restraint is defined as any limitation on an individual's freedom of movement by using such devices as a 'geriatric' chair with table, belts tied to a chair or bed and bedrails. ${ }^{5}$ Although the use of various types of restraint have been reported in the literature, some studies do not categorize the use of bed rails as a restraint method. ${ }^{\circ}$ Physical restraint use seems to occur most often in nursing home residents with poor mobility, high dependency and impaired cognitive status. ${ }^{2,-9}$ Other characteristics, such as old age and fall risk, have also been related to the use of physical restraints. ${ }^{4}$ The main reason for using physical restraints is the prevention of falls and fall-related injuries. ${ }^{2,5,7-10}$ Hamers et al. ${ }^{2}$ reported that $80 \%$ of the restrained residents in Dutch nursing homes were in restraint to prevent falls and fall-related injuries. However, recent studies have shown that restraints are inadequate measures for preventing falls and fall-related injuries. ${ }^{7,10-12}$ Capezuti et al. ${ }^{11}$ showed that the use of restraints was not associated with a lower risk of falls or injuries in residents likely to be restrained. Furthermore, several studies showed that a decrease in restraint use did not result in an increase in fall incidence and serious fall-related injuries. ${ }^{6,10,12}$ Both prolonged and short periods of restraint use have negative physical, psychological and social consequences for nursing home residents. ${ }^{2,4,13-15}$ The use of restraints may cause immobility, incontinence, pressure ulcers, depression, agitation, aggression and mortality in residents. ${ }^{15}$ Reducing the use of restraints in daily practice is recommended because physical restraints seem to be inadequate and harmful to nursing home residents. ' A study demonstrated that an educational programme combined with consultation reduces the use of restraints in nursing homes effectively and safely. ${ }^{6}$ The effects of these types of intervention on restraint use with Dutch psychogeriatric nursing homes residents are not yet known. Therefore, it is relevant to gain insight into the effects of these types of interventions on physical restraint use in Dutch nursing homes.

The objective of this study was to investigate whether an educational intervention has an effect on the use of physical restraints on psychogeriatric nursing home residents. The hypothesis was put forward that an educational intervention will lead to a reduction of restraint prevalence and intensity, to a reduction in multiple restraint use, and to the use of less restrictive restraint types in residents (e.g. the use of infrared systems instead of waist belts). The following research questions were formulated: 
- What is the effect of the educational intervention on restraint prevalence and intensity of use in psychogeriatric nursing home residents?

- What is the effect of the educational intervention on multiple restraint use in psychogeriatric nursing home residents?

- What is the effect of the educational intervention on different restraint types used in psychogeriatric nursing home residents?

\section{Methods}

\section{Design and sample}

A cluster randomized trial was applied to five psychogeriatric nursing home wards that belonged to one nursing home. The total number of subjects was 167 residents with dementia. Residents suffering from Korsakov's disease and psychiatric diseases were excluded because these residents in general differ from other residents with dementia (e.g., in being younger and having better mobility) and live in special Korsakov's or psychiatric wards in the nursing homes. The wards were assigned at random to either educational intervention (three experimental wards) or control status (two wards). Nurses in the experimental group attended an educational programme on restraint use. Furthermore, consultation with a registered nurse specialized in the use of restraints and in their reduction (nurse specialist) was introduced on the experimental wards. There was no educational intervention in the control group and residents received the normal care.

\section{Intervention}

The intervention consisted of an educational programme combined with consultation with a nurse specialist. ${ }^{6}$ The educational programme developed was based on an educational programme of restraint use in Dutch hospitals ${ }^{16}$ and on advice of the Dutch Institute for Healthcare Improvement (CBO) about the decision-making process concerning restraint use in care situations. ${ }^{17}$ The educational programme was designed to encourage nurses to embrace a philosophy of restraint-free care and be familiar with techniques of individualized care. $^{18}$ The educational programme was taught by the nurse specialist and was carried out over a two-month period. Several subjects concerning physical restraints were discussed during five meetings each lasting for two hours, such as the decision-making process towards restraint use, the effects and consequences of restraint use, strategies to analyse risk behaviour of residents and alternatives for restraints. Nurses were also invited to discuss real-life cases during the educational meetings. The nurses could, therefore, combine practical experience with information from the educational 
programme. There are indications in the literature that interactive and personal educational meetings are more effective than passive education. ${ }^{19}$ Therefore, this educational programme consisted of small-scale meetings with an active learning environment for the nurses. The basic principle for selection of nurses for the educational programme was the inclusion of 'key figures' ${ }^{119}$ and the inclusion of nurses with different degrees of innovativeness (different types of 'adopters $\left.{ }^{12}\right)$. Seven nurses, about one third of the nurses per ward and including the charge nurse, from each experimental ward, were invited to attend the meetings. A total of 23 nurses were divided into three groups. Each group consisted of nurses from different wards and 1 charge nurse, in order to promote the exchange of knowledge and experiences between wards. A plenary session, lasting for one and a half hours, was organized after the five educational meetings for all the nurses of the experimental wards to inform them about restraint use and restraint-free care.

The consultation with the nurse specialist focused on supporting nurses in achieving restraint-free care and complying with the decision-making process concerning restraint use as defined in the Dutch guideline for restraint use in care situations. ${ }^{17,18}$ The nurse specialist was, therefore, available for consultation for 28 hours a week, visited the wards once a week, attended multidisciplinary meetings about residents and stimulated nurses to use alternatives for physical restraints, such as electronic devices. During the visits to the wards and the multidisciplinary meetings the nurse specialist evaluated the use of restraints on residents and discussed difficulties in achieving restraintfree care.

\section{Data collection}

Data was collected via observers and from questionnaires at baseline (November 2003) and 1 month post-intervention (June 2004). Restraint use with psychogeriatric nursing home residents was measured during observations. Restraint use was confirmed visually by independent, trained observers on four separate occasions during a 24-hour period for each measurement (see Appendix). The observers (two nurses, one occupational therapist and one member of management) were not told to the exact design of the study, the intervention and the division into experimental and control wards. All three shifts were included in the observations and the day of visit to each unit was randomized to discourage any artificial removal of restraints by staff. ${ }^{6}$ The restraint prevalence, intensity, types and multiple restraint use were determined. Restraint prevalence was defined as the percentage of residents observed restrained at any time during the 24-hour period. Restraint intensity indicated the number of times in four observations that a particular resident 
was restrained. Restraint types were also recorded in order to gain insight into the types of restraint used with residents. Any device with limitation on an individual's freedom of movement was regarded as a restraint. Examples of restraint types are chairs with tables, belts tied to a chair or bed, bilateral bedrails, sleep suits, special sheets (a fitted sheet including a coat that encloses a mattress), chairs with a board (a chair with chair legs fixed to a board), infrared systems, sensor mats, and deep or overturned chairs. Multiple restraints indicated the number of different restraint types used per resident recorded during the four observations. The value of Cohen's kappa was calculated to test the inter-rater reliability between observers. The value obtained showed that this was good.

The Minimum Data Set (MDS) version 2.1, which is part of the Resident Assessment Instrument (RAl), was used to collect background data, such as age, gender and other characteristics of residents. The MDS was completed by, especially for this study, trained nurses who worked on the wards. The nurses completed the questionnaires for residents that they cared for. Different scales based on items in the MDS were used to determine characteristics of residents. The Cognitive Performance Scale (CPS) ${ }^{21}$ was used to determine the cognitive status of residents. This scale consists of five MDS items. The scores range from 0 (intact) to 6 (very severe impairment). The CPS scale corresponded closely with scores generated by the Mini-Mental State Examination and the Test for Severe Impairment, nursing judgement of disorientation, and neurological diagnosis of Alzheimer's disease and other dementias. ${ }^{21}$ Self performance in activities in daily living (ADL) was measured with the MDS ADL Selfperformance Hierarchy. This scale is based on four MDS items and the scores range from 0 (independent) to 6 (total dependency). ${ }^{22}$ The Depression Rating Scale (DRS) ${ }^{23}$ was used to determine depression in residents. This scale contains seven items from the MDS with scores ranging from 0 to 14. Residents who score $\geq 3$ (cut-off score) on the scale need further evaluation to diagnose depression. The Social Engagement Scale (SES) was used to determine social engagement in residents. ${ }^{24}$ The scale contains six MDS items with scores ranging from 0 (lowest level of social engagement) to 6 (highest level of social engagement). A mobility scale was developed from seven MDS items to determine mobility in residents. The MDS items were: 1) movement in bed; 2) transfer in and out of bed; 3) transfer to standing up; 4) walking in the room; 5) walking in the corridor; 6) movement in the ward; 7) movement outside the ward. The scores of the mobility scale range from 0 (independent) to 28 (totally dependent). The internal consistency of the scale was high, with the value of Cronbach's alpha=0.97. Psycho-active drug use was determined from one item (O6) of the MDS and was recorded as yes, no, when necessary, yes and when 
necessary. The reliability and validity of the Minimum Data Set and related scales were tested in different studies and found to be sufficient. ${ }^{21-26}$

The accident registration form was used to determine fall incidence and fallrelated injuries. ${ }^{27}$ The accident registration form was completed by employees of the wards who witnessed an accident or cared for the resident after the accident, or were informed about the accident by the resident, family or a visitor. Fall incidence was defined as the number of residents with at least one fall during the period of measurement (one month). Fall-related injuries were defined as the number of residents with any injury, from pain to fractures, as a result of a fall incident during the period of measurement.

\section{Ethical considerations}

Approval was obtained from the Medical Ethical Committee of the University Hospital Maastricht and Maastricht University. Representatives of the residents received written information about the study from the nursing home and Maastricht University. Based on this information the representatives were asked for written consent for the use of personal data of the residents in this study. Nurses and other employees of the nursing homes were informed about the study by presentations and written information.

\section{Data analysis}

Descriptive statistics were computed for the characteristics of the residents. The prevalence, intensity and types of restraint use were examined using frequency tables. Means were computed for intensity and the number of different restraint types used per resident. A chi-square test and a t-test were used to investigate whether there was a significant difference between restraint use in the control and experimental group. Fisher's exact test values were computed when a table had a cell with an expected frequency of less than 5 . The value of alpha with regard to analyses of restraint types was set at 0.01 in order to correct for multiple testing because of the increasing risk of type 1 errors. McNemar tests and gain scores were calculated and tested by a t-test to investigate changes over time in both groups. Logistic regression analysis was used to compare restraint use post-intervention, controlling for characteristics of residents. Since the number of wards is limited and the variables were not defined on ward level, multilevel analysis was not appropriate. The dependent variable restraint use indicates residents observed under restraint at any time during the 24-hour period. Characteristics of residents that were assumed to be correlated with restraint use, based on literature and baseline differences across the control and experimental groups, were entered as covariates in the logistics regression analysis. These included age, gender, cognitive status, self performance in 
activities of daily living, depression, social engagement, mobility, fall incidence, fall-related injuries and psychoactive drug use. The variable of psychoactive drug use was dichotomised. Interactions between covariates were tested with chi-square tests $(p<0.001)$. The final logistic model was selected by the backwards stepwise procedure, with a significant level of $\alpha=0.10$ for backward deletion.

\section{Results}

\section{Sample}

A total of 167 residents were selected for participation in this study and informed consent was obtained for 157 of them. Unfortunately, 12 residents died before the baseline measurement started. A total of 145 psychogeriatric nursing home residents were measured at baseline. As can be seen from Table 1 there were no differences between the experimental and control groups in the characteristics of the residents at baseline, except for depression. However, the depression scores in both groups were below the cut-off point, indicating no symptoms of depression. After the baseline measurement, 19 residents (8 in the control group, 11 in the experimental group) dropped out (mortality), while 18 new residents (4 in the control group, 14 in the experimental group) were included. Post-intervention, the control and experimental groups only differed on depression and cognitive status (Table 1).

Data from residents measured at baseline $(n=145)$ or post-intervention $(n=144)$ will be used to describe the situation for the measurements separately. Data from residents with complete data $(n=126)$ will be used to compare between measurements. 
Table 1 Characteristics of psychogeriatric nursing home residents at baseline $(n=145)$ and postintervention $(n=144)$

\begin{tabular}{|c|c|c|c|c|c|c|}
\hline \multirow[b]{2}{*}{ Residents' characteristics } & \multicolumn{3}{|c|}{ Baseline } & \multicolumn{3}{|c|}{ Post-intervention } \\
\hline & $\begin{array}{l}\text { Missing } \\
\text { values }\end{array}$ & $\begin{array}{l}\text { Experimental } \\
(n=83)\end{array}$ & $\begin{array}{l}\text { Control } \\
(n=62)\end{array}$ & $\begin{array}{l}\text { Missing } \\
\text { values }\end{array}$ & $\begin{array}{l}\text { Experimental } \\
(n=86)\end{array}$ & $\begin{array}{l}\text { Control } \\
(n=58)\end{array}$ \\
\hline Age in years (mean, SD) & 0 & $82.4(7.6)$ & $82.3(6.4)$ & 0 & $81.8(7.7)$ & $82.7(6.6)$ \\
\hline $\begin{array}{l}\text { Gender } \\
\text { Male } \\
\text { Female }\end{array}$ & 0 & $\begin{array}{l}18(21.7 \%) \\
65(78.3 \%)\end{array}$ & $\begin{array}{l}18(29 \%) \\
44(71 \%)\end{array}$ & 0 & & $\begin{array}{l}18(31 \%) \\
40(69 \%)\end{array}$ \\
\hline Cognitive status (mean, SD) ${ }^{1}$ & 1 & $4.2(1.7)$ & $4.1(1.8)$ & 2 & $4.4(1.5)^{*}$ & $3.3(2.0)^{*}$ \\
\hline $\begin{array}{l}\text { Self performance in } \\
\text { activities of daily living }^{2}\end{array}$ & 15 & $3.6(1.8)$ & $3.5(1.9)$ & 13 & $3.7(1.8)$ & $3.5(2.0)$ \\
\hline Depression $^{3}$ & 0 & $2.5(2.5)^{*}$ & $1.3(1.8)^{*}$ & 6 & $2.6(2.5)^{*}$ & $0.7(1.3)^{*}$ \\
\hline Social engagement ${ }^{4}$ & 0 & $1.9(1.9)$ & $1.3(1.7)$ & 1 & $1.4(1.6)$ & $1.0(1.5)$ \\
\hline Mobility $^{5}$ & 3 & $12.0(11.9)$ & $12.8(12.0)$ & 4 & $12.2(12.2)$ & $13.2(11.8)$ \\
\hline $\begin{array}{l}\text { Fall }^{6} \\
\text { Incidence } \\
\text { Related injuries }\end{array}$ & & $\begin{array}{l}10(12 \%) \\
9(10.8 \%)\end{array}$ & $\begin{array}{l}6(9.7 \%) \\
2(3.2 \%)\end{array}$ & & $\begin{array}{l}4(4.7 \%) \\
2(2.3 \%)\end{array}$ & $\begin{array}{l}7(12.1 \%) \\
2(3.4 \%)\end{array}$ \\
\hline $\begin{array}{l}\text { Psychoactive drug use } \\
\text { No } \\
\text { Yes } \\
\text { When necessary } \\
\text { Yes and when necessary }\end{array}$ & 0 & $\begin{array}{l}49(59 \%) \\
32(39 \%) \\
0(0 \%) \\
2(2 \%)\end{array}$ & $\begin{array}{l}28(45 \%) \\
32(52 \%) \\
0(0 \%) \\
2(3 \%)\end{array}$ & 1 & $\begin{array}{l}36(42 \%) \\
45(53 \%) \\
2(2 \%) \\
2(2 \%)\end{array}$ & $\begin{array}{l}25(43 \%) \\
33(57 \%) \\
0(0 \%) \\
0(0 \%)\end{array}$ \\
\hline
\end{tabular}

*Indicates statistically significant difference between experimental and control group tested with chisquare test or an independent-samples t-test, $p$-value $\leq 0.05$;

'Cognitive scores from MDS Cognitive performance scale, range 0-6; score $0=$ Intact, $1=$ Borderline intact, 2=Mild impairment, $3=$ Moderate impairment, 4=Moderate severe impairment, $5=$ Severe impairment, $6=$ Very severe impairment;

${ }^{2}$ Self-performance level from MDS ADL Self-performance hierarchy, range 0-6; score $0=$ Independent, 1=Supervision, 2=Limited, 3=Extensive 1, 4=Extensive 2, 5=Dependent, $6=$ Total dependency;

${ }^{3}$ Depression level from MDS Depression rating scale, range $0-14$; scores $\geq 3$ indicate symptoms of depressions;

${ }^{4}$ Social engagement level from MDS Social engagement scale, range $0-6$; score 0 indicates low social engagement, score 6 indicates high social engagement;

${ }^{5}$ Mobility level from 7 items of the Minimum Data Set, range 0-28; score 0 indicates independent, score 28 indicates total dependency;

${ }^{6}$ Fall incidence and fall-related injuries from items of the Accident Registration Form;

${ }^{7}$ Psychoactive drug use from items of the Minimum Data Set

\section{Restraint prevalence}

Physical restraints were used with $85(59 \%)$ residents at baseline. Restraints were used most often at night (57\%) compared to restraint use in the morning $(32 \%)$, afternoon (32\%) and evening (39\%). As can been seen in Table 2, the prevalence of restraint use at baseline did not differ between the control and 
the experimental groups. However, at post-intervention the control group had a higher prevalence of restraint use $(69 \%)$ compared to the experimental group $(52 \%)$ and more residents in the control group were restrained at night.

Table 2 The number of psychogeriatric nursing home residents restrained at both measurements (absolute numbers and (\%))

\begin{tabular}{lll}
\hline & $\begin{array}{l}\text { Experimental group } \\
\text { (n (tO)=83; } \mathrm{n}(\mathrm{t} 1)=86)\end{array}$ & $\begin{array}{l}\text { Control group } \\
\text { (n (tO)=62; n (t1)=58) }\end{array}$ \\
\hline At baseline (=t0) & $47(56.6 \%)$ & $38(61.3 \%)$ \\
Morning & $29(34.9 \%)$ & $17(27.4 \%)$ \\
Afternoon & $26(31.3 \%)$ & $20(32.3 \%)$ \\
Evening & $31(37.3 \%)$ & $26(41.9 \%)$ \\
Night & $45(54.2 \%)$ & $37(59.7 \%)$ \\
\hline Post-intervention (=t1) & $45(52.3 \%)^{*}$ & $40(69.0 \%)^{*}$ \\
Morning & $28(32.6 \%)$ & $21(36.2 \%)$ \\
Afternoon & $25(29.1 \%)$ & $21(36.2 \%)$ \\
Evening & $24(27.9 \%)$ & $23(39.7 \%)$ \\
Night & $45(52.3 \%)^{*}$ & $40(69.0 \%)^{*}$ \\
\hline
\end{tabular}

*Indicates statistically significant difference between experimental and control group tested with chi-square test, $p$-value $\leq 0.05$

As the study progressed, restraint prevalence in the experimental group did not change significantly. Restraint prevalence during the morning, afternoon, evening and at night did also not change over time. However, restraint prevalence in the control group increased significantly from $56 \%$ to $70 \%$ $(p=0.021)$ (Figure 1), and there was a statistically significant increase in restraint use in the morning and at night.

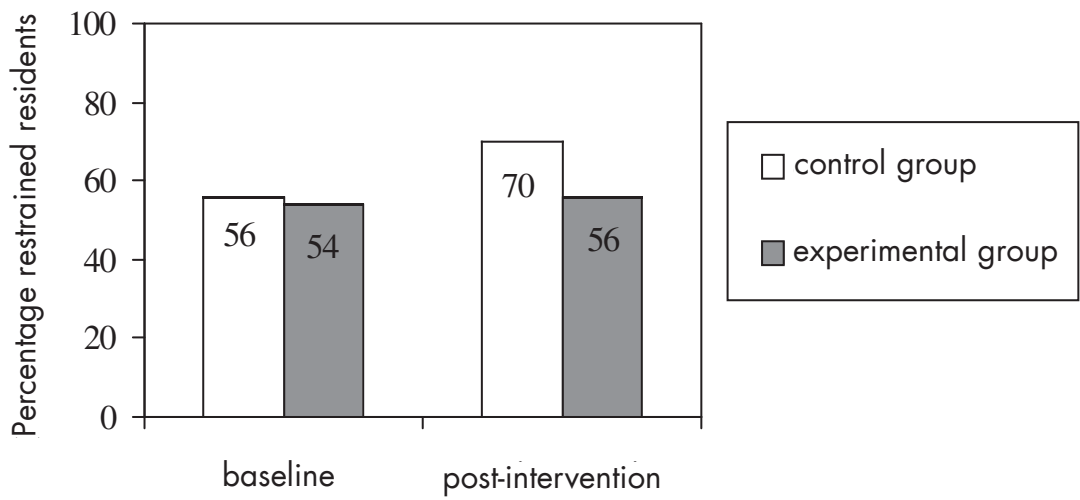

Figure 1 The percentage of psychogeriatric nursing home residents restrained by group over time $(n=126)$ 


\section{Restraint intensity}

The number of times during four observations that a resident was restrained during one day was studied in order to further explore restraint use with nursing home residents. At baseline, residents $(n=145)$ were restrained once $(17 \%)$, twice $(9 \%)$, three $(6 \%)$ or four times $(27 \%)$ a day, with a mean of 1.59 a day.

Comparison of restraint intensity and the average score of restraint intensity at both measurements showed no statistically significant differences between the experimental and control groups.

As shown in Table 3, there was a significant increase in the mean score of restraint intensity over time in the control group from 1.41 to 1.89 . The mean restraint intensity did not change over time in the experimental group. Although the mean score in the control group increased more (gain score $=0.48$ ) compared to the experimental group (gain score $=0.13$ ), the gain score difference was not statistically significant $(p=0.133)$.

Table 3 The restraint intensity of psychogeriatric nursing home residents by group over time (absolute numbers and (\%))

\begin{tabular}{lllll}
\hline & \multicolumn{2}{c}{ Experimental group $(\mathrm{n}=72)$} & \multicolumn{2}{c}{ Control group $(\mathrm{n}=54)$} \\
\cline { 2 - 5 } & At baseline & Post-intervention & At baseline & Post-intervention \\
\hline Not restrained & $33(45.8 \%)$ & $32(44.4 \%)$ & $24(44.4 \%)$ & $16(29.6 \%)$ \\
Once restrained & $12(16.7 \%)$ & $13(18.1 \%)$ & $10(18.5 \%)$ & $15(27.8 \%)$ \\
Twice restrained & $6(8.3 \%)$ & $3(4.2 \%)$ & $5(9.3 \%)$ & $1(1.9 \%)$ \\
Three times restrained & $4(5.6 \%)$ & $2(2.8 \%)$ & $4(7.4 \%)$ & $3(5.6 \%)$ \\
Four times restrained & $17(23.6 \%)$ & $22(30.6 \%)$ & $11(20.4 \%)$ & $19(35.2 \%)$ \\
\hline Mean restraint intensity & 1.44 & 1.57 & $1.41^{*}$ & $1.89 *$ \\
& $($ sd=1.652) & $($ sd=1.751) & $(\mathrm{sd}=1.596)$ & $(\mathrm{sd}=1.723)$ \\
\hline
\end{tabular}

* Indicates statistically significant difference between baseline and post-intervention tested with McNemar test and paired samples t-test (mean scores), $p$-value $\leq 0.05$

\section{Multiple restraints}

The number of different restraint types used per resident during 24 hours was calculated to investigate multiple restraint use. Up to five different types of restraint were used with residents during 24 hours (mean=1.05, sd=1.2) at baseline. Most often one restraint type (30\%) was used compared to two $(16 \%)$, three $(10 \%)$, four $(3 \%)$ and five $(1 \%)$ restraint types a day. The control group had a significantly higher mean score of multiple restraint use at postintervention compared to the experimental group ( $p=0.033$ ). The change in the average score of multiple restraint between both measurements was calculated for each subject with complete data to further explore changes in multiple restraint use. The mean multiple restraint use in the experimental group did not change over time $(p=0.874)$. However, this did increase in the control group 
from 1.04 to $1.39(p=0.006)$. The differences between groups in gain scores were also statistically significant $(p=0.026)$.

\section{Restraint types}

Based on data from both the measurements, 12 different restraint types were found to be used with nursing home residents. The most frequently used restraints at baseline were bilateral bedrails $(57 \%)$, sleep suits $(14 \%)$, belts in bed $(11 \%)$, belts in chairs $(8 \%)$, and chairs with a table (8\%). Bedrails were the most common restraint type used during the morning, afternoon, evening and at night. Bedrails were used at least once a day with $82(97 \%)$ restrained residents at baseline. Only infrared systems were not used besides or in combination with bilateral bedrails.

Comparison in the use of different restraint types at baseline between the control and experimental groups showed that more sleep suits were used with the control group (23\%) compared to the experimental group (7\%) $(p=0.008)$. At post-intervention, even more sleep suits were used with the control group $(36 \%)$ compared to the experimental group (12\%) ( $p \leq 0.001)$.

The use of sleep suits in the control group increased significantly over time from $22 \%$ to $38.9 \%(p=0.012)$. The increased use of belts in bed with the control group, from $9 \%$ to $19 \%$, nearly reached the level of statistical significance $(p=0.063)$. No significant changes occurred over time in the experimental group (Table 4).

Table 4 Types of restraints used in residents by group over time (absolute numbers and (\%))

\begin{tabular}{lllll}
\hline & \multicolumn{2}{c}{ Experimental group (n=72) } & \multicolumn{1}{c}{ Control group $(\mathrm{n}=54)$} \\
\cline { 2 - 5 } & At baseline & Post-intervention & At baseline & Post-intervention \\
\hline Bilateral bedrails & $38(52.8 \%)$ & $38(52.8 \%)$ & $28(51.9 \%)$ & $31(57.4 \%)$ \\
Sleep suit & $6(8.3 \%)$ & $8(11.1 \%)$ & $12(22.2 \%)^{*}$ & $21(38.9 \%)^{*}$ \\
Belt in bed & $10(13.9 \%)$ & $7(9.7 \%)$ & $5(9.3 \%)$ & $10(18.5 \%)$ \\
Belt in chair & $6(8.3 \%)$ & $5(6.9 \%)$ & $5(9.3 \%)$ & $8(14.8 \%)$ \\
Chair with a table & $5(6.9 \%)$ & $5(6.9 \%)$ & $3(5.6 \%)$ & $3(5.6 \%)$ \\
Chair with a board & $4(5.6 \%)$ & $2(2.8 \%)$ & $0(0 \%)$ & $0(0 \%)$ \\
Special sheet & $2(2.8 \%)$ & $5(6.9 \%)$ & $1(1.9 \%)$ & $1(1.9 \%)$ \\
Deep or overturned chair & $0(0 \%)$ & $0(0 \%)$ & $0(0 \%)$ & $1(1.9 \%)$ \\
Infrared system & $0(0 \%)$ & $0(0 \%)$ & $1(1.9 \%)$ & $0(0 \%)$ \\
Sensor mat & $0(0 \%)$ & $1(1.4 \%)$ & $0(0 \%)$ & $0(0 \%)$ \\
Vest with belt & $0(0 \%)$ & $0(0 \%)$ & $1(1.9 \%)$ & $0(0 \%)$ \\
Bedroom door locked & $0(0 \%)$ & $1(1.4 \%)$ & $0(0 \%)$ & $0(0 \%)$ \\
\hline
\end{tabular}

${ }^{*} p$-value $\leq 0.01$ (correction for multiple testing) 


\section{Logistic regression}

Logistic regression analyses were performed to compare restraint use between groups at post-intervention, controlling for ten characteristics of residents (Table 1). Table 5 shows the results of the backwards stepwise logistic regression. The final model demonstrated a significant treatment effect $(O R=0.129)$ on restraint use. Residents in the experimental group had a lower risk of restraint use compared to the control group. Cognitive status $(O R=2.051)$ and mobility $(O R=1.732)$ acted as confounding factors in the logistic regression analysis. The model also demonstrated that the effect of mobility on restraint use is lower for ADL-dependent residents compared to ADL-independent residents.

Table 5 Odds Ratios (OR) and 95\% Confidence Intervals (Cl) for restraint use post-intervention

\begin{tabular}{lllll}
\hline & $\beta$ & $p$-value & OR & $95 \% \mathrm{Cl}$ \\
\hline Treatment (1 =experimental) & -2.049 & 0.005 & 0.129 & $0.031-0.541$ \\
Cognitive status & 0.719 & 0.004 & 2.051 & $1.253-3.359$ \\
Mobility & 0.549 & 0.000 & 1.732 & $1.285-2.334$ \\
$\mathrm{ADL}^{*}$ & -0.314 & 0.258 & 0.731 & $0.424-1.258$ \\
$\mathrm{ADL}^{*} \times$ mobility & -0.066 & 0.012 & 0.936 & $0.889-0.986$ \\
Constant term & -2.427 & 0.004 & 0.088 & \\
\hline
\end{tabular}

*Self performance in activities of daily living

\section{Discussion}

The predominant finding of this study is that an educational programme for nurses combined with a nurse specialist does not decrease the use of physical restraints on psychogeriatric nursing home residents in the short term. However, the study showed that residents in the control group experienced more physical restraint use during the study period compared to the experimental group. The educational intervention seems to protect psychogeriatric nursing home residents from an increasing use of physical restraints.

\section{Methodological considerations}

A total of 167 psychogeriatric nursing home residents were selected for this study. The results must be interpreted with caution because of the relatively small number of residents. The residents were selected from five nursing home wards that belonged to one nursing home, which may limit the generalization of the study results. In addition, randomization on only five nursing homes wards probably increased the risk of type 2 errors occurring. ${ }^{28}$ The nursing home wards were assigned at random to the educational intervention. Efforts were made to reduce contamination bias between wards by limiting 
information for nurses about the study at the start of the study. The nurses and nurse staff were unaware of the aim and design of the study. After randomization the experimental wards were informed about the precise aim and design of the study and were requested to be careful with the information in regard to the control wards. An educational programme for nurses combined with consultation with a nurse specialist was introduced on the experimental nursing home wards. The implementation of nursing consultation in the nursing home wards is time-consuming. Therefore, the short-term effects of the educational intervention can be attributed only to the educational programme. The nurse specialist fulfilled her tasks during the educational programme. However, time was too short for the nurse specialist to perform all her tasks, such as visiting wards once a week and attending multidisciplinary meetings about residents in the nursing home wards. Follow-up studies are necessary to expand consultation with a nurse specialist in practice and to investigate the long-term effects of the educational intervention. Logistic regression analysis was performed to compare restraint use between groups at post-intervention, controlling for ten characteristics of residents. It might be possible that not all possible confounding factors were included in this analysis, because numerous characteristics of residents have been related to the use of physical restraints in the literature. ${ }^{4}$

\section{Results}

An educational programme for nurses combined with a nurse specialist did not decrease the use of physical restraints on psychogeriatric nursing home residents in the short term. There are some possible explanations for these results. First, changes in care generally take place slowly and change processes require a certain amount of time. ${ }^{19}$ Furthermore, reduction of restraint use in practice probably involves a 'paradigm shift'. ${ }^{18}$ From viewing behaviour as a problem to be controlled with physical restraints, nurses need to view behaviour as a communication of health state change or a need that is not met. ${ }^{18}$ Therefore, one month post-intervention might be a too short period to measure an effect on restraint use. Finally, another explanation for the fact that there was no decrease in physical restraint might be that the short-term effects of the educational intervention can be attributed only to the educational programme. Education is often a necessary first step in a process of implementation of innovations, although, Grol et al. ${ }^{19}$ also reported that there is still little research evidence to support the effectiveness of education. Additional interventions are probably necessary to change behaviour and to maintain the changes. ${ }^{19}$ The findings of Evans et al. ${ }^{6}$ also showed that although education is useful, a far greater effect on reducing restraints is achieved when 
education is combined with consultation. Therefore, studies concerning the long-term effects of educational interventions on restraint use are recommended.

Logistic regression analysis showed that residents in the control group were more likely to experience increased restraint use than residents in the experimental group. Mobility and cognitive status acted as confounding factors in the regression analysis. This can be confirmed by other studies showing that poor mobility and cognitive status are predictors of restraint use. ${ }^{2,7 \cdot 9}$ The analysis also showed that the control group had a significantly increased use of physical restraints over time compared to no significant changes in the experimental group. Residents became older during the study period, so an increased use of physical restraints in the control group was not unexpected. A recent study about restraint reduction also showed an increased use of restraints in the control group over time. ${ }^{29}$ The characteristics of the residents in the control group, with the exception of cognitive status and depression, were similar to the characteristics of those in the experimental group at postintervention. The residents in the experimental group were cognitively more impaired and had more symptoms of depression. In spite of the poorer cognitive status of residents in the experimental group, nurses were able to care for these residents without an increased use of physical restraints. The lower level of depression in the control group might have influenced the increased restraint use, due to a possible higher activity level associated with less depression. Furthermore, differences in organisational characteristics, such as the workload of the nurses and the staffing level, and other characteristics, like the level of fall prevention on the ward and attitudes of nurses, might explain the increased use of restraints in the control group. However, differences in these characteristics between both groups are unknown. Further research is recommended to gain insight into the relationship between these aspects and the use of physical restraints. Since the use of psychoactive drugs might be considered as chemical restraint and is related to the use of physical restraints, this relationship needs also further investigation.

The results regarding mean restraint intensity and mean multiple restraint use were in agreement with the restraint prevalence - the results showed no decrease in the experimental group and an increase in the control group. The same types of restraint were used with both groups, only sleep suits were used more often with residents in the control group. The hypothesis that the educational intervention leads to the use of less restrictive restraint types with residents could not be confirmed by this study.

Bilateral bedrails are the most frequently used restraint in psychogeriatric nursing home residents. Bedrails were used at least once a day with $97 \%$ of 
the restrained residents. Use of bedrails can be interpreted as standard for restrained residents based on these results. Hamers et al. ${ }^{2}$ reported that some nurses did not categorize the use of bedrails as a restraint method and probably regarded bedrails as a safe and routine intervention to prevent falls. Some nurses probably translate the use of bedrails as safe patient care. ${ }^{2,30}$ The efficacy, hazardous nature and restrictiveness of restraints, such as bedrails, are also under discussion in the literature. ${ }^{14,15,31}$ The use of bedrails is, for example, not always defined as a restraint. ${ }^{6,712}$ Viewing bedrails as a restraint that needs to be reduced in practice is recommended when the ineffectiveness and negative consequences of bedrails are taken into account. ${ }^{32}$ Further, more insight into the efficacy, hazardous nature and restrictiveness of physical restraints is necessary to gain a better understanding of restraint use with psychogeriatric nursing home residents. Therefore, insight into opinions and attitude of, for example, residents, family, nurses and other carers is essential to accomplish restraint-free care.

\section{Conclusions}

The conclusion from this study is that an educational programme for nurses seems to protect psychogeriatric nursing home residents from an increasing use of physical restraints, but that it does not decrease the use of restraints on residents in the short term. Before we can make recommendations regarding the usefulness of the educational intervention in clinical practice, however, further research is needed. In an ongoing study, with an increased sample size, we examine whether a reduction of restraint use can be obtained by expanding the consultation with the nurse specialist following on the educational programme. That study will also gain more insight into the longterm effects of the educational intervention. In addition, it is important to conduct a process evaluation to explain the success or failure of the intervention. Therefore, it is necessary to get more insight into the influence of organisational characteristics, like workload, autonomy and staff-mix, and the attitude of nurses towards restraint use and change. The challenge still remains to develop measures to expel the use of physical restraints from clinical practice.

\section{References}

1. Hamers JPH, Strik W, Smulders DCA, Gulpers MM, Lijnkamp LGAM. Het fixeren van bewoners in het verpleeghuis (Use of physical restraints with nursing home residents). Verpleegkunde 2001;16(4):188-96.

2. Hamers JPH, Gulpers MM, Strik W. Use of physical restraints with cognitively impaired nursing home residents. Journal of Advanced Nursing 2004;45(3):246-251. 
3. Koopmans RTCM. Beschermende maatregelen in een psychogeriatrisch verpleeghuis (Protective measures in a psychogeriatric nursing home). Tijdschr Gerontol Geriatr $1991 ; 22: 45-52$.

4. Hamers JPH, Huizing AR. Why do we use physical restraints in the elderly? Z Gerontol Geriat 2005;38:19-25.

5. Hantikainen V. Physical restraint: a descriptive study in Swiss nursing homes. Nursing Ethics 1998;5(4):330-346.

6. Evans LK, Strumpf NE, Allen-Taylor SL, Capezuti E, Maislin G, Jacobsen B. A clinical trial to reduce restraints in nursing homes. J Am Geriatr Soc 1997;45(6):675-681.

7. Dielis-van Houts AM, Lendemeijer BHGM, Hamers JPH. Op zoek naar een balans tussen: Veiligheid, Vrijheid en Vrijheidsbeperking. Een literatuuronderzoek naar het gebruik van vrijheidsbeperkende interventies in de zorg voor ouderen in ziekenhuizen en verpleeghuizen (Finding the balance between safety, freedom and restraint use. A state-of-the-art study on the use of restraints with elderly people in hospitals and nursing homes). In: Jongerden I, HeijenKaales Y, eds. State of the Art Studie verpleging \& verzorging. Utrecht: LEVV, 2003:29-62.

8. Sullivan-Marx EM, Strumpf NE, Evans LK, Baumgarten M, Maislin G. Predictors of continued physical restraint use in nursing home residents following restraint reduction efforts. J Am Geriatr Soc 1999;47(3):342-348.

9. Karlsson S, Bucht G, Eriksson S, Sandman PO. Physical restraints in geriatric care in Sweden: prevalence and patient characteristics. J Am Geriatr Soc 1996;44(1 1):1348-1354.

10. Capezuti E, Strumpf NE, Evans LK, Grisso JA, Maislin G. The relationship between physical restraint removal and falls and injuries among nursing home residents. Journal of Gerontology: MEDICAL SCIENCES 1998;53A(1):M47-M52.

11. Capezuti E, Evans L, Strumpf N, Maislin G. Physical restraint use and falls in nursing home residents. J Am Geriatr Soc 1996;44(6):627-633.

12. Neufeld RR, Libow LS, Foley WJ, Dunbar JM, Cohen C, Breuer B. Restraint reduction reduces serious injuries among nursing home residents. J Am Geriatr Soc 1999;47(10):1202-1207.

13. Burton LC, German PS, Rovner BW, Brant L. Physical restraint use and cognitive decline among nursing home residents. J Am Geriatr Soc 1992;40(8):811-6.

14. Miles SH, Irvine P. Deaths caused by physical restraints. The Gerontologist 1992;32(6):762766.

15. Castle NG, Mor V. Physical restraints in nursing homes: a review of the literature since the nursing home reform act of 1987. Medical Care Research and Review 1998;55(2):139-170.

16. Dielis-van Houts A, Schuurmans M. Een balans tussen: Veiligheid, Vrijheid en Vrijheidsbeperking (The balance between safety, freedom of movement and use of restraints). Utrecht, 2004.

17. $C B O, V W R$. Het gebruik van vrijheidsbeperkende interventies in de zorg. Een richtlijn voor verpleegkundigen en verzorgenden in een multidisciplinaire omgeving (The use of restraints in care situations. A guideline for nurses in a multidisciplinary environment). Utrecht: Kwaliteitsinstituut voor de Gezondheidszorg CBO, 2001. 
18. Strumpf NE, Robinson JP, Wagner JS, Evans LK. Restraint-free care; Individualized approaches for frail elders. New York: Springer Publishing Company, Inc., 1998.

19. Grol R, Wensing M, Eccles M. Improving Patient Care. The implementation of change in clinical practice. London: Elsevier, 2005.

20. Rogers EM. Diffusion of innovations. Fifth ed. New York: Free Press, 2003.

21. Morris JN, Fries BE, Mehr DR, et al. MDS Cognitive Performance Scale. Journal of Gerontology: MEDICAL SCIENCES 1994;49(4):M174-182.

22. Morris JN, Fries BE, Morris SA. Scaling ADLs within the MDS. Journal of Gerontology: MEDICAL SCIENCES 1999;54A(1 1):M546-53.

23. Burrows AB, Morris JN, Simon SE, Hirdes JP, Phillips C. Development of a Minimum Data Setbased depression rating scale for use in nursing homes. Age and Ageing 2000;29(165-172).

24. Mor V, Branco K, Fleishman J, et al. The structure of social engagement among nursing home residents. Journal of Gerontology: PSYCHOLOGICAL SCIENCES 1995;50B(1):P1-P8.

25. Achterberg WP, Pot AM, Van Campen C, Ribbe MW. Het Resident Assessment Instrument (RAl): een overzicht van internationaal onderzoek naar de psychometrische kwaliteiten en effecten van implementatie in verpleeghuizen (The Resident Assessment Instrument (RAl): a review of international research on the psychometric qualities and effects of implementation in nursing homes). Tijdschr Gerontol Geriatr 1999;30:264-70.

26. Holtkamp CCM. Effects of the Resident Assessment Instrument on Quality of Care and Quality of Life in Nursing Homes. Utrecht: NIVEL, 2003.

27. Arcares. Melding Incidenten Cliënten. In verpleeg- en verzorgingshuizen (Registration Accidents Clients. In nursing homes and homes for the elderly). Utrecht: Arcares, 2002.

28. Imbos T, Jansen MPE, Berger MPF. Methodologie en Statistiek (Methodology and Statistics). Maastricht: Universitaire Pers Maastricht, 1996.

29. Testad I, Aasland AM, Aarsland D. The effect of staff training on the use of restraint in dementia: a single-blind randomised controlled trial. Int J Geriatr Psychiatry 2005;20(6):58790.

30. Hoffman SB, Powell-Cope G, MacClellan L, Bero K. BedSAFE. A bed safety project for frail older adults. J Gerontol Nurs 2003;29(1 1):34-42.

31. Gallinagh R, Slevin E, McCormack B. Side rails as physical restraints in the care of older people: a management issue. J Nurs Manag 2002;10(5):299-306.

32. Inspectie voor de Gezondheidszorg. Veiligheidsrisico's bij het gebruik van bedden, bedhekken en fixatiemateriaal in verpleeghuizen (Risks in using bed rails and physical restraints in nursing homes). Den Haag: Inspectie voor de Gezondheidszorg, 2000. 
Effect evaluation: short-term effects 


\section{Chapter 5}

\section{A cluster-randomized trial of an educational intervention to reduce the use of physical restraints with psychogeriatric nursing home residents}

Anna R Huizing, Jan PH Hamers, Math JM Gulpers, Martijn PF Berger

Submitted for publication 


\section{Abstract}

Objectives: To investigate the effects of an educational intervention on the use of physical restraints with psychogeriatric nursing home residents.

Design: Cluster-randomized trial.

Setting: Fifteen psychogeriatric nursing home wards.

Participants: Four hundred thirty-two psychogeriatric nursing home residents from fifteen psychogeriatric nursing home wards.

Intervention: The nursing home wards were assigned at random to either educational intervention or control status. The educational intervention consisted of an educational programme for nurses combined with the consultation of a nurse specialist.

Measurements: Data were collected at baseline, one, four and eight months post-intervention. At each measurement, the use of physical restraints was measured using observations by blinded, trained observers on four separate occasions over a 24-hour period. Other resident characteristics, such as cognitive status, were determined using the Minimum Data Set (MDS).

Results: A total of 241 residents, who were involved in all four measurements, were included in the analyses. Logistic and linear regression analyses showed no treatment effect on the restraint status, restraint intensity and multiple restraint use in all three measurements post-intervention. Furthermore, only small changes occurred in the types of restraints used with residents in the experimental group.

Conclusion: An educational programme for nurses combined with the consultation of a nurse specialist had no effect on the use of physical restraints with psychogeriatric nursing home residents. In addition to restraint education and consultation, new measures to reduce the use of physical restraints with psychogeriatric nursing home residents should be developed. 


\section{Introduction}

Over the last decades reduction in the use of physical restraints on older persons has often been recommended in the literature. ${ }^{1.3}$ Nevertheless, physical restraints are still frequently used in nursing homes, with prevalence values ranging from $15 \%$ to $66 \%{ }^{2,4,5}$ Preventing falls and fall-related injuries is the main reason for using physical restraints on psychogeriatric nursing home residents. ${ }^{1,4,69}$ There are, however, various studies that conclude that the use of physical restraints is ineffective in preventing fall-related injuries. ${ }^{10-13}$ Furthermore, both prolonged and short periods of restraint use have negative physical, psychological and social consequences for nursing home residents. ${ }^{2,4,14,15}$ In addition, restraint use may increase the risk of serious injury and death., ${ }^{2,16}$ Despite the ineffectiveness and negative consequences of physical restraints, nurses still use restraints on psychogeriatric nursing home residents. Therefore, the challenge remains to develop measures to reduce the use of physical restraints in clinical practice.

Studies examining the effectiveness of restraint reduction programmes have been sparsely reported in the literature. ${ }^{17}$ So far, only two randomized controlled trials (RCT) have been performed to evaluate the effect of a restraint reduction programme in residential care. ${ }^{18,19}$ Evans et al. ${ }^{18}$ have shown that restraint education combined with specialist nurse consultation is effective in safely reducing the use of physical restraints. Testad et al. ${ }^{19}$ have shown that an education programme led to a reduced use of restraints on patients with dementia in nursing homes. The findings of both RCTs are supported by various other types of studies (see review by Evans et al. ${ }^{17}$ ), such as pre-post test design studies, suggesting that physical restraints can safely be reduced in residential care. However, in view of the limited number of RCT investigations, more RCTs on education and consultation are needed..$^{17}$

The aim of this study is to investigate the effects of an educational intervention, consisting of an educational programme combined with a nurse specialist's consultation, on the use of physical restraints on psychogeriatric nursing home residents. The following four hypotheses will be tested:

1. Educational intervention can decrease the use of physical restraints with psychogeriatric nursing home residents;

2. Educational intervention can change the types of physical restraints used with psychogeriatric nursing home residents so that the least restrictive restraint types will be used instead of more restrictive types;

3. Educational intervention can decrease the number of times within four observations over a 24-hour period that a psychogeriatric nursing home resident is restrained; 
4. Educational intervention can decrease the number of different types of physical restraints used per psychogeriatric nursing home resident as recorded in four observations over a 24-hour period.

\section{Methods}

\section{Design and sample}

Data were obtained in a cluster-randomized trial involving fifteen Dutch psychogeriatric nursing home wards, totaling 432 psychogeriatric nursing home residents. This sample did not include residents suffering from Korsakov's disease and psychiatric diseases residing in special Korsakov's or psychiatric wards. The fifteen psychogeriatric nursing home wards were assigned at random to either educational intervention (eight experimental wards) or control status (seven control wards). Nurses in the experimental group attended an educational programme on restraint use. Furthermore, consultation with a registered nurse specialized in the use of restraints and in their reduction (nurse specialist) was introduced in the experimental wards. There was no educational intervention in the control group and residents received care as usual. Data were collected at baseline and one, four and eight months post-intervention (Post-test 1, Post-test 2, Post-test 3).

\section{Intervention}

The intervention consisted of an educational programme combined with the consultation of a nurse specialist. The educational programme was designed to encourage nurses to adopt a philosophy of restraint-free care and to familiarize themselves with the techniques of individualized care. ${ }^{1}$ The educational programme, based on an educational programme of restraint use in hospital $\mathrm{s}^{20}$ and a paper about the decision-making process ${ }^{21}$, was taught by the nurse specialist and carried out over a two-month period. Several topics concerning physical restraints were discussed in five small-scale meetings, each lasting two hours. Seven nurses per experimental ward (key figures ${ }^{22}$ and different types of adopters ${ }^{23}$ ), including the charge nurse, were invited to attend the meetings. A 90-minute plenary session was organized for all the nurses of each experimental ward after the five small-scale meetings.

The nurse specialist was available for consultation 28 hours per week, visited the wards once a week, attended multidisciplinary meetings about residents and stimulated nurses to use alternatives for physical restraints and to use the least restrictive restraints, such as sensor mats. More detailed information concerning the intervention was described earlier. ${ }^{5}$ 


\section{Measures}

Any limitation on an individual's freedom of movement was regarded as a physical restraint. For this study an observation tool was designed to record the restraint data per resident (see Appendix). Types of restraints were recorded as absent or present. Examples of restraint types are belts tied to a chair or bed, bilateral bedrails, chairs with tables, deep or overturned chairs, chairs on a board (a chair with chair legs fixed to a board), special sheets (a fitted sheet including a coat enclosing a mattress), sleep suits, sensor mats (including sensor strips in beds) and infrared systems. The use of physical restraints was measured by trained observers $(n=11)$, who were blinded to the experimental and control conditions, on four separate occasions (morning, afternoon, evening, night) over a 24-hour period. The day of visit to each ward was unannounced to discourage any artificial removal of restraints by staff. ${ }^{18}$ Two of the eleven observers were selected to measure the inter-rater reliability. They scored the same residents with restraints $(K a p p a=1.0)$. The restraint status indicates whether the resident was observed to be restrained at any time in four observations over a 24-hour period (yes/no) (Hypothesis 1). All types of restraints used with psychogeriatric nursing home residents over the 24-hour period were also recorded (Hypothesis 2). Restraint intensity indicated the number of times in four observations over a 24-hour period that a resident was restrained (range 0-4) (Hypothesis 3). Multiple restraints indicated the number of different types of restraints used per resident recorded in four observations over a 24-hour period (Hypothesis 4).

The Minimum Data Set (MDS) version 2.1, which is part of the Resident Assessment Instrument (RAI) ${ }^{24}$, was used to collect data about age, gender, cognitive status, self-performance in activities of daily living, mobility, depression and social engagement of the residents at each measurement. The MDS was completed by trained nurses who worked on the wards. The nurses completed the questionnaires for residents in their care. Different scales based on items in the MDS were used to determine residents' characteristics. The Cognitive Performance Scale ${ }^{25}$ was used to determine the cognitive status of residents. The scores range from 0 (intact) to 6 (very severe impairment). Cronbach's alpha was 0.64 for the sample at baseline $(n=371)$. Selfperformance in activities of daily living (ADL status) was measured with the MDS ADL Self-performance Hierarchy. The scores range from 0 (independent) to 6 (total dependency). ${ }^{26}$ Cronbach's alpha was 0.86 . A mobility scale was developed from seven MDS items (movement in bed, transfer in and out of bed, transfer to standing up, walking in the room, walking in the corridor, locomotion on ward, locomotion outside the ward) to determine mobility in residents. The scores of the mobility scale range from 0 (independent) to 28 
(total dependency). Cronbach's alpha was 0.97. The Depression Rating Scale ${ }^{27}$ was used to determine depression in residents. The scores range from 0 to 14. Residents who score $\geq 3$ (cut-off score) on the scale require further evaluation to diagnose depression. Cronbach's alpha was 0.66 . The Social Engagement Scale was used to determine social engagement in residents. ${ }^{28}$ The scores range from 0 (lowest level of social engagement) to 6 (highest level of social engagement). Cronbach's alpha was 0.77 . The reliability and validity of the MDS and related scales have been tested and found to be sufficient in other studies. ${ }^{25.30}$

\section{Ethical considerations}

Approval for the study was obtained from the Medical Ethical Committee of the University Hospital Maastricht and Maastricht University. Representatives of the residents received written information about the study from the nursing home and the university. Based on this information the representatives were asked for written consent for the use of personal data on the residents in this study. Nurses and other employees of the nursing homes were informed about the study through presentations and written information. The trial identification number of this study is ISRCTN10117742.

\section{Data analysis}

Missing data analysis was performed to assess if any selective loss to followup or dropping out occurred during follow-up. Differences between the control and experimental group in restraint use and residents' characteristics were investigated using the chi-square test for variables at a dichotomous level and the independent samples t-test for variables at an interval and ratio level. The normality of variables was checked by frequencies and distribution tables. Based on these results the variable mobility was categorized into five groups (range: 0 "independent" to 4 "total dependency"). Within-group changes were evaluated by the $\mathrm{McNemar}$ test (restraint status, restraint types) and paired samples t-test (restraint intensity, multiple restraint). $P \leq 0.05$ was considered to be statistically significant.

Logistic regression analysis was performed within each measurement postintervention to examine the effect of the intervention on the restraint status of psychogeriatric nursing home residents (Hypothesis 1). Residents' characteristics, assumed to be correlated with restraint use, were entered as covariates in the analysis. The covariates included restraint status at baseline, age, gender, cognitive status, ADL status, mobility, depression and social engagement. The covariates were statistically tested in accordance with topdown procedure with a significance level of $\alpha=0.05$ for backward deletion. 
To examine changes in the types of restraints (Hypothesis 2) used during the measurements, the value of alpha was set at 0.01 in order to correct for multiple testing because of the increasing risk of Type 1 errors.

To examine the effect of the intervention on restraint intensity and multiple restraint (Hypothesis 3 and 4) change scores were calculated by subtracting scores at Post-test 1, 2 and 3 from baseline scores. Between-group differences in effect were compared by applying the independent samples t-test. Furthermore, linear regression analysis was performed within each measurement post-intervention. The covariates and top-down procedure were similar to the logistic regression analysis for restraint status.

The analyses were based on list-wise deletion of missing data and performed using SPSS, version 13.0.

\section{Results}

\section{Sample}

\section{Residents}

As can be seen from Figure 1, a total of 432 residents were selected for participation in this study and informed consent was obtained for 404 of them. At baseline, 371 psychogeriatric nursing home residents were included. During the study 130 residents dropped out, mainly because these residents died. A total of 241 residents attended all four measurements. At baseline, the mean age of the residents was 83 years $(S D=7.1)$ and the sample consisted of 51 $(21 \%)$ men and $190(79 \%)$ women. As can be seen from Table 1, there were no differences between the experimental and control group in resident characteristics at baseline. 


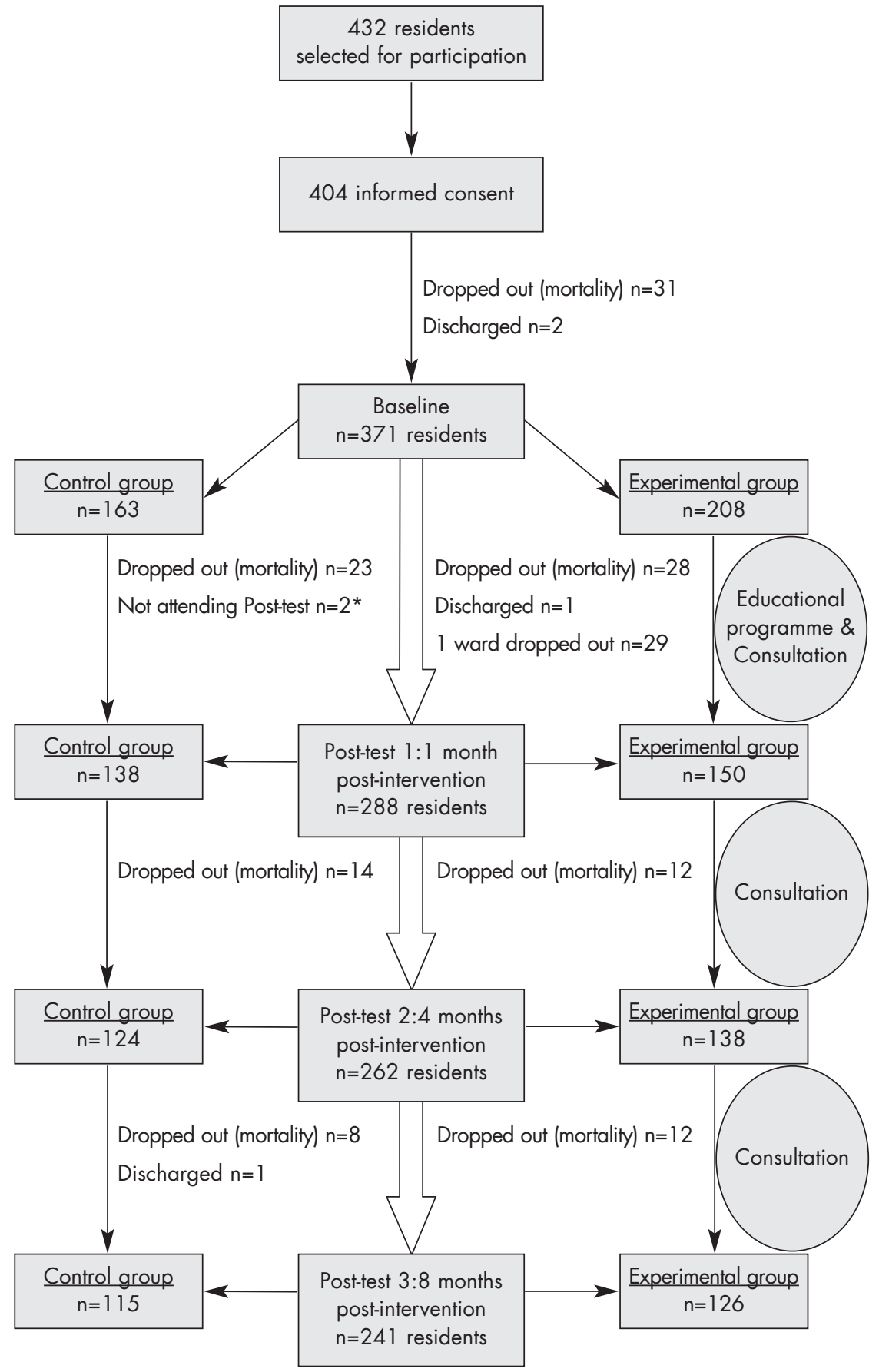

*One resident was admitted to a hospital at Post-test 1 and for one resident the reason is unknown

Figure 1 Response flow 
Comparison of baseline characteristics of residents who attended all four measurements and residents who dropped out during the study showed that these groups differed on most of the characteristics (Table 1). Moreover, more restraints $(p=0.032)$ were used with residents who dropped out and the restraint intensity $(p=0.004)$ was significantly higher among this group at baseline. The multiple restraint use was not significantly different in both groups.

Table 1 Baseline comparison of residents characteristics in the experimental group versus control group ( $n=241)$ and residents who attended all four measurements versus dropouts $(n=371)$

\begin{tabular}{|c|c|c|c|c|c|c|c|c|}
\hline $\begin{array}{l}\text { Resident } \\
\text { characteristics } \\
(M, S D)\end{array}$ & $\begin{array}{l}\text { Missing } \\
\text { values }\end{array}$ & $\begin{array}{l}\text { Control } \\
(n=115)\end{array}$ & $\begin{array}{l}\text { Experimental } \\
(n=126)\end{array}$ & p-value & $\begin{array}{l}\text { Missing } \\
\text { values }\end{array}$ & $\begin{array}{l}4 \text { measure- } \\
\text { ments } \\
(n=241)\end{array}$ & $\begin{array}{l}\text { Dropouts } \\
(n=130)\end{array}$ & p-value \\
\hline Age in years & 0 & $83.4(6.5)$ & $82.0(7.7)$ & 0.124 & 0 & $82.7(7.1)$ & $84.5(6.2)$ & 0.012 \\
\hline Gender & 0 & & & 0.673 & 0 & & & 0.537 \\
\hline male & & $23(20.0 \%$ & $28(22.2 \%)$ & & & $51(21.2 \%)$ & $24(18.5 \%)$ & \\
\hline female & & $92180.0 \%$ & $98(77.8 \%)$ & & & $190(78.8 \%)$ & $106(81.5 \%)$ & \\
\hline Cognitive status ${ }^{\dagger}$ & 0 & $3.6(1.7)$ & $3.9(1.7)$ & 0.202 & 3 & $3.8(1.7)$ & $4.2(1.7)$ & 0.029 \\
\hline ADL status ${ }^{\ddagger}$ & 12 & $3.2(2.0)$ & $3.4(1.8)$ & 0.412 & 22 & $3.3(1.9)$ & $4.1(1.8)$ & $<0.001$ \\
\hline Mobility ${ }^{\S}$ & 2 & $1.6(1.6)$ & $1.7(1.7)$ & 0.639 & 6 & $1.6(1.7)$ & $2.3(1.7)$ & $<0.001$ \\
\hline Depression ${ }^{\varphi}$ & 6 & $1.6(1.9)$ & $2.1(2.2)$ & 0.091 & 9 & $1.9(2.1)$ & $1.8(2.2)$ & 0.655 \\
\hline $\begin{array}{l}\text { Social } \\
\text { engagement }^{\sigma}\end{array}$ & 0 & $1.8(1.7)$ & $1.9(1.8)$ & 0.561 & 2 & $1.8(1.7)$ & $1.4(1.7)$ & 0.010 \\
\hline
\end{tabular}

"absolute numbers and (\%)

${ }^{\dagger}$ MDS Cognitive Performance Scale, range 0 (intact) to 6 (very severe impairment)

${ }^{\ddagger}$ MDS ADL Self-performance Hierarchy, range 0 (independent) to 6 (total dependency)

${ }^{\S}$ Scale developed from seven MDS items; the variable mobility was categorized into five groups, range 0 (independent) - 4 (total dependency)

MDS Depression Rating Scale, range 0-14; scores $\geq 3$ indicate symptoms of depression ${ }^{\sigma} M D S$ Social Engagement Scale, range 0 (lowest level of social engagement) to 6 (highest level of social engagement)

\section{Nurses altending educational programme}

A total of 48 nurses were selected to attend the educational programme. Out of this sample, one person attended none of the meetings. The sample consisted mostly of women $(80 \%)$ and the mean age was 37 years (SD=10.0). These persons were qualified as care workers $(64 \%)$, charge nurses $(13 \%)$, registered nurses $(11 \%)$, care helpers $(4 \%)$, care assistants $(2 \%)$ and student care workers $(2 \%)$.

\section{The effects of the intervention on the use of physical restraints}

\section{Restraint status}

At baseline, physical restraints were used with 124 (52\%) psychogeriatric nursing home residents (residents who attended all four measurements: 
$n=241$ ). Restraint use did not differ between the control and experimental group (Figure 2; Chart A). During the three post-tests there also was no statistically significant difference between the control and experimental group in restraint use. In both groups the use of restraints increased over time (Figure 2; Chart A). The control group increased significantly from $49 \%$ (baseline) to $57 \%$ (Post-test 2; $p=0.021$ ) and to 60\% (Post-test 3; $p=0.007$ ). In the experimental group only the change between baseline $(54 \%)$ and Post-test 3 $(64 \%)(p=0.019)$ was statistically significant. Logistic regression analyses, performed for the three measurements post-intervention, showed that there was no treatment effect in these three measurements (Table 2).

Table 2 Logistic regression for restraint status and linear regression for restraint intensity and multiple restraints at each measurement post-intervention $(n=241)$

\begin{tabular}{|c|c|c|c|c|c|c|}
\hline Outcome & Post-test & Variables & $\beta$ & p-value & OR & $95 \% \mathrm{Cl}$ \\
\hline \multirow[t]{12}{*}{ Restraint status } & \multirow[t]{3}{*}{ Post-test 1} & Treatment $(1=$ experimental) & -0.115 & 0.795 & 0.891 & $0.373-2.128$ \\
\hline & & Restraint status at baseline & 2.677 & $<0.001$ & 14.539 & $5.815-36.352$ \\
\hline & & Mobility at Post-test 1 & 0.810 & $<0.001$ & 2.247 & $1.656-3.049$ \\
\hline & \multirow[t]{4}{*}{ Post-test 2} & Treatment ( $1=$ experimental) & -0.040 & 0.927 & 0.960 & $0.405-2.280$ \\
\hline & & Restraint status at baseline & 2.788 & $<0.001$ & 16.253 & $5.992-44.084$ \\
\hline & & Cognitive status at Post-test 2 & 0.442 & 0.003 & 1.556 & $1.167-2.075$ \\
\hline & & Mobility at Post-test 2 & 0.709 & $<0.001$ & 2.033 & $1.476-2.799$ \\
\hline & \multirow[t]{5}{*}{ Post-test 3} & Treatment $(1=$ experimental) & -0.077 & 0.850 & 0.926 & $0.415-2.063$ \\
\hline & & Restraint status at baseline & 1.909 & $<0.001$ & 6.747 & $2.647-17.197$ \\
\hline & & Cognitive status at Post-test 3 & 0.445 & 0.001 & 1.560 & $1.194-2.039$ \\
\hline & & Mobility at Post-test 3 & 0.658 & $<0.001$ & 1.930 & $1.434-2.598$ \\
\hline & & & $\beta$ & se & $t$ & p-value \\
\hline \multirow[t]{10}{*}{ Restraint intensity } & \multirow[t]{3}{*}{ Post-test 1} & Treatment $(1=$ experimental) & -0.120 & 0.121 & -0.991 & 0.323 \\
\hline & & Restraint intensity at baseline & 0.583 & 0.051 & 11.459 & $<0.001$ \\
\hline & & Mobility at Post-test 1 & 0.291 & 0.049 & 5.896 & $<0.001$ \\
\hline & \multirow[t]{3}{*}{ Post-test 2} & Treatment ( $1=$ experimental) & 0.066 & 0.136 & 0.486 & 0.627 \\
\hline & & Restraint intensity at baseline & 0.464 & 0.056 & 8.318 & $<0.001$ \\
\hline & & Mobility at Post-test 2 & 0.464 & 0.055 & 8.425 & $<0.001$ \\
\hline & \multirow[t]{4}{*}{ Post-test 3} & Treatment ( $1=$ experimental) & -0.106 & 0.149 & -0.711 & 0.478 \\
\hline & & Restraint intensity at baseline & 0.345 & 0.061 & 5.678 & $<0.001$ \\
\hline & & Cognitive status at Post-test 3 & 0.158 & 0.052 & 3.049 & 0.003 \\
\hline & & Mobility at Post-test 3 & 0.457 & 0.063 & 7.260 & $<0.001$ \\
\hline \multirow[t]{10}{*}{ Multiple restraints } & \multirow[t]{3}{*}{ Post-test 1} & Treatment $(1=$ experimental $)$ & -0.141 & 0.082 & -1.731 & 0.085 \\
\hline & & Multiple restraints at baseline & 0.679 & 0.048 & 14.260 & $<0.001$ \\
\hline & & Mobility at Post-test 1 & 0.123 & 0.031 & 3.956 & $<0.001$ \\
\hline & \multirow[t]{4}{*}{ Post-test 2} & Treatment ( $1=$ experimental) & -0.120 & 0.107 & -1.120 & 0.264 \\
\hline & & Multiple restraints at baseline & 0.549 & 0.062 & 8.854 & $<0.001$ \\
\hline & & Cognitive status at Post-test 2 & 0.080 & 0.035 & 2.315 & 0.022 \\
\hline & & Mobility at Post-test 2 & 0.130 & 0.045 & 2.876 & 0.004 \\
\hline & \multirow[t]{3}{*}{ Post-test 3} & Treatment ( 1 =experimental) & -0.094 & 0.117 & -0.803 & 0.423 \\
\hline & & Multiple restraints at baseline & 0.497 & 0.066 & 7.535 & $<0.001$ \\
\hline & & Mobility at Post-test 3 & 0.183 & 0.045 & 4.112 & $<0.001$ \\
\hline
\end{tabular}




\section{Restraint types}

The most frequently used restraints at baseline were bilateral bedrails $(45 \%)$, belts in chair $(10 \%)$, belts in bed $(9 \%)$ and sleep suits $(8 \%)$. At baseline, there were no statistically significant differences per restraint type between the control and experimental group (Table 3). However, at Post-test 1, 2 and 3 the control group had a higher use of sleep suits than did the experimental group. Comparison at Post-test 2 showed that the experimental group had a higher use of deep or overturned chairs $(18 \%)$ as compared to the control group (6\%) $(p=0.004)$. In the experimental group the use of belts in bed decreased significantly over time from baseline to Post-test 2 ( $p=0.001)$. The use of deep or overturned chairs in the experimental group increased significantly from baseline to Post-test $2(p<0.001)$ and to Post-test $3(p<0.001)$. Furthermore, the use of infrared systems increased significantly $(p=0.004)$ from $2 \%$ (baseline) to 9\% (Post-test 3). In the control group the use of bilateral bedrails increased significantly from baseline to Post-test $3(p=0.004)$.

Table 3 Difference between the experimental $(E)(n=126)$ and control $(C)$ group $(n=115)$ in the use of physical restraints with psychogeriatric nursing home residents per restraint type (\%)

\begin{tabular}{llllllllll}
\hline & \multicolumn{3}{c}{ Baseline } & \multicolumn{2}{c}{ Post-test 1 } & \multicolumn{2}{c}{ Post-test 2 } & \multicolumn{2}{l}{ Post-test 3 } \\
Restraint type (\%) & C & E & C & E & C & E & C & E \\
\hline Belt in chair & 10 & 9 & 11 & 6 & 12 & 8 & 9 & 13 \\
Belt in bed & 6 & 12 & 10 & 7 & 10 & $3^{\dagger}$ & 10 & 4 \\
Bilateral bedrails & 41 & 48 & 45 & 49 & 48 & 52 & $52^{\dagger}$ & 52 \\
Chair with a table & 4 & 8 & 4 & 5 & 5 & 6 & 14 & 5 \\
Deep or overturned chair & 5 & 6 & 5 & 10 & $6^{*}$ & $18^{* \dagger}$ & 12 & $20^{\dagger}$ \\
Chair on a board & 0 & 3 & 0 & 2 & 0 & 2 & 0 & 2 \\
Special sheet & 4 & 2 & 4 & 3 & 5 & 4 & 7 & 5 \\
Sleep suit & 10 & 5 & $17^{*}$ & $6^{*}$ & $16^{*}$ & $6^{*}$ & $17^{*}$ & $4^{*}$ \\
Sensor mat & 4 & 4 & 4 & 5 & 1 & 3 & 1 & 3 \\
Infrared system & 4 & 2 & 2 & 2 & 6 & 3 & 5 & $9^{\dagger}$ \\
Bedroom door locked & 0 & 0 & 0 & 1 & 0 & 0 & 0 & 0 \\
(Wheel)chair on the & 0 & 0 & 0 & 0 & 0 & 1 & 0 & 2 \\
\multicolumn{1}{l}{ brakes at the table } & & & & & & & & \\
\hline
\end{tabular}

* statistically significant difference (between groups) tested with chi-square test; $p \leq 0.01$ (correction for multiple testing)

† statistically significant difference (within-group changes compared to baseline) tested with McNemar test; $p \leq 0.01$ (correction for multiple testing)

\section{Restraint intensity}

At baseline, residents were restrained once (17\%), twice $(6 \%)$, three $(7 \%)$, or four $(22 \%)$ times $(M=1.36, \mathrm{SD}=1.62)$ in four observations over a 24 -hour period. The restraint intensity did not differ statistically significant between the experimental and control group (Figure 2; Chart B). Also no differences were found during the three post-tests. In both groups the restraint intensity increased 
over time (Figure 2; Chart B). The increase was statistically significant for both groups from baseline to Post-test $2\left(p_{\text {control }}=0.002 ; p_{\text {experimental }}=0.008\right)$ and to Post-test 3 ( $\left.p_{\text {control }}<0.001 ; p_{\text {experimental }}=0.001\right)$. Wilcoxon Signed Ranks Test was also used because of a non-normality in variable restraint intensity, and the same results were found. Between-group changes were not significant at all three measurements. Linear regression analyses, performed for the three measurements post-intervention, showed that there was no treatment effect on restraint intensity in these three measurements (Table 2)

\section{Multiple restraints}

At baseline, a total of one (23\%), two (17\%), three $(10 \%)$ or four $(2 \%)$ different restraint types were used per resident $(M=0.93, S D=1.10)$, recorded in four observations over a 24-hour period. The difference in multiple restraint use was not statistically significant between the experimental and control group at baseline (Figure 2; Chart C). Also no differences were found during the three post-tests. In the control group, multiple restraint use showed a statistically significant increase over time (Figure 2; Chart $C$ ). The control group increased from 0.89 ( $S D=1.07$ ) (baseline) to $1.03(S D=1.13$ ) (Post-test 1; $p=0.029$ ), to $1.10(\mathrm{SD}=1.20)$ (Post-test 2; $p=0.017)$ and to 1.17 (SD=1.21) (Post-test 3; $p=0.002)$. In the experimental group, the within-group change from baseline to Post-test $3(p=0.039)$ was statistically significant. Wilcoxon Signed Ranks Test was also used because of a non-normality in variable multiple restraint, showing the same results. Furthermore, between-group changes were statistically significant from baseline to Post-test 1 ( $p=0.044)$. Multiple restraint use in the experimental group decreased (gain score $=0.02$ ) as compared to increased multiple restraint use (gain score $=-0.15$ ) in the control group. However, between-group changes from baseline to Post-test 2 and Post-test 3 were not statistically significant. Linear regression analyses, performed for the three measurements post-intervention, showed that there was no treatment effect on multiple restraint in these three measurements (Table 2).

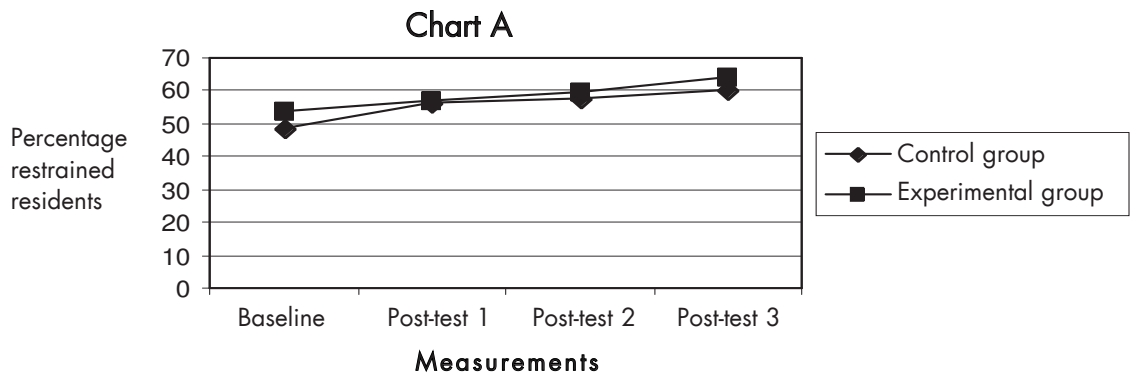


Chart B
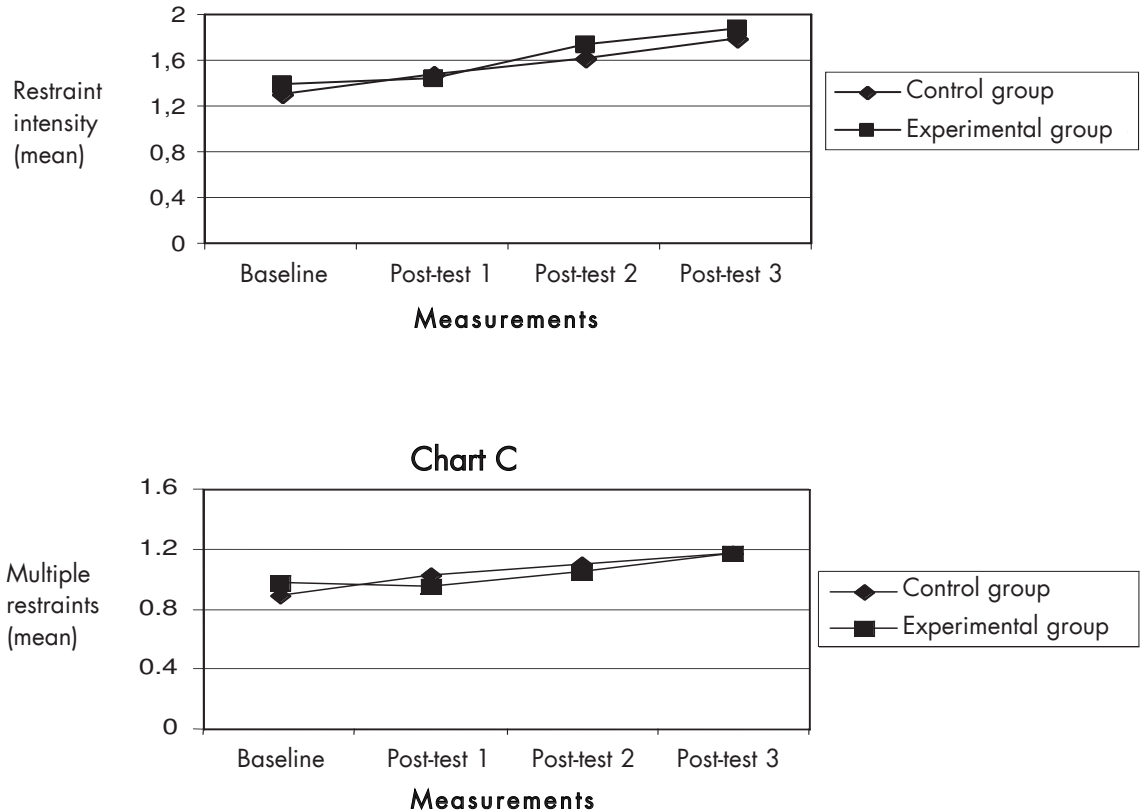

Figure 2 Changes in the use of physical restraints (Chart A), restraint intensity (Chart B) and multiple restraints (Chart C) with psychogeriatric nursing home residents by group over time $(n=241)$

\section{Discussion}

This study has shown that an educational programme for nurses combined with the consultation of a nurse specialist was not effective in reducing the use of physical restraints with psychogeriatric nursing home residents. Logistic and linear regression analyses showed no treatment effect in all three measurements post-intervention for restraint status, restraint intensity and multiple restraint (Hypotheses 1, 3, 4). Only small changes occurred in the types of restraints used with residents (Hypotheses 2). In order to compare these results with other studies on restraint use, the analyses concerning restraint status were also performed excluding the use of bilateral bedrails, sensor mats and infrared systems. However, the intervention was still shown to be ineffective in reducing restraint use. The results of this study did not confirm the results of two other RCT studies showing the effectiveness of restraint reduction programmes in residential care. ${ }^{18,19}$ Only one pre-post test design study evaluating restraint education also failed to demonstrate a reduction in restraint use. ${ }^{31}$

There are some possible explanations for the findings in this study. First, 
studies about restraint-reduction programmes collected restraint data using different data collection methods, such as residents' records, questionnaires and interviews ${ }^{12,19,32}$, in which those persons involved in data collection sometimes also participated in the intervention. This may result in an overestimation of the intervention effect. To maximize the reliability of the restraint data in the present study, these data were collected by blinded, trained observers, just like in Evans et al. ${ }^{18}$ Second, carrying out the educational programme for nurses only might explain the ineffectiveness of the intervention. Although nurses in Dutch nursing homes play an important role in the decisionmaking process regarding restraint $u^{33} \mathrm{e}^{33}$, a continuing multidisciplinary educational programme may be worthwhile. In addition, the intervention was implemented on a nursing home ward level as compared to other restraintreduction programmes involving the entire organization. 18,34,35 However, the educational programme was comparable for duration and content with restraint education in other studies. ${ }^{17}$ Third, changes in care generally take place slowly and change processes require a certain amount of time. ${ }^{22}$ With regard to the transition to restraint-free care, which involves a "paradigm shift", the process of change can be slow.' The present study showed no effect from the intervention at one, four and eight month post-intervention. This result might imply that more effort is needed to change practice regarding restraint use.

The effect of the intervention on the types of restraints used with residents was small. Considering the use of belts to be one of the most restrictive types of restraints, a positive change did occur in the experimental group with regard to decreasing the use of belts in bed from baseline to Post-test 2. In addition, the increased use of infrared systems from baseline to Post-test 3 can be interpreted as positive. However, the use of most of the restraint types did not change. More effort is needed to further stimulate use of the least restrictive restraints and their alternatives. In an ongoing international study about nurses' attitudes towards restraint use, coordinated by the second author of this article, the opinion of nurses about restrictiveness per restraint type will be examined in order to improve the understanding of the process towards restraint-free care.

During the study, the use of physical restraints (restraint status), restraint intensity and multiple restraint use increased over time in both groups, except for a decreased (not significant) multiple restraint use from baseline to Post-test 1 in the experimental group. In view of the increasing age of the residents and the accompanying infirmities, an increase in restraint use, restraint intensity and multiple restraints in the control group was not unexpected. Testad et al. ${ }^{19}$ also showed an increase in restraint use in the control group over time.

Logistic and linear regression analyses showed that the covariates restraint 
use at baseline (restraint status, restraint intensity, multiple restraint), mobility and cognitive status of residents were associated with restraint use. The associations between the use of restraints and mobility and cognitive status are in line with other studies. ${ }^{4,36} \cdot 38$ These results imply that mobilization of psychogeriatric nursing home residents is very important in preventing restraint use. Efforts to promote and maintain mobility of residents are, therefore, strongly recommended.

Physical restraints were used with $52 \%$ of the psychogeriatric nursing home residents. This high prevalence value is in line with other studies showing that restraints are frequently used with nursing home residents. ${ }^{4,12,39}$ However, comparison of international prevalence values of physical restraints is limited, given the different definitions of restraint and different data collection methods used. $^{2,3}$ For example, some studies ${ }^{12,18}$ do not categorize bedrails and sensor devices as restraint methods. To emphasize that any limitation on an individual's freedom of movement may prove harmful for psychogeriatric nursing home residents and should be carefully evaluated, a broad definition of restraints was used in this study. However, this influences the high prevalence value of restraint use.

This study has some limitations. First off, the sample consisted of nursing home residents from fifteen nursing home wards belonging to one coordination organization for the care of older people in the south of the Netherlands, which may limit the generalization of the results. Secondly, comparison between residents who attended all four measurements and residents who dropped out during the study on baseline characteristics showed that dropped-outs were older, more functionally impaired, and concurrently showed that more restraints were used. Although the loss of older residents with more functional impairments during the study period was not surprising, it implies that the intervention was tested with less impaired residents. Thirdly, contamination bias might be a problem in this study. However, efforts were made to reduce contamination bias between wards by limiting information for nurses concerning the aim and design of the study from the start of the study. After randomization the experimental wards were fully informed and were requested to be careful with the information vis-à-vis the control wards. Fourthly, consultation, as part of the intervention, was carried out by only one nurse specialist, which might not be enough to assist nurses sufficiently in reducing restraint use. Fifthly, the extent to which nurses embraced a philosophy of restraint-free care and amassed knowledge about restraint use through this intervention is unknown. Furthermore, no information is available about factors influencing the effectiveness of the intervention. In further studies, effect evaluation combined with process evaluation is, therefore, recommended. 
Despite these limitations, the study demonstrated that an educational programme for nurses combined with the consultation of a nurse specialist does not decrease the use of physical restraints with psychogeriatric nursing home residents. In addition to restraint education and consultation, new measures to reduce the use of physical restraints with psychogeriatric nursing home residents should be developed.

\section{References}

1. Strumpf NE, Robinson JP, Wagner JS, Evans LK. Restraint-free care; Individualized approaches for frail elders. New York: Springer Publishing Company, Inc., 1998.

2. Hamers JPH, Huizing AR. Why do we use physical restraints in the elderly? Z Gerontol Geriat 2005;38:19-25.

3. Dielis-van Houts AM, Lendemeijer BHGM, Hamers JPH. Op zoek naar een balans tussen: Veiligheid, Vrijheid en Vrijheidsbeperking. Een literatuuronderzoek naar het gebruik van vrijheidsbeperkende interventies in de zorg voor ouderen in ziekenhuizen en verpleeghuizen (Finding the balance between safety, freedom and restraint use. A state-of-the-art study on the use of restraints with elderly people in hospitals and nursing homes). In: Jongerden I, HeijenKaales Y, eds. State of the Art Studie verpleging \& verzorging. Utrecht: LEVV, 2003:29-62.

4. Hamers JPH, Gulpers MM, Strik W. Use of physical restraints with cognitively impaired nursing home residents. Journal of Advanced Nursing 2004;45(3):246-251.

5. Huizing AR, Hamers JPH, Gulpers MM, Berger MPF. Short-term effects of an educational intervention on physical restraint use: a cluster randomized trial. BMC Geriatrics 2006;6(17).

6. Hantikainen V. Physical restraint: a descriptive study in Swiss nursing homes. Nursing Ethics 1998;5(4):330-346.

7. Retsas AP, Crabbe H. Use of physical restraints in nursing homes in New South Wales, Australia. Int J Nurs Stud 1998;35(3):177-183.

8. Evans LK, Strumpf NE. Myths about elder restraint. Image J Nurs Sch 1990;22(2):124-8.

9. Evans $D$, FitzGerald $B$. Reasons for physically restraining patients and residents: a systematic review and content analysis. Int J Nurs Stud 2002;39:735-743.

10. Capezuti E, Evans L, Strumpf N, Maislin G. Physical restraint use and falls in nursing home residents. J Am Geriatr Soc 1996;44(6):627-633.

11. Kron M, Loy S, Sturm E, Nikolaus T, Becker C. Risk indicators for falls in institutionalized frail elderly. Am J Epidemiol 2003;158(7):645-653.

12. Neufeld RR, Libow LS, Foley WJ, Dunbar JM, Cohen C, Breuer B. Restraint reduction reduces serious injuries among nursing home residents. J Am Geriatr Soc 1999;47(10):1202-1207.

13. Dunn KS. The effect of physical restraints on fall rates in older adults who are institutionalized. J Gerontol Nurs $2001 ; 27(10): 40-48$.

14. Burton LC, German PS, Rovner BW, Brant L. Physical restraint use and cognitive decline among nursing home residents. J Am Geriatr Soc 1992;40(8):81 1-6.

15. Castle NG, Mor V. Physical restraints in nursing homes: a review of the literature since the 
nursing home reform act of 1987. Medical Care Research and Review 1998;55(2):139-170.

16. Evans D, Wood J, Lambert L. Patient injury and physical restraint devices: a systematic review. Journal of Advanced Nursing 2003;41(3):274-282.

17. Evans D, Wood J, Lambert L. A review of physical restraint minimization in the acute and residential care settings. Journal of Advanced Nursing 2002;40(6):616-25.

18. Evans LK, Strumpf NE, Allen-Taylor SL, Capezuti E, Maislin G, Jacobsen B. A clinical trial to reduce restraints in nursing homes. J Am Geriatr Soc 1997;45(6):675-681.

19. Testad I, Aasland AM, Aarsland D. The effect of staff training on the use of restraint in dementia: a single-blind randomised controlled trial. Int J Geriatr Psychiatry 2005;20(6):58790.

20. Dielis-van Houts A, Schuurmans M. Een balans tussen: Veiligheid, Vrijheid en Vrijheidsbeperking (The balance between safety, freedom of movement and use of restraints). Utrecht, 2004.

21. $C B O$, VWR. Het gebruik van vrijheidsbeperkende interventies in de zorg. Een richtlijn voor verpleegkundigen en verzorgenden in een multidisciplinaire omgeving (The use of restraints in care situations. A guideline for nurses in a multidisciplinary environment). Utrecht: Kwaliteitsinstituut voor de Gezondheidszorg CBO, 2001.

22. Grol R, Wensing M, Eccles M. Improving Patient Care. The implementation of change in clinical practice. London: Elsevier, 2005.

23. Rogers EM. Diffusion of innovations. Fifth ed. New York: Free Press, 2003.

24. interRAI. RAl for Nursing Home Care (RAI 2.1). Utrecht: interRAI Corporation, 2002.

25. Morris JN, Fries BE, Mehr DR, et al. MDS Cognitive Performance Scale. Journal of Gerontology: MEDICAL SCIENCES 1994;49(4):M174-182.

26. Morris JN, Fries BE, Morris SA. Scaling ADLs within the MDS. Journal of Gerontology: MEDICAL SCIENCES 1999;54A(1 1):M546-53.

27. Burrows AB, Morris JN, Simon SE, Hirdes JP, Phillips C. Development of a Minimum Data Setbased depression rating scale for use in nursing homes. Age and Ageing 2000;29(165-172).

28. Mor V, Branco K, Fleishman J, et al. The structure of social engagement among nursing home residents. Journal of Gerontology: PSYCHOLOGICAL SCIENCES 1995;50B(1):P1-P8.

29. Achterberg WP, Pot AM, Van Campen C, Ribbe MW. Het Resident Assessment Instrument (RAl): een overzicht van internationaal onderzoek naar de psychometrische kwaliteiten en effecten van implementatie in verpleeghuizen (The Resident Assessment Instrument (RAI): a review of international research on the psychometric qualities and effects of implementation in nursing homes). Tijdschr Gerontol Geriatr 1999;30:264-70.

30. Holtkamp CCM. Effects of the Resident Assessment Instrument on Quality of Care and Quality of Life in Nursing Homes. Utrecht: NIVEL, 2003.

31. Strumpf NE, Evans LK, Wagner J, Patterson J. Reducing physical restraints: developing an educational program. J Gerontol Nurs 1992;18(1 1):21-7.

32. Mason $R, O^{\prime}$ Connor $M$, Kemble $S$. Untying the elderly: response to quality of life issues. Geriatric Nursing 1995;16(2):68-72. 
33. Hamers JPH, Van Wijmen FCB. Vrijheidsbeperking in de zorg: een verpleegkundige beslissing (The use of restraints in health care: a nursing decision). TvZ Tijdschrift voor Verpleegkundigen 2003(3):30-33.

34. Dunbar JM, Neufeld RR, Libow LS, Cohen CE, Foley WJ. Taking charge: the role of nursing administrators in removing restraints. Journal of Nursing Administration 1997;27(3):42-48.

35. Sundel M, Garrett RM, Horn RD. Restraint reduction in a nursing home and its impact on employee attitudes. J Am Geriatr Soc 1994;42(4):381-387.

36. Burton LC, German PS, Rovner BW, Brant L, Clark RD. Mental illness and the use of restraints in nursing homes. The Gerontologist 1992;32(2): 164-170.

37. Karlsson S, Bucht G, Eriksson S, Sandman PO. Factors relating to the use of physical restraints in geriatric care settings. J Am Geriatr Soc 2001;49(12):1722-1728.

38. Sullivan-Marx EM, Strumpf NE, Evans LK, Baumgarten M, Maislin G. Predictors of continued physical restraint use in nursing home residents following restraint reduction efforts. J Am Geriatr Soc 1999;47(3):342-348.

39. Capezuti E, Maislin G, Strumpf N, Evans LK. Side rail use and bed-related fall outcomes among nursing home residents. J Am Geriatr Soc 2002;50(1):90-96. 
Effect evaluation: reduction 


\section{Chapter 6}

\section{Preventing the use of physical restraints with residents newly admitted to psychogeriatric nursing home wards: a cluster-randomized trial}

Anna R Huizing, Jan PH Hamers, Math JM Gulpers, Martijn PF Berger

Submitted for publication 


\section{Abstract}

Background: Although there is an urgent need for restraint-free care, the number of randomized clinical trials on preventing or reducing physical restraints has been limited.

Objectives: To investigate the effectiveness of an educational intervention to prevent the use of physical restraints on residents newly admitted to psychogeriatric nursing home wards.

Design: Cluster-randomized trial

Setting: Fourteen Dutch psychogeriatric nursing home wards

Participants: 138 residents admitted to 14 psychogeriatric nursing home wards after baseline measurement of the trial were selected, out of which 105 residents were included in the analyses.

Methods: The nursing home wards were randomly assigned to either educational intervention or control status. The educational intervention consisted of an educational programme for nurses combined with a nurse specialist's consultation. The data were collected at one, four and eight months post-intervention. The use of physical restraints was measured by blinded, trained observers on four separate occasions over a 24-hour period. The Minimum Data Set was used to determine residents' characteristics, such as their cognitive status.

Results: During the study period, no statistically significant differences between the experimental group and the control group regarding restraint status, restraint intensity, multiple restraints and types of restraints were found. One month post-intervention, $38 \%$ of the residents newly admitted to the experimental wards were restrained. Bilateral bedrails were the most frequently used restraints at Post-test 1 (24\%), Post-test 2 (23\%) and Post-test $3(28 \%)$, followed by the use of infrared systems at Post-tests 2 and 3 .

Conclusion: An educational programme combined with the consultation of a nurse specialist does not prevent the use of physical restraints on residents newly admitted to psychogeriatric nursing home wards. Although other studies have shown promising results with the effectiveness of these types of intervention on restraint reduction, the development of additional interventions to prevent restraint usage is recommended. 


\section{Introduction}

Physical restraints are commonly used on psychogeriatric nursing home residents. High prevalence values have been reported in several studies, ranging from $15 \%$ to $66 \% .^{1.3}$ In nursing homes, physical restraints are in most cases used for more than three months and as a routine measure.' The use of physical restraints is based mainly on the assumption that restraints prevent falls and fall-related injuries. ${ }^{1,4,5}$ However, various studies conclude that the use of physical restraints is ineffective in preventing falls and fall-related injuries and may also lead to negative consequences. ${ }^{3,6,7}$ The need to reduce physical restraint use in nursing homes has, therefore, often been recommended in the literature. ${ }^{6,8}$

The transition to restraint-free care involves a "paradigm shift" from viewing behaviour as a problem to be controlled with physical restraints to viewing behaviour as a communication of health-state change or unmet need. ${ }^{8}$ This process of change can be complex and slow ${ }^{8}$, just like other processes of change in healthcare. ${ }^{9,10}$ So far, a limited number of RCT investigations has examined the effectiveness of programmes on the reduction of restraint use. $^{2,11,12}$ Comparable interventions, mostly consisting of education and consultation, were tested in these studies. Restraint education for (nursing) staff, usually combined with support and advice in practice, was an important component in these interventions. Although Huizing et al. ${ }^{2}$ showed no effect on restraint reduction, two of the RCT studies reported positive effects in reducing the use of physical restraints. ${ }^{11,12}$ However, it is unclear whether education and consultation prevent the use of physical restraints on newly admitted nursing home residents.

The aim of this study was to determine whether an educational intervention, consisting of an educational programme for nurses combined with the consultation of a nurse specialist, has a preventive effect on the use of physical restraints with residents newly admitted to psychogeriatric nursing home wards.

\section{Methods}

\section{Design and sample}

A cluster-randomized trial was performed to examine the preventive effect of educational intervention on the use of physical restraints with residents newly admitted to psychogeriatric nursing home wards. The study was part of a larger study focusing on the use of physical restraints on psychogeriatric nursing home residents. ${ }^{\text {se also } 2}$ Residents admitted to fourteen Dutch psychogeriatric nursing home wards after baseline measurement were enrolled at each subsequent measurement. This sample did not include residents suffering from Korsakov's 
disease and from psychiatric diseases residing in special Korsakov's or psychiatric wards. The fourteen psychogeriatric nursing home wards were randomly assigned to educational intervention (seven experimental wards) or control status (seven control wards). Nurses in the experimental group attended an educational programme on the use of physical restraints. Further, consultation with a registered nurse specialized in the use of physical restraints and in their reduction (nurse specialist) was introduced in the experimental wards. There was no educational intervention in the control group and residents received care as usual. Data were collected at one, four and eight months post-intervention (Post-test 1, Post-test 2, Post-test 3).

\section{The intervention}

An educational programme, combined with the consultation of a nurse specialist, made up the components of the educational intervention..$^{\text {see also } 2}$ The educational intervention was designed to encourage nurses to adopt a philosophy of restraintffree care and to familiarize themselves with the techniques of individualized care. ${ }^{8}$ The educational programme, developed as part of the educational intervention, was based on an educational programme of restraint use in Dutch hospitals ${ }^{13}$ and on a paper about the decision-making process concerning restraint use in care situations. ${ }^{14}$ The educational programme was carried out over a two-month period and taught by the nurse specialist. In five meetings, each lasting two hours, several topics concerning physical restraints were discussed. Examples of these topics are the decisionmaking process for restraint use, the effectiveness and consequences of restraint use, the strategies for analysing the risk behaviour of residents and the alternatives to restraint use. Furthermore, the nurses were invited to discuss reallife cases during the educational meetings, which provided supporting evidence about how they combined their practical experience with the information from the educational programme. The educational programme consisted of small-scale meetings with an active learning environment for the nurses, meaning that an active participation by the nurses during the meetings was stimulated. As described in the literature, it seems that interactive and personal educational meetings are more effective than passive education. ${ }^{9}$ The inclusion of key figures ${ }^{9}$ and different types of adopters ${ }^{10}$ was the basic principle for the selection of the nurses for the educational programme. Seven nurses per experimental ward, including the charge nurse, were invited to attend the meetings and these nurses were divided into seven groups. To promote the exchange of knowledge and experiences among the experimental wards, each group consisted of nurses from different experimental wards and 
one charge nurse. After the five educational meetings, a 90-minute plenary session was organized for all the nurses from each experimental ward (including nurses who were not invited to attend the five educational meetings) to inform them about restraint use and restraint-free care as well. As part of the educational intervention, the nurse specialist was available for consultation 28 hours per week, visited the wards once a week, attended multidisciplinary meetings about residents and stimulated nurses to use alternatives to physical restraints and to use the least restrictive restraints, such as sensor mats. During the visits to the experimental wards and the multidisciplinary meetings the nurse specialist evaluated the use of physical restraints on residents and discussed difficulties in achieving restraint-free care with the nurses on the wards and with the persons present at the multidisciplinary meetings.

\section{Measures}

\section{Physical restraints}

The use of physical restraints per resident was measured using an observation tool, which had been designed for the study (see Appendix). Types of physical restraints were recorded as absent or present. Any limitation on an individual's freedom of movement was regarded as a physical restraint. Examples of restraint types are belts tied to a chair or bed, bilateral bedrails, tight sheets (a sheet over belly and upper legs that is tightened at both sides of a bed), chairs with tables, deep or overturned chairs, chairs on a board (a chair with chair legs fixed to a board), special sheets (a fitted sheet including a coat enclosing a mattress), sleep suits, sensor mats (including sensor strips in beds) and infrared systems. The use of physical restraints was measured by trained observers $(n=8)$ on four separate occasions (morning, afternoon, evening, night) over a 24-hour period. The observers were blinded to the experimental and control conditions. The day of visit to each ward was unannounced to discourage any artificial removal of restraints by staff. " To measure the interrater reliability, two of the eight observers were selected and they scored the same residents with restraints $(\mathrm{Kappa}=1.0)$. Four variables concerning restraint use were used in the study. Firstly, the restraint status indicates whether the resident was observed to be restrained at any time in the four observations over a 24-hour period (yes/no). Secondly, all types of restraints used with psychogeriatric nursing home residents over the 24-hour period were recorded. Thirdly, restraint intensity indicated the number of times in four observations over a 24-hour period that a resident was restrained (range 0-4). Fourthly, multiple restraints indicated the number of different types of restraints used per resident recorded in four observations over a 24 -hour period. 


\section{Residents' characteristics}

Residents' characteristics, such as cognitive status, self-performance in activities of daily living, mobility, depression and social engagement, were measured at each Post-test using the Minimum Data Set (MDS) version 2.1, which is part of the Resident Assessment Instrument (RAI). ${ }^{15}$ The MDS was completed by trained nurses working on the wards, who filled out the questionnaires for residents in their care. Different scales based on MDS items were used to determine the residents' characteristics. The cognitive status of residents was measured using the Cognitive Performance Scale. ${ }^{16}$ The scores of the scale ranged from 0 (intact) to 6 (very severe impairment). Self-performance in activities of daily living ( $A D L$ status) was measured using the MDS ADL Self-performance Hierarchy, in which the scores ranged from 0 (independent) to 6 (total dependency)..$^{17}$ A mobility scale was developed from seven MDS items (movement in bed, transfer in and out of bed, transfer to standing up, walking in the room, walking in the corridor, locomotion on ward, locomotion outside the ward) to determine mobility in residents. The scores of the mobility scale ranged from 0 (independent) to 28 (total dependency). Depression in residents was measured using the Depression Rating Scale, in which the scores ranged from 0 to $14 .{ }^{18}$ Residents who scored $\geq 3$ (cut-off score) on the scale required further evaluation to diagnose depression. The Social Engagement Scale was used to determine social engagement in residents. ${ }^{19}$ The scores ranged from 0 (lowest level of social engagement) to 6 (highest level of social engagement). Cronbach's alphas for the scales have been tested in a previous study (submitted for publication) and found to be sufficient for all the scales $\left(\alpha_{\text {cognitive status }}=0.64, \alpha_{A D L}\right.$ status $=0.86, \alpha_{\text {mobility }}=0.97, \alpha_{\text {depression }}=0.66$, $\left.\alpha_{\text {social engagement }}=0.77\right)$. In addition, the reliability and validity of the MDS and related scales have been found to be sufficient in other studies. ${ }^{16 \cdot 20}$

\section{Ethical considerations}

Approval for the study was obtained from the Medical Ethical Committee of the University Hospital Maastricht and the University Maastricht. Representatives of the residents received written information about the study from the nursing home and the university. Based on this information the representatives were asked to give written consent for the use of personal data on the residents in the study. Nurses and other employees of the nursing homes were informed about the study through presentations and written information. The trial identification number of the study is ISRCTN10117742. 


\section{Data analysis}

Descriptive statistics were computed for the characteristics of the psychogeriatric nursing home residents. Differences between the experimental and the control group in restraint use and residents' characteristics were investigated using the chi-square test for variables at a dichotomous level, and the independent samples t-test for variables at an interval and ratio level. Fisher's Exact Test values were computed for tables including a cell with a frequency less than 5 . The normality of the variables was checked using frequencies and distribution tables. Based on these results the variable mobility was categorised into five groups, ranging from 0 'independent' to 4 'total dependency'. Furthermore, differences between the experimental and the control group in restraint intensity and multiple restraints were also tested using the Mann-Whitney $U$ Test because of a non-normality in these variables. $P \leq 0.050$ was considered to be statistically significant. However, to examine differences between the experimental and the control group per restraint type, the value of alpha was set at 0.010 in order to correct for multiple testing because of the increasing risk of Type 1 errors. The data were analyzed using SPSS, version 13.0.

\section{Results}

\section{Sample}

A total of 138 residents were admitted to the wards during the study period. Of this sample, 33 residents were not included in the analyses, mainly because these residents died or informed consent had not been obtained. A total of 105 residents were included in the analyses. The total response flow of the study is shown in Figure 1. 


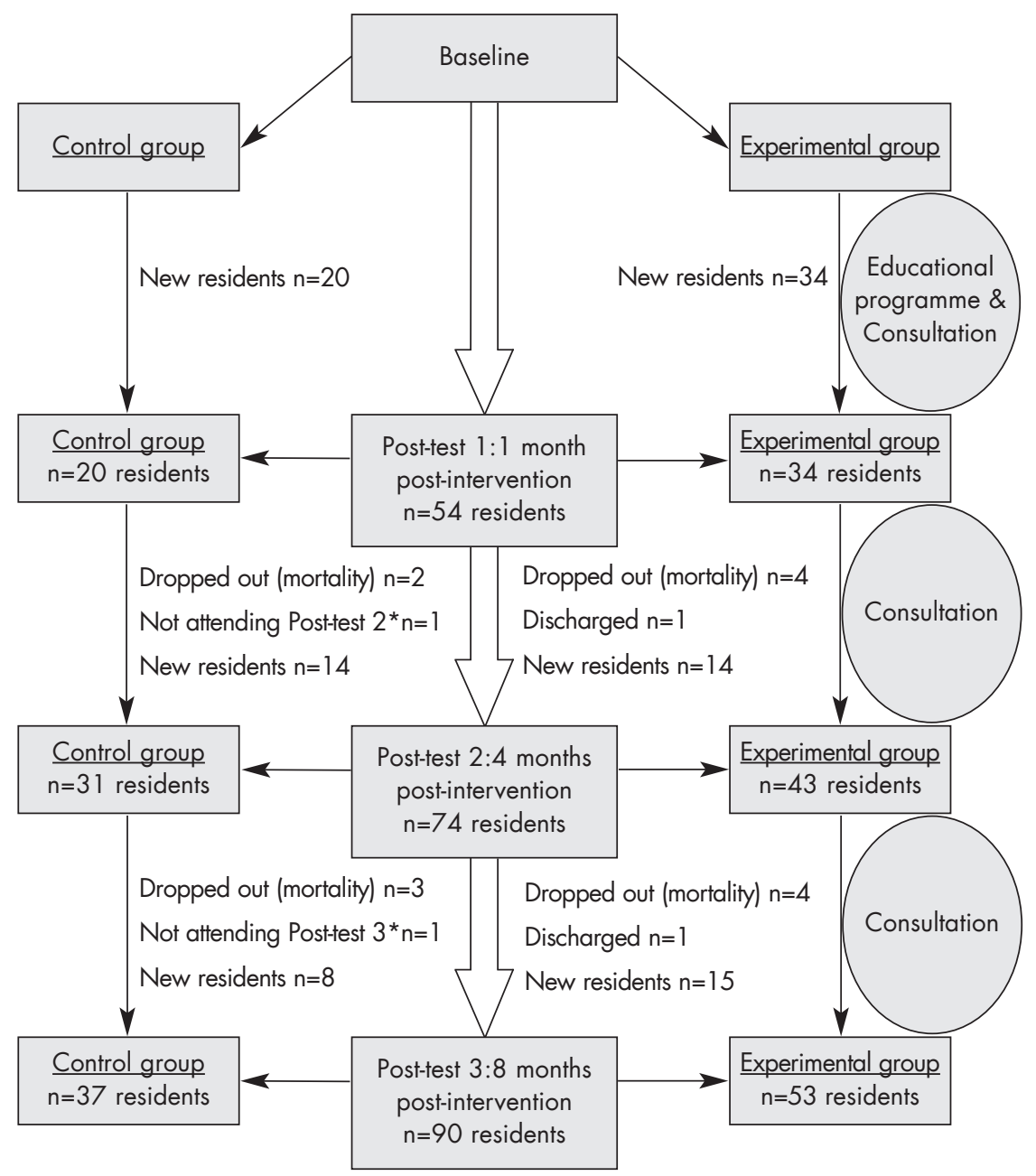

* Resident was admitted to a hospital at Post-test 2 (attended Post-tests 1 and 3)

Figure 1 Response flow of the study

As can been seen from Table 1, the residents admitted to the experimental wards were statistically significantly more dependent in $\operatorname{ADL}(p=0.045)$ as compared to the residents admitted to the control wards at Post-test 1. Furthermore, the residents in the experimental group tended to be more dependent in mobility at Post-test $1 \quad(p=0.068)$ and Post-test $2(p=0.072)$. Moreover, residents in the experimental group tended to be more dependent in ADL $(p=0.079)$ at Post-test 2 . The residents in the control group tended to be older $(p=0.079)$ than the residents in the experimental group at Post-test 3 .

Forty-eight nurses were selected to attend the educational programme, one 


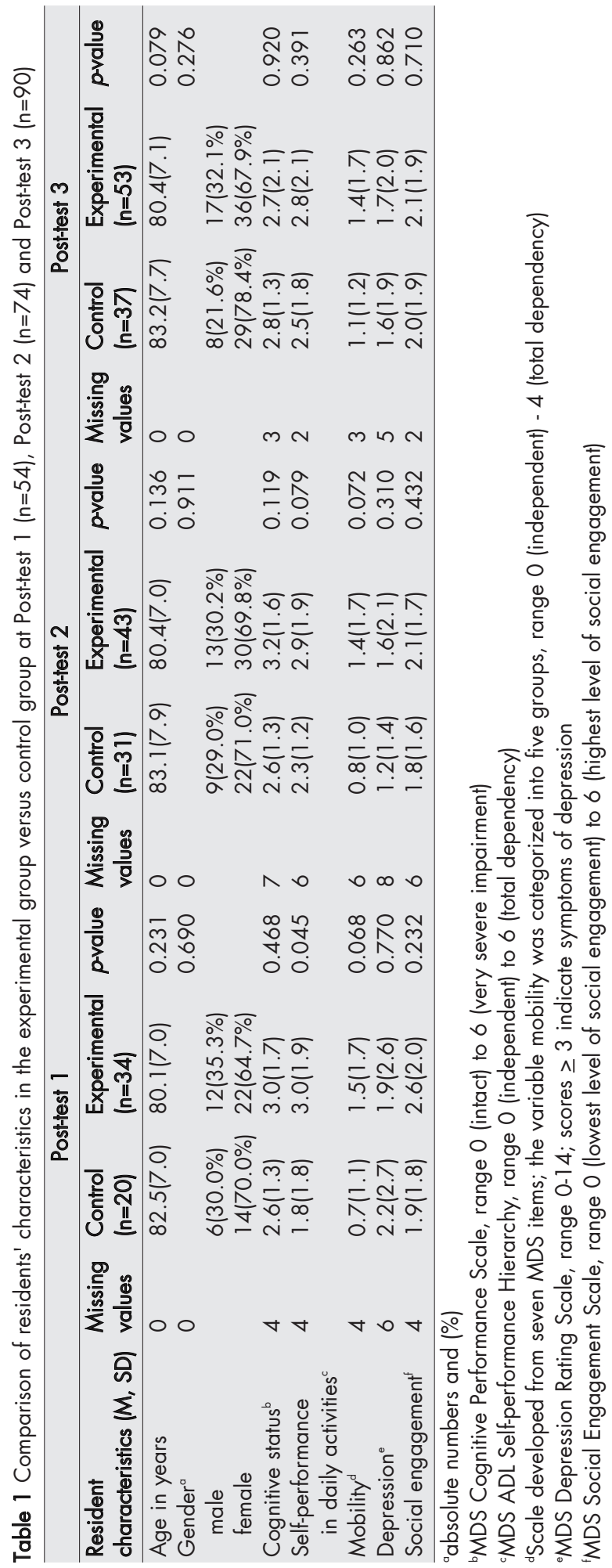


of whom attended none of the meetings. The mean age of the sample was 37 years $(S D=10.0)$ and most of the nurses were women $(80 \%)$. These persons were qualified as charge nurses $(13 \%)$, registered nurses (1 1\%), care workers $(64 \%)$, care helpers $(4 \%)$, care assistants $(2 \%)$ and student care workers $(2 \%)$.

\section{The effect of the educational intervention}

At Post-test 1, a total of $13(38.2 \%)$ residents newly admitted to the experimental wards were restrained (Table 2). There was no statistically significant difference between the experimental and the control group in restraint status at Post-test 1 . Moreover, restraint intensity and multiple restraints did not differ between groups. At Post-test 2, a total of 22 (51.2\%) residents in the experimental wards were restrained. For the residents newly admitted to the experimental wards after Post-test 1, a total of $7(50.0 \%)$ residents were restrained as compared to $5(35.7 \%)$ residents in the control group $(p=0.445)$. At Post-test 2, the restraint status, restraint intensity and multiple restraints did not differ statistically significantly between groups (Table 2). Also at Post-test 3, no statistically significant differences were found between groups. A total of 25 $(47.2 \%)$ residents in the experimental wards were restrained. From the residents newly admitted to the experimental wards after Post-test 2, a total of $3(20.0 \%)$ was restrained at Post-test 3 as compared to $3(37.5 \%)$ residents in the control group $(p=0.621)$.

During the study period, several types of restraints were used in residents newly admitted to the nursing home wards (Table 3). Bilateral bedrails were the most frequently used restraints at Post-test 1 (13 (24.1\%)), Post-test 2 (17 $(23.0 \%))$ and Post-test $3(25(27.8 \%))$. After the use of bilateral bedrails,

infrared systems were the most commonly used at Post-tests 2 and 3 . For each type of restraint no statistically significant differences between groups were found at Post-tests 1, 2 and 3. Only the use of belts in bed tended to be lower in the experimental group $(0(0 \%))$ as compared to the control group $(3(8.1 \%))$ at Post-test $3(p=0.066)$. At Post-test 2 , the use of bilateral bedrails tended to be higher in the experimental group $(14(32.6 \%))$ as compared to the control group $(3(9.7 \%))(p=0.026)$. Furthermore, the use of deep and overturned chairs tended to be higher in the experimental group $(6(11.3 \%)$ than in the control group $(0(0 \%))(p=0.041)$ at Post-test 3 . 


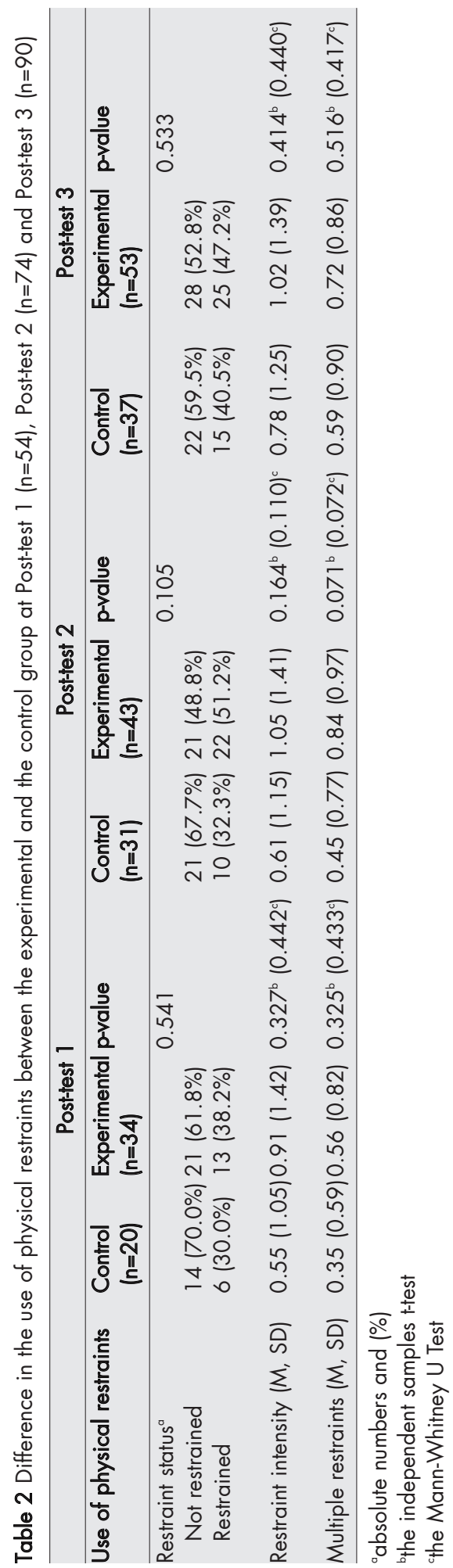


Table 3 Differences between the experimental and the control group in the use of physical restraints with psychogeriatric nursing home residents per restraint type at Post-test $1 \quad(n=54)$, Post-test 2 $(n=74)$ and Post-test $3(n=90)$

\begin{tabular}{|c|c|c|c|c|c|c|}
\hline \multirow[b]{2}{*}{$\begin{array}{l}\text { Restraint type } \\
\text { (absolute numbers } \\
\text { and }(\%) \text { ) }\end{array}$} & \multicolumn{2}{|c|}{ Post-test 1} & \multicolumn{2}{|c|}{ Post-test 2} & \multicolumn{2}{|c|}{ Post-test 3} \\
\hline & $\begin{array}{l}\text { Control } \\
(n=20)\end{array}$ & $\begin{array}{l}\text { Experimental } \\
(n=34)\end{array}$ & $\begin{array}{l}\text { Control } \\
(n=31)\end{array}$ & $\begin{array}{l}\text { Experimental } \\
(n=43)\end{array}$ & $\begin{array}{l}\text { Control } \\
(n=37)\end{array}$ & $\begin{array}{l}\text { Experimental } \\
(n=53)\end{array}$ \\
\hline Belt in chair & $0(0.0 \%)$ & $1(2.9 \%)$ & $1(3.2 \%)$ & 1 (2.3\%) & 2 (5.4\%) & 1 (1.9\%) \\
\hline Belt in bed & - & - & $2(6.5 \%)$ & $1(2.3 \%)$ & $3(8.1 \%)$ & $0(0.0 \%)$ \\
\hline Bilateral bedrails & $2(10 / 0 \%)$ & $11(32.4 \%)$ & $3(9.7 \%)$ & $14(32.6 \%)$ & $9(24.3 \%)$ & $16(30.2 \%)$ \\
\hline Tight sheet & $0(0.0 \%)$ & $1(2.9 \%)$ & - & - & - & \\
\hline Chair with a table & $1(5.0 \%)$ & $318 . \varepsilon$ & $1(3.2 \%)$ & $2(4.7$ & $1(2.7 \%)$ & $1(1.9 \%)$ \\
\hline $\begin{array}{l}\text { Deep or overturned } \\
\text { chair }\end{array}$ & $0(0.0 \%)$ & $1(2.9 \%)$ & $1(3.2 \%)$ & $5(11.6 \%)$ & $0(0.0 \%)$ & $6(11.3 \%)$ \\
\hline Chair on a board & - & - & $0(0.0 \%)$ & $1(2.3 \%)$ & - & 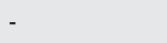 \\
\hline Special sheet & - & - & $0(0.0 \%)$ & $1(2.3 \%)$ & $0(0.0 \%)$ & 1 (1.9\%) \\
\hline Sleep suit & $1(5.0 \%)$ & $2(5.9 \%)$ & $1(3.2 \%)$ & $2(4.7 \%)$ & $1(2.7 \%)$ & $4(7.5 \%)$ \\
\hline Sensor mat & $2(10.0 \%$ & $0(0.0 \%)$ & $1(3.2 \%)$ & $4(9.3 \%)$ & $0(0.0 \%)$ & $3(5.7 \%)$ \\
\hline Infrared system & $1(5.0 \%)$ & $0(0.0 \%)$ & 4 (12.9\%) & 5 (11.6\%) & $6(16.2 \%)$ & $5(9.4 \%)$ \\
\hline $\begin{array}{l}\text { (Wheel)chair on the } \\
\text { brakes at the table }\end{array}$ & - & - & . & - & $0(0.0 \%)$ & $1(1.9 \%)$ \\
\hline
\end{tabular}

*statistically significant difference (between groups) tested with chi-square test (or Fisher's Exact Test when appropriate); $p \leq 0.010$ (correction for multiple testing)

\section{Discussion}

This study has shown that an educational intervention does not prevent the use of physical restraints on residents newly admitted to psychogeriatric nursing home wards. The use of physical restraints on residents newly admitted to the wards in the experimental group was not statistically significantly different from that of the control group at each Post-test. Furthermore, no significant differences in restraint status, restraint intensity, multiple restraints and types of restraints were found between the groups. To the best of our knowledge, this was the first RCT study investigating the effectiveness of an educational intervention in preventing the use of physical restraints with newly admitted residents. The results are, however, not in line with the positive effects of education and consultation in reducing the use of physical restraints found in the two previous RCT studies ${ }^{11,12}$, albeit that Huizing et al. ${ }^{2}$ showed no effect on restraint reduction. In the RCT studies comparable interventions were tested, mostly consisting of education and consultation. Nevertheless, differences in research, such as data-collection methods used, and differences among the countries involved regarding legislation concerning restraint use and the job responsibilities of nurses in nursing homes, might be an explanation for the differences in the study results. 
Although education seems to be a necessary component of implementation strategies ${ }^{9}$, the intervention in the present study did not change behaviour and maintain changes in the target group. However, by using interactive education and a nurse specialist's consultation, the intervention does seem to fulfil the conditions for the dissemination of an innovation. ${ }^{\text {see } 9}$ Furthermore, the educational programme, as part of the intervention, was comparable for duration and content with restraint education in other studies showing positive effects on reducing restraints..$^{\text {see review } 21}$ However, Grol et al. ${ }^{9}$ stated that effective dissemination does not guarantee implementation of the intervention. Therefore, additional strategies, such as organizational interventions, may be necessary to bring about restraint-free care. In the present study, the ineffectiveness of the intervention may, therefore, also be related to the implementation on a ward level, which may limit an organizational commitment concerning restraint-free care. Implementation of the intervention on a nursing home level, as in other RCT studies ${ }^{11,12}$, involving the entire organization and overcoming organisational hindering may therefore be worthwhile.

The ineffectiveness of the intervention in preventing physical restraints may also imply a mainly routine usage of physical restraints on psychogeriatric nursing home residents. This is certainly not in accordance with the principles of individualized care. ${ }^{8}$ It was hypothesized that preventing the use of restraints on these residents may be a first step in the transition to restraint-free care, given the new situation where nurses can implement individualized care and break with routines concerning restraint use. However, for changing the routine usage of physical restraints, education and consultation were not sufficient in the short and in the long term. Although it is unknown to what extent nurses acquired any knowledge about restraint use through this intervention, and so embraced a philosophy of restraint-free care, the necessary "paradigm shift" was clearly not attained. More efforts are therefore needed to break the routine usage of physical restraints with psychogeriatric nursing home residents.

During the study period, the types of restraints used with residents did not differ between the experimental and the control group. Bilateral bedrails were the most frequently used restraints with newly admitted residents, which is in line with the common use of bilateral bedrails shown in other studies. ${ }^{1.3}$ However, the types of restraints subsequent to the use of bedrails differed from other studies, which have shown more restrictive types of restraints. ${ }^{1,2,22}$ Whereas other studies showed that belts and chairs with a table were, after bedrails, the most frequently used, in the present study bedrails were followed by infrared systems at Post-tests 2 and 3 . Although the most restrictive types of restraints, such as belt in bed and chair, seemed to be replaced by less 
restrictive restraint types, such as infrared systems, the small sample size and the small differences in the use of these different types of restraints must be taken into account. Unfortunately, the use of the most restrictive types of restraints were still used with residents newly admitted to the experimental wards, and no statistically significant differences were found between the experimental and the control group.

There are some limitations to this study that need to be discussed. In the first place, a generalization of the results may be limited by the small sample size and the fact that the sample consisted of nursing home residents from fourteen nursing home wards belonging to one coordination organization for the care of older people in the south of the Netherlands. Secondly, contamination bias among wards might be a problem in the study. However, efforts were made to reduce the contamination bias by limiting information for nurses concerning the aim and design of the study from the outset. After randomization the experimental wards were fully informed and were requested to be careful with the information in relation to the control wards. Thirdly, with the inclusion of residents newly admitted to the wards, no distinction was made concerning the previous place of residence and no information was available about restraint status before admission. However, it was assumed that it would be easier to introduce restraint-free care to residents newly admitted to a nursing home ward than to residents already residing in these wards. Fourthly, the consultation of the nurse specialist, as part of the intervention, was carried out by only one nurse specialist. This possibly might not have been enough to assist nurses sufficiently in reducing restraint use.

\section{Conclusion}

An educational programme combined with a nurse specialist's consultation does not prevent the use of physical restraints on residents newly admitted to psychogeriatric nursing home wards. The continued high prevalence values for restraint use and the ineffectiveness of the intervention in preventing physical restraints seem to imply a mainly routine usage of physical restraints on psychogeriatric nursing home residents, which is certainly not in accordance with the principles of individualized care. Although other studies have shown promising results with these types of interventions with regard to restraint reduction, it is important to develop additional interventions in order to prevent restraint usage with newly admitted psychogeriatric nursing home residents. 


\section{References}

1. Hamers JPH, Gulpers MM, Strik W. Use of physical restraints with cognitively impaired nursing home residents. Journal of Advanced Nursing 2004;45(3):246-251.

2. Huizing AR, Hamers JPH, Gulpers MM, Berger MPF. Short-term effects of an educational intervention on physical restraint use: a cluster randomized trial. BMC Geriatrics 2006;6(17).

3. Capezuti E, Wagner LM, Brush BL, Boltz M, Renz S, Talerico KA. Consequences of an intervention to reduce restrictive side rail use in nursing homes. J Am Geriatr Soc 2007;55:334-341.

4. Evans LK, Strumpf NE. Myths about elder restraint. Image J Nurs Sch 1990;22(2):124-8.

5. Evans D, FitzGerald B. Reasons for physically restraining patients and residents: a systematic review and content analysis. Int J Nurs Stud 2002;39:735-743.

6. Hamers JPH, Huizing AR. Why do we use physical restraints in the elderly? Z Gerontol Geriat 2005;38:19-25.

7. Evans D, Wood J, Lambert L. Patient injury and physical restraint devices: a systematic review. Journal of Advanced Nursing 2003;41(3):274-282.

8. Strumpf NE, Robinson JP, Wagner JS, Evans LK. Restraint-free care; Individualized approaches for frail elders. New York: Springer Publishing Company, Inc., 1998.

9. Grol R, Wensing M, Eccles M. Improving Patient Care. The implementation of change in clinical practice. London: Elsevier, 2005.

10. Rogers EM. Diffusion of innovations. Fifth ed. New York: Free Press, 2003.

11. Evans LK, Strumpf NE, Allen-Taylor SL, Capezuti E, Maislin G, Jacobsen B. A clinical trial to reduce restraints in nursing homes. J Am Geriatr Soc 1997;45(6):675-681.

12. Testad I, Aasland AM, Aarsland D. The effect of staff training on the use of restraint in dementia: a single-blind randomised controlled trial. Int J Geriatr Psychiatry 2005;20(6):58790.

13. Dielis-van Houts A, Schuurmans M. Een balans tussen: Veiligheid, Vrijheid en Vrijheidsbeperking (The balance between safety, freedom of movement and use of restraints). Utrecht, 2004.

14. $\mathrm{CBO}, \mathrm{VWR}$. Het gebruik van vrijheidsbeperkende interventies in de zorg. Een richtlijn voor verpleegkundigen en verzorgenden in een multidisciplinaire omgeving (The use of restraints in care situations. A guideline for nurses in a multidisciplinary environment). Utrecht: Kwaliteitsinstituut voor de Gezondheidszorg CBO, 2001.

15. interRAI. RAI for Nursing Home Care (RAI 2.1). Utrecht: interRAl Corporation, 2002.

16. Morris JN, Fries BE, Mehr DR, et al. MDS Cognitive Performance Scale. Journal of Gerontology: MEDICAL SCIENCES 1994;49(4):M174-182.

17. Morris JN, Fries BE, Morris SA. Scaling ADLs within the MDS. Journal of Gerontology: MEDICAL SCIENCES 1999;54A(1 1):M546-53.

18. Burrows AB, Morris JN, Simon SE, Hirdes JP, Phillips C. Development of a Minimum Data Setbased depression rating scale for use in nursing homes. Age and Ageing 2000;29(165-172).

19. Mor V, Branco K, Fleishman J, et al. The structure of social engagement among nursing home 
residents. Journal of Gerontology: PSYCHOLOGICAL SCIENCES 1995;50B(1):P1-P8.

20. Holtkamp CCM. Effects of the Resident Assessment Instrument on Quality of Care and Quality of Life in Nursing Homes. Utrecht: NIVEL, 2003.

21. Evans D, Wood J, Lambert L. A review of physical restraint minimization in the acute and residential care settings. Journal of Advanced Nursing 2002;40(6):616-25.

22. Hantikainen V. Physical restraint: a descriptive study in Swiss nursing homes. Nursing Ethics 1998;5(4):330-346. 
Effect evaluation: prevention 


\section{Introduction}

The primary aim of this thesis is to contribute to restraint-free care in psychogeriatric nursing home residents. Therefore, the following three research questions were answered:

- What is the current knowledge of the use of physical restraints on elderly people?

- What is the relationship between organizational characteristics (i.e., job and ward characteristics) and the use of physical restraints on psychogeriatric nursing home residents?

- What is the effectiveness of an educational intervention aimed at achieving restraint-free care for psychogeriatric nursing home residents?

This chapter will begin with a summary of the main conclusions of the studies presented in this thesis. Following this, some theoretical and methodological reflections will be discussed. Finally, the implications of this study for both practice and further research will be described.

\section{Main conclusions}

Three conclusions concerning the use of physical restraints on psychogeriatric nursing home residents, as well as achieving restraint-free care for this population can be drawn:

- The use of physical restraints is still a common procedure in nursing homes, with recently (1999-2004) reported prevalence values ranging from 41 to $64 \%$. This is in line with the prevalence of physical restraint use for Dutch psychogeriatric nursing home residents (Chapters 3 to 6). It can be concluded that the use of physical restraints has adverse effects for elderly people, and is ineffective in preventing falls and fall-related injuries (Chapter 2). Therefore, there is a strong need to achieve restraint-free care.

- High workload and low social support experienced by nursing staff as well as a low percentage of registered nurses and a high rate of sickness absence on the wards, were not associated with increased physical restraint use (Chapter 3). The use of physical restraints was in fact strongly associated with residents' characteristics. More specifically, impairment in mobility was shown to be the most important determinant. In order to achieve restraint-free care, it is more important to focus on impairments in residents than on the job characteristics of nursing staff and on ward characteristics. 
- The educational intervention, consisting of an educational programme combined with the consultation of a nurse specialist, was not effective in reducing or preventing the use of physical restraints with psychogeriatric nursing home residents. Although the educational intervention seemed to protect psychogeriatric nursing home residents from an increase in the use of physical restraints in the short term (Chapter 4), this was not confirmed in the long term nor in the short term including increased sample size (Chapter 5). Furthermore, the educational intervention was ineffective in preventing the use of physical restraints with residents newly admitted to psychogeriatric nursing home wards (Chapter 6). It can be concluded therefore that other interventions aiming at restraint-free care will be required in order to reduce and prevent the use of physical restraints with psychogeriatric nursing home residents.

\section{Theoretical and methodological reflections}

In the present thesis three research questions concerning the use of physical restraints have been answered. Related to this, we will now discuss some theoretical and methodological reflections concerning the studies presented in this thesis.

\section{The use of physical restraints on psychogeriatric nursing home residents}

The use of physical restraints is evidently a common procedure in the care of psychogeriatric nursing home residents since approximately $50 \%$ of the research sample were physically restrained. Furthermore, it has been shown that the use of physical restraints was positively associated with impairments in residents' characteristics, such as impairment in mobility and low cognitive status. These findings are in accordance with the results of other studies. ${ }^{1.6}$ Moreover, both impairment in mobility and poor cognitive status are clearly related to the most important reason for restraint usage: prevention of falls and fall-related injuries.

\section{Relationship between restraint use and organizational characteristics}

High workload and low social support experienced by the nursing staff as well as a low percentage of registered nurses and a high rate of sickness absence on the wards, were not associated with an increased use of physical restraints. On the contrary, an increased use of physical restraints proved to be associated with a higher job autonomy experienced by nursing staff and a higher FTE ratio in the wards. Thus, improvement of job and ward characteristics will probably not lead to restraint reduction. Our results are in 
line with previous studies that also suggest that organizational characteristics may be less significant than resident characteristics when it comes to the use of physical restraints. ${ }^{4,5}$ However, the results of our study were in contrast with the common assumption of nursing staff that the use of physical restraints increases with an insufficient number of nursing staff. ${ }^{7}$ Furthermore, the results were inconsistent with some of the research on this topic, which did show an association with part of the job and ward characteristics. ${ }^{6,8,9}$ The differences in these study findings could be explained by the differences in definitions and data-collection methods used to determine the use of physical restraints and ward characteristics. Moreover, differences in study population and the level of analyses (resident versus ward level) could also explain the inconsistent results reported in the literature ${ }^{\text {see e. } .9 .5,6,8}$ For example, the use of physical restraints in some studies ${ }^{5,6,8}$ was determined by using staff reports of Minimum Data Set (MDS) information instead of determining restraint use by blinded, trained observers.

The positive association of a higher job autonomy and a higher FTE ratio with an increased use of physical restraints could be explained by the fact that this increased autonomy and FTE ratio potentially strengthened the effect of the inadequate knowledge of nursing staff, which appears to be related to increased restraint use. ${ }^{4,10,11}$ When nursing staff experience more job autonomy, and consequently are more persuasive and have more control in the decisionmaking process when it comes to restraint use, their inadequate knowledge may lead to increased restraint use.

\section{The effectiveness of the educational intervention}

Our educational intervention showed no effect on reducing and/or preventing the use of physical restraints with psychogeriatric nursing home residents, in contrast to other studies on restraint reduction. ${ }^{\text {see e.g. 1,12,13 }}$ To explain the lack of effectiveness of the present study's educational intervention, several arguments will be used in this section. For some of these arguments a comparison has been made between our cluster-randomized trial and the trials performed by Evans et al. ${ }^{14}$ and Testad et al. ${ }^{13}$

The lack of effectiveness of the educational intervention in our study could be explained by the firmly entrenched beliefs about the use of physical restraints, which appear to support the continuing practice of restraint use with elderly people. " For example, the nursing staff seemed to believe that 'failure' to use physical restraints puts them at risk for legal liability. " Such beliefs would seem to limit the process towards restraint-free care. It is hardly surprising, therefore, that the transition to restraint-free care, which involves a 'paradigm shift', is so slow ${ }^{15}$, which is in accordance with the literature on the 
implementation of change in clinical practice. ${ }^{16}$

A broad definition of physical restraints was used in our trial, which included a wide variety of restraint types. As a result, the nursing staff involved in the educational intervention was oriented towards a wide variety of restraint types with different degrees of restrictiveness. This may have prevented a change in practice regarding restraint use. Moreover, our broad definition of physical restraints differed from the definition as used in the trial of Evans et al. ${ }^{14}$, which excluded the use of bedrails, the most prevalent type of restraint in our trial. These differences could explain the differences in study results. However, in our trial the analyses concerning restraint status were also performed excluding the use of bilateral bedrails, sensor mats and infrared systems. These analyses showed that with a narrower definition of physical restraints, our educational intervention was still ineffective. The data-collection method used to determine physical restraints in our trial differed from the datacollection method used by Testad et al. ${ }^{13}$, who interviewed nurses that participated in the intervention. In the present trial, the use of physical restraints was determined by blinded and trained observers.

The educational programme in the present trial consisted of five small-scale meetings, each lasting for two hours, that were carried out over a two-month period, plus a ninety-minute plenary session. The teaching hours were comparable to the educational programme of Evans et al. ${ }^{14}$ However, the teaching hours were spread out over a longer period in the trial of Evans et al. ${ }^{14}$ (six months versus two months). Spreading out the teaching hours over a six-month period may have improved the chances of a lasting impression. However, in our study we assumed that a more intensive, condensed programme would prove more effective.

The nurse specialist in our trial was a registered nurse specialized in the use of physical restraints and in their reduction. A registered nurse has a lower educational level than the master's-prepared gerontologic nurse specialist in the study of Evans et al. ${ }^{14}$ It may well be possible that a master's-prepared nurse specialist is more qualified and has a more persuasive influence when it comes to breaking routine use of restraints and coping with resistance of nursing staff. However, we assumed that a nurse specialist familiar with care giving in nursing homes and with the organization of the nursing homes involved in the trial, would have more impact on the intervention, since this nurse specialist would be an easily accessible person for the nursing staff. However, it should be noted that the consultation in this trial and the trial of Evans et al. ${ }^{14}$ was carried out by one person, which means that the performance of the consultation was also dependent on the specific characteristics of this person. Differences in study results may, therefore, also be explained by differences in 
the characteristics of the persons who play a prominent role in the interventions.

Cluster randomized trials are prone to potential bias at the cluster level. ${ }^{17}$ The treatment effect cannot be separated from the potential cluster effect, and the treatment effect could be increased or decreased by the characteristics of a cluster. The nursing home policy towards restraint use and the regulations in nursing homes may be quite different. In all three studies a cluster-randomized trial was performed to examine the effectiveness of the interventions. In the trials of Evans et al. ${ }^{14}$ and Testad et al. ${ }^{13}$, only three and four nursing homes were as a whole randomly assigned to the intervention or control status, and the differences in policy for handling restraint-free care could have influenced the final treatment effect. In our study we decided to perform randomization at the ward level ( $n=15$ wards) instead of the nursing home level, thus limiting this potential threat. On the other hand, the problem of treatment contamination could have played a role in our study, i.e., information about the treatment could have leaked from the experimental wards to the control wards in the same nursing homes. At the start of the study, efforts were therefore made to prevent this contamination bias by limiting the information given to the nurses concerning the aim and design of the study. After randomization the experimental wards were fully informed and were requested to be careful with the information vis-à-vis the control wards. Since we did not find any decrease in restraint use in both experimental and control wards, it is unlikely that this effect could have influenced the treatment effect.

The treatment effect may have also been influenced by the characteristics of the country, in this case the Netherlands. The differences between countries regarding the regulations for the use of physical restraints on elderly people ${ }^{10}$ may, in the end, explain the differences in treatment effects as shown in the different trials. Research on other health care issues, such as pressure ulcers, also suggest that variations in study results are probably influenced by differences in policies among facilities or health care systems. ${ }^{18}$

During the present trial, a total of 130 residents dropped out mainly because these residents died. This group of dropouts also included all the residents from one experimental ward, who dropped out after the baseline measurement. This ward refused the educational intervention due to lack of time, due to their participation in other educational programmes at the same time. The dropout in our study was not seen as a problem because the characteristics of the dropouts and the reasons for dropout were comparable in the experimental group and the control group. Therefore, it can be assumed that the dropout did not bias the results of the present trial.

To further explain the lack of effectiveness of the educational intervention, 
a process evaluation would have been valuable. However, the intervention process was not evaluated in the present trial. Besides, no information was gathered regarding the extent to which nurses had embraced the philosophy of restraint-free care and had gained knowledge about restraint use through the educational intervention. As a result, this study can give no information about factors potentially influencing the lack of effectiveness of the educational intervention. Information, for example, about the performance of the educational intervention or whether the intervention was performed according to the protocol is lacking. Nonetheless, the educational intervention was carefully implemented in the nursing home wards and the educational programme was attended sufficiently by the nursing staff. As a result, no systematic problems in the intervention process are suspected. All the same, in further research an RCT should include both an effect evaluation and a process evaluation.

\section{Implications for practice and research}

Restraint-free care is essential for good quality of care for psychogeriatric nursing home residents. Currently, the use of physical restraints is still very common in nursing homes. Attention to this topic is, therefore, very important. Not only nursing home organizations, but also the Dutch media and politics, are increasingly focused on this topic. It is important then that initiatives to achieve restraint-free care be undertaken. The results of the studies presented in this thesis have shown that an educational programme combined with the consultation of a nurse specialist is not effective in reducing or preventing the use of physical restraints. As a result, this educational intervention, as it was organized for the present trial, should not be implemented in nursing homes to achieve restraint-free care. Further research should focus instead on the development and testing of new or additional interventions in order to achieve restraint-free care. In this respect, we can make several recommendations.

Firstly, to develop and test new or additional interventions aimed at restraint-free care, it would seem very important to further analyse the target groups of these interventions first. This would mean analysing the (nursing) staff population, as well as the residents and their representatives. To this end, research examining the attitudes and knowledge of these populations about restraint use, as well as the ethical dilemmas and the fears that go along with the use and non-use of physical restraints, is recommended. An international comparison of all these aspects should be required so as to clarify differences between countries about their use of physical restraints and the effectiveness of their restraint-reduction programmes. It is certainly possible that some countries might be in the lead in their attitudes towards the use of restraints (i.e., have 
more negative attitudes towards restraint use). In our opinion, analysing the (nursing) staff population, as well as the residents and their representatives, would appear to be an important first step in order to develop effective interventions for nursing home staff and residents.

Secondly, it is still imperative to educate (nursing) staff concerning the use of physical restraints and restraint-free care, in light of the established myths and assumptions on the use of restraints described in the literature. ${ }^{11,19}$ It is, therefore, recommended that nursing homes should educate their (nursing) staff about the ineffectiveness and consequences of restraint use, along with the urgent need to perform restraint-free and individualized care. In addition, including these topics in the basic education of nursing staff, physicians and the other health care providers would seem to be invaluable in establishing a foundation for the transition to restraint-free care in nursing homes. However, it should be emphasized that education alone is not a sufficient strategy for achieving restraint-free care. In our opinion, consultation is still an important addition to education as well, although this certainly requires another approach than the one used in this trial. Further research examining the most effective approach towards consultation is therefore recommended. In this respect, our suggestion would be to examine the effects of consultation performed by a multidisciplinary team. While in the process of changing practice, it appears important for the (nursing) staff to experience support from the different levels of the organization. However, further research is needed to confirm these assumptions.

Thirdly, interventions aimed at achieving restraint-free care should primarily focus on the individual resident instead of on the job characteristics of the nursing staff and the characteristics of the wards. Achieving restraint-free care should thus be possible within the existing organizational characteristics of the nursing home wards and nursing staff. The focus on the individual resident corresponds to client-oriented approaches in health care. Since the seventies, client-oriented care has become a well-known concept in nursing homes. ${ }^{20}$ Over the years nursing home care is being practiced more and more in conformity with this concept. ${ }^{21}$ However, in our opinion, client-oriented care (i.e., individualized care) has not yet been completely implemented in nursing homes, given the still common use of physical restraints in these settings. The fact is that restraint use is inconsistent with the approach to client-oriented care. ${ }^{15}$ It appears that nursing staff still control the behaviour of residents by using physical restraints instead of making sense of the residents' behaviour and fulfilling their unmet needs. Further research examining the barriers for implementing client-oriented care, as well as restraint-free care, is therefore highly recommended. In this respect, we would support the recommendations 
of Strumpf and colleagues ${ }^{15}$ that changes in practice only succeed when the nursing home organization and their (nursing) staff embrace a philosophy of restraint-free care, implement policies and procedures that support these changes in practice and educate all (nursing) staff in the techniques of individualized care.

Fourthly, the strong association between restraint use and impairment in mobility strengthens the importance of stimulating the mobilization of psychogeriatric nursing home residents. To this end, more involvement of physiotherapists and occupational therapists in the care of these residents may be useful. Furthermore, assessment and analysis of fall risk in psychogeriatric nursing home residents by a multidisciplinary team might be important in reducing the use of physical restraints.

Fifthly, the use of physical restraints for the prevention of falls and fallrelated injuries in nursing home residents should be strongly discouraged, given the results of several studies showing that the use of physical restraints is ineffective in preventing falls and fall-related injuries and, moreover, has several negative consequences.

Finally, it is important to note that achieving restraint-free care might also depend on the definition of physical restraints (i.e., inclusion and exclusion criteria for restraint types) used in research and in practice. Considering the broad definition of physical restraints used in this thesis, it is questionable whether all limitation on freedom of movement can be expelled completely from the care of psychogeriatric nursing home residents. It is possible that the use of some of the least restrictive types of restraints, such as sensor mats and infrared systems, will be inevitable in the care of psychogeriatric nursing home residents. Nevertheless, the use of these devices must also be kept to a minimum as much as possible. In this respect, it is therefore recommended that the opinions of residents, representatives and (nursing) staff towards the restrictiveness of the different types of restraints be examined. It would be very important, for example, to examine their opinions concerning the use of bedrails, the most common type of restraint. Such a classification should contribute to a better understanding of the process towards restraint-free care. Furthermore, investigating the determinants of each restraint type separately will also increase the understanding of restraint practices. The results of these studies can be used to initiate a more gradual process of change towards restraint-free care. Types of restraints considered as restrictive and undesirable may be the easiest to reduce. In this respect, removing first the most restrictive type of restraints - belts tied to a chair or bed - should be recommended. When belts are expelled from practice, one can continue with the reduction of the other types of restraints so as to finally achieve restraint-free care. 


\section{References}

1. Capezuti E, Wagner LM, Brush BL, Boltz M, Renz S, Talerico KA. Consequences of an intervention to reduce restrictive side rail use in nursing homes. J Am Geriatr Soc 2007; 55:334-341.

2. Hamers JPH, Gulpers MM, Strik W. Use of physical restraints with cognitively impaired nursing home residents. Journal of Advanced Nursing 2004;45(3):246-251.

3. Karlsson S, Bucht G, Eriksson S, Sandman PO. Physical restraints in geriatric care in Sweden: prevalence and patient characteristics. J Am Geriatr Soc 1996;44(1 1):1348-1354.

4. Karlsson S, Bucht G, Eriksson S, Sandman PO. Factors relating to the use of physical restraints in geriatric care settings. J Am Geriatr Soc 2001;49(12):1722-1728.

5. Sullivan-Marx EM, Strumpf NE, Evans LK, Baumgarten M, Maislin G. Predictors of continued physical restraint use in nursing home residents following restraint reduction efforts. J Am Geriatr Soc 1999;47(3):342-348.

6. Pekkarinen L, Elovainio $M$, Sinervo $T$, Finne-Soveri $H$, Noro A. Nursing working conditions in relation to restraint practices in long-term care units. Medical Care 2006;44(12):1 11 14-1 120.

7. Hantikainen V. Physical restraint: a descriptive study in Swiss nursing homes. Nursing Ethics 1998;5(4):330-346.

8. Castle NG, Fogel B, Mor V. Risk factors for physical restraint use in nursing homes: pre- and post-implementation of the nursing home reform act. Gerontologist 1997;37(6):737-747.

9. Phillips CD, Hawes C, Mor V, Fries BE, Morris JN, Nennstiel ME. Facility and area variation affecting the use of physical restraints in nursing homes. Medical Care 1996;34(11):114962.

10. Karlsson S, Bucht G, Sandman PO. Physical restraints in geriatric care. Knowledge, attitudes and use. Scand J Caring Sci 1998; 12(1):48-56.

11. Evans LK, Strumpf NE. Myths about elder restraint. Image J Nurs Sch 1990;22(2):124-8.

12. Evans $D$, Wood J, Lambert L. A review of physical restraint minimization in the acute and residential care settings. Journal of Advanced Nursing 2002;40(6):616-25.

13. Testad I, Aasland AM, Aarsland D. The effect of staff training on the use of restraint in dementia: a single-blind randomised controlled trial. Int J Geriatr Psychiatry 2005;20(6):58790.

14. Evans LK, Strumpf NE, Allen-Taylor SL, Capezuti E, Maislin G, Jacobsen B. A clinical trial to reduce restraints in nursing homes. J Am Geriatr Soc 1997;45(6):675-681.

15. Strumpf NE, Robinson JP, Wagner JS, Evans LK. Restraint-free care; Individualized approaches for frail elders. New York: Springer Publishing Company, Inc., 1998.

16. Grol R, Wensing M, Eccles M. Improving Patient Care. The implementation of change in clinical practice. London: Elsevier, 2005.

17. Murphy AW, Esterman A, Pilotto LS. Cluster randomized controlled trials in primary care: an introduction. European Journal of General Practice 2006;12:70-73.

18. Tannen A, Bours $G$, Halfens R, Dassen T. A comparison of pressure ulcer prevalence rates in nursing homes in the Netherlands and Germany, adjusted for population characteristics. 
Research in Nursing \& Health 2006;29:588-596.

19. Blakeslee JA, Goldman BD, Papougenis D, Torell CA. Making the transition to restraint-free care. J Gerontol Nurs 1991;17(2):4-8.

20. Van den Heuvel WJA. Het verpleegtehuis. Leven van huis uit. Nijmegen: Dekker \& van de Vegt, 1977.

21. Hamers JPH. De ouderenzorg verdient beter $(p<0.001)$. Maastricht: Universiteit Maastricht, 2005. 
General Introduction 


\section{Appendix}

| Observational tool |

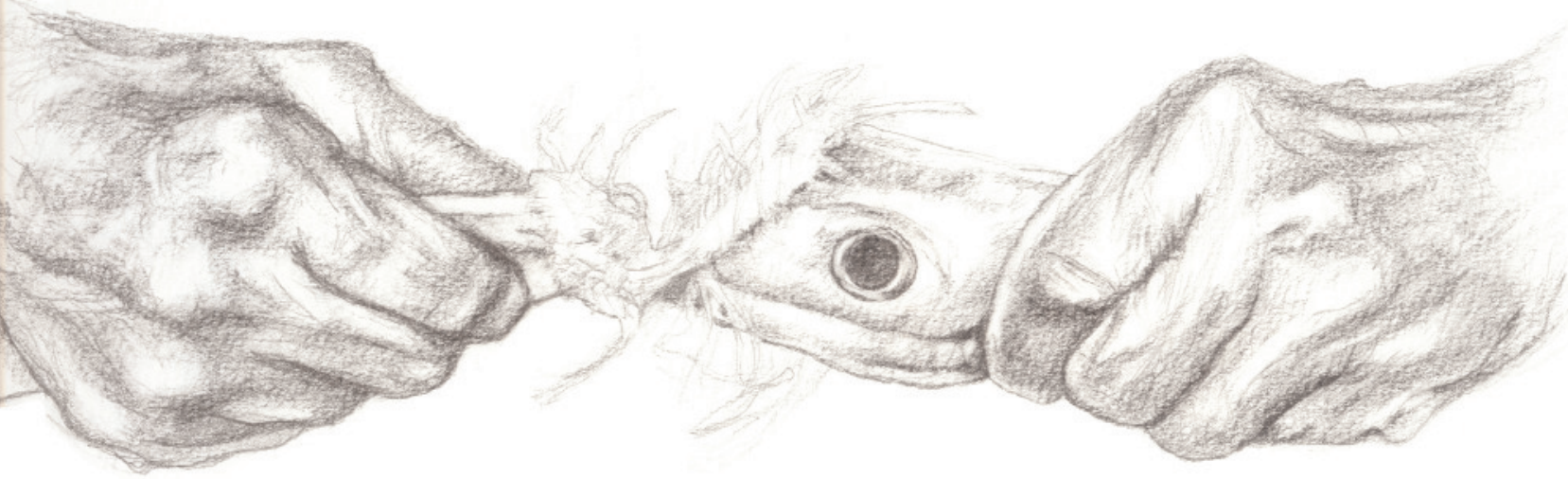


Appendix 


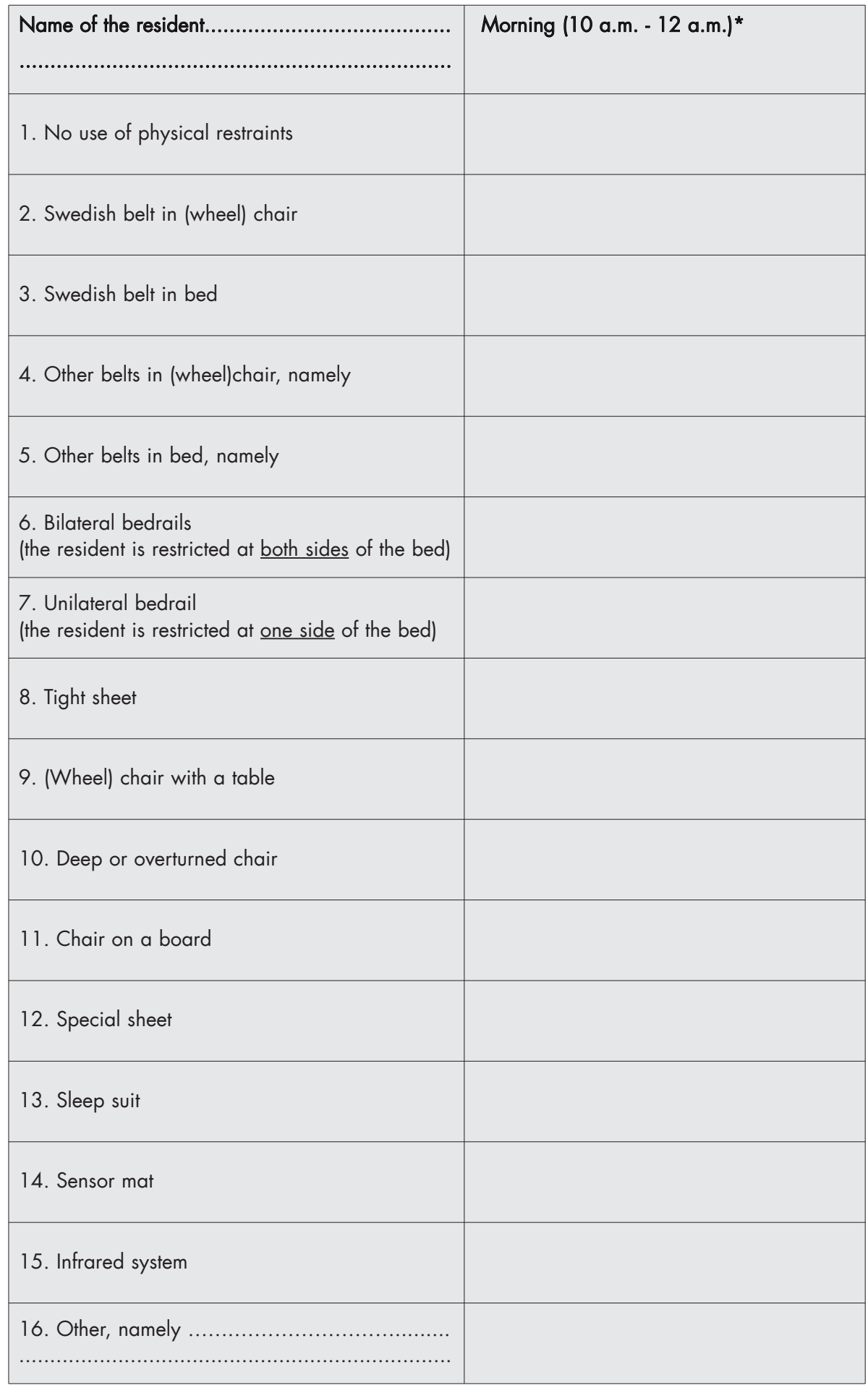

*Four versions of this observation tool were used: one for the morning, afternoon, evening and night 


\section{Summary}

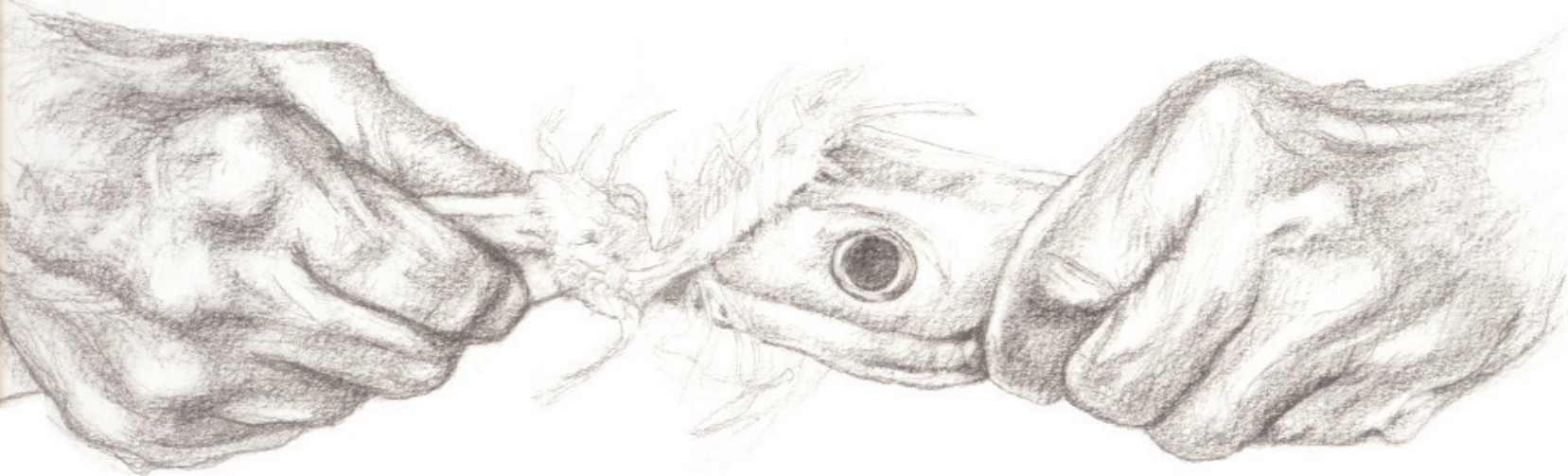


Summary 
The use of physical restraints is a common procedure in the care of psychogeriatric nursing home residents. In view of the ineffectiveness and negative consequences of restraint use, several studies have shown a need for restraint-free care in nursing homes. Insight into the determinants for restraint use is necessary to engage the discussion concerning restraint use in nursing homes and to improve programmes for restraint reduction. In the literature, several residents' characteristics are associated with the use of physical restraints with psychogeriatric nursing home residents. However, consistent associations with organizational characteristics (i.e., job and ward characteristics) have not been found. Furthermore, the number of randomized clinical trials (RCT) investigating the effectiveness of restraint reduction programmes has been limited. The primary aim of this thesis is, therefore, to contribute to restraint-free care in psychogeriatric nursing home residents by answering the following three research questions:

- What is the current knowledge of the use of physical restraints on elderly people?

- What is the relationship between organizational characteristics (i.e., job and ward characteristics) and the use of physical restraints on psychogeriatric nursing home residents?

- What is the effectiveness of an educational intervention aimed at achieving restraint-free care for psychogeriatric nursing home residents?

Chapter 1 is a general introduction to the research. This chapter begins with a brief introduction to nursing home care in the Netherlands, followed by information about the use of physical restraints on psychogeriatric nursing home residents. Next, information about restraint-free care, including the development of the educational intervention, is presented. Finally, the outline of the thesis is given.

Chapter 2 presents a literature review on the use of physical restraints on elderly people. The prevalence, reasons, predictors, effectiveness and consequences of the use of physical restraints are discussed by summarizing the current knowledge about the use of restraints in nursing homes, hospitals and home care. In this chapter it is stressed that the use of physical restraints on elderly people has adverse effects and negative consequences. Furthermore, there is a growing evidence that physical restraints are not adequate measures for preventing falls and fall-related injuries. As a result of these adverse effects and the growing evidence that physical restraints are not adequate measures for the prevention of falls, we discuss the possible measures for the reduction of physical restraints and make recommendations for future research.

Chapter 3 reports on a cross-sectional study examining the relationship between the use of physical restraints with psychogeriatric nursing home 
residents and organizational characteristics (i.e., perceived job characteristics of nursing staff and characteristics of nursing home wards). In this study, it was hypothesized that impairments in residents and organizational characteristics, such as a high workload of nursing staff and a low full-time equivalent (FTE) ratio on the wards, would be associated with increased restraint use. In the study, involving 15 Dutch nursing home wards, 432 psychogeriatric nursing home residents were selected for participation, of which 371 actually participated after giving informed consent. Restraint status was measured using observations. Self-reported measures for the job characteristics (e.g., workload) were completed by 193 of the 306 nursing staff. Ward characteristics (e.g., full-time equivalent (FTE) ratio) were collected using the registration systems of the wards. The results showed that a high workload and a low social support experienced by the nursing staff, as well as a low percentage of registered nurses and a high rate of sickness absence on the wards, were not associated with an increased use of physical restraints. On the contrary, an increased use of physical restraints proved to be associated with a higher job autonomy experienced by nursing staff and a higher FTE ratio on the wards. The use of physical restraints was strongly associated with residents' characteristics, of which impairment in mobility was shown to be the most important determinant.

Chapter 4, Chapter 5 and Chapter 6 report on an evaluation of the effectiveness of the educational intervention. In a cluster-randomized trial, applied to fifteen psychogeriatric nursing home wards, the effectiveness of the educational intervention on reducing and preventing restraint use was evaluated. The educational intervention was therefore compared with usual care. Data were collected at baseline and then at one, four and eight months post-intervention. At each measurement, the use of physical restraints was measured using observations by blinded, trained observers on four separate occasions over a 24-hour period.

In Chapter 4 presents a study investigating the short-term effects of this educational intervention on the use of physical restraints on psychogeriatric nursing home residents. Data from five psychogeriatric nursing home wards were used to measure the effectiveness of the educational intervention on restraint reduction at one month post-intervention. The predominant finding of this study was that the educational intervention did not decrease the use of physical restraints in the short term. However, the study did show that residents in the control group experienced more restraint use during the study period as compared with residents in the experimental group. The educational intervention did seem, therefore, to protect psychogeriatric nursing home residents from an increased use of physical restraints in the short term.

Chapter 5 reports on a study investigating the effectiveness of the educational intervention in reducing the use of physical restraints at one, four and eight months post-intervention. Data were obtained in a clusterrandomized trial involving fifteen Dutch psychogeriatric nursing home wards, 
totalling 432 psychogeriatric nursing home residents. A total of 241 residents, who were involved in all four measurements, were included in the analyses. Logistic and linear regression analyses showed no treatment effect on restraint status, restraint intensity and multiple restraint use in any of the three measurements post-intervention. Only minor changes occurred in terms of the types of restraints used with residents in the experimental group. The results of this study showed that an educational programme for nurses, combined with the consultation of a nurse specialist, was not effective in reducing the use of physical restraints with psychogeriatric nursing home residents. In addition to restraint education and consultation, new measures to reduce the use of physical restraints with psychogeriatric nursing home residents will then need to be developed.

Chapter 6 describes the effectiveness of the educational intervention in preventing the use of physical restraints with residents newly admitted to psychogeriatric nursing home wards. A total of 138 residents admitted to 14 psychogeriatric nursing home wards after baseline measurement of the trial were selected, out of which 105 residents were included in the analyses. The data were collected at one, four and eight months post-intervention. This study showed that the educational intervention was not effective in preventing the use of physical restraints on residents newly admitted to psychogeriatric nursing home wards. During the study period, no statistically significant differences between the experimental group and the control group regarding restraint status, restraint intensity, multiple restraints and types of restraints were found. These results further strengthen the need for the development of new or additional interventions to prevent restraint use.

Chapter 7 is a general discussion of the studies presented in this thesis. A summary of the main conclusions of these studies are presented in this chapter. In addition, some theoretical and methodological reflections are discussed here. The chapter ends with the implications of the thesis both for practice and for further research. 


\section{Samenvatting}

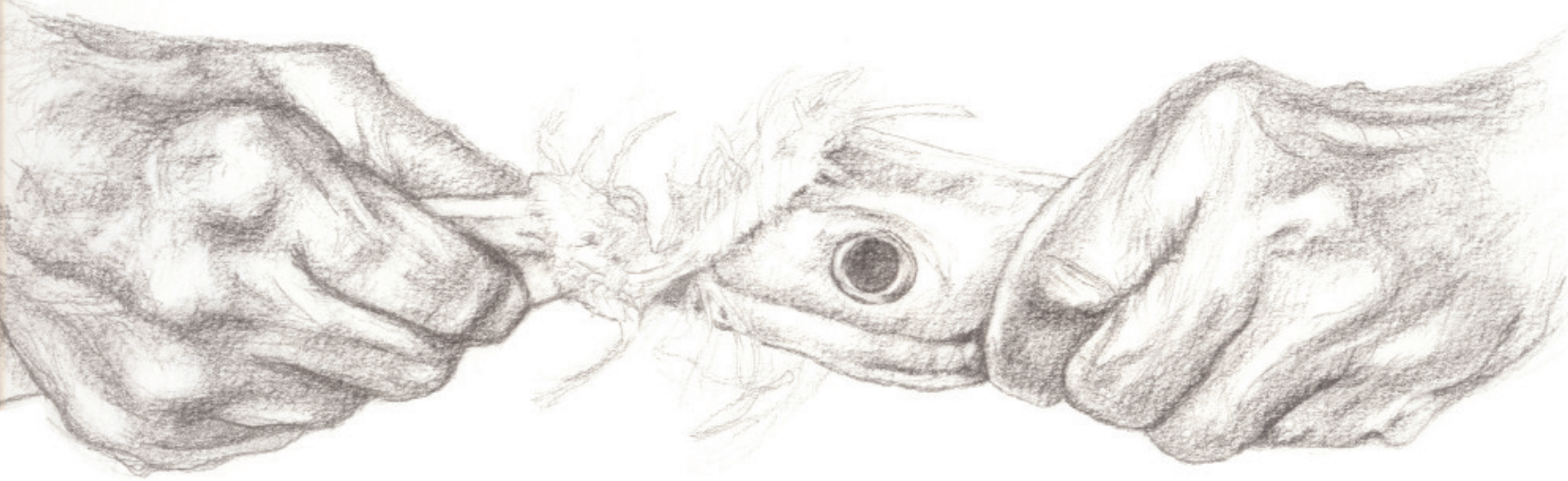


Samenvatting 
In de zorg voor psychogeriatrische verpleeghuisbewoners is vaak sprake van beperking van de bewegingsvrijheid van de bewoners. Dit blijkt echter ineffectief te zijn en brengt ook negatieve consequenties met zich mee. Daarom is de noodzaak tot verpleeghuiszorg zonder vrijheidsbeperking hoog. In de (inter)nationale literatuur is het ook een veelbesproken onderwerp. Inzicht in de determinanten van vrijheidsbeperking is vereist om de discussies over het toepassen van vrijheidsbeperking in verpleeghuizen te ondersteunen. Tevens kunnen programma's die zijn gericht op het verminderen van vrijheidsbeperking hierdoor worden verbeterd. In de literatuur zijn verschillende kenmerken van bewoners in verband gebracht met het toepassen van vrijheidsbeperking bij psychogeriatrische verpleeghuisbewoners. Echter, duidelijke relaties met organisatorische kenmerken (werk- en afdelingskenmerken) zijn niet gevonden. Verder zijn er maar een beperkt aantal gerandomiseerde experimenten bekend over de effectiviteit van programma's die zich richten op het verminderen van vrijheidsbeperking. Het hoofddoel van dit proefschrift is daarom het leveren van een bijdrage aan een zorgverlening zonder vrijheidsbeperking dan wel een "vrijheidsbeperkingarme" zorg voor psychogeriatrische verpleeghuisbewoners. Hiervoor zijn de volgende drie onderzoeksvragen beantwoord:

- Wat is de huidige kennis over het toepassen van vrijheidsbeperking bij psychogeriatrische verpleeghuisbewoners?

- Wat is de relatie tussen organisatorische kenmerken (werk- en afdelingskenmerken) en het gebruik van vrijheidsbeperking bij psychogeriatrische verpleeghuisbewoners?

- Wat is de effectiviteit van een educatieve interventie gericht op het bereiken van een "vrijheidsbeperking-arme" zorg voor psychogeriatrische verpleeghuisbewoners?

Hoofdstuk 1 betreft de algemene introductie van het onderzoek. Dit hoofdstuk begint met een korte inleiding over verpleeghuiszorg in Nederland, gevolgd door informatie over de toepassing van vrijheidbeperking bij psychogeriatrische verpleeghuisbewoners. Daarna wordt ingegaan op "vrijheidsbeperking-arme" zorg, waarbii de ontwikkeling van de educatieve interventie ook aan bod komt. Ten slotte wordt een kort overzicht van het proefschrift gegeven.

Hoofdstuk 2 rapporteert over een literatuurstudie naar het toepassen van vrijheidsbeperking bij ouderen. De prevalentie, redenen, voorspellers, effectiviteit en consequenties van het toepassen van vrijheidsbeperking worden besproken. Hiervoor is de bestaande kennis over het toepassen van vrijheidsbeperking in verpleeghuizen, ziekenhuizen en de thuiszorg 
samengevat. In dit hoofdstuk wordt benadrukt dat het toepassen van vrijheidsbeperking bij ouderen nadelige effecten en negatieve consequenties heeft. Daarnaast zijn er steeds meer aanwijzingen dat vrijheidsbeperking geen goede methode is om vallen en valgerelateerde verwondingen te voorkomen. In de literatuurstudie zijn ook mogelijke maatregelen besproken om vrijheidsbeperking te kunnen verminderen en worden aanbevelingen gedaan voor toekomstig onderzoek.

In hoofdstuk 3 worden de resultaten gepresenteerd van een cross-sectioneel onderzoek naar de relatie tussen het toepassen van vrijheidsbeperking bij psychogeriatrische verpleeghuisbewoners en organisatorische kenmerken. Onder organisatorische kenmerken worden verstaan de werkkenmerken van het verzorgend personeel en de kenmerken van de verpleeghuisafdelingen. In het onderzoek werd voorondersteld dat beperkingen bij bewoners en organisatorische kenmerken, zoals een hoge werkdruk bij het verzorgend personeel en een lage fulltime equivalent (FTE) ratio op de afdeling, zouden leiden tot een toename in de toepassing van vrijheidsbeperking. In het onderzoek, waarbij 15 Nederlandse verpleeghuisafdelingen betrokken waren, werden 432 psychogeriatrische verpleeghuisbewoners geselecteerd voor deelname, waarvan 371 daadwerkelijk hebben deelgenomen na het geven van geïnformeerde toestemming. Er werden observaties vitgevoerd om vrijheidsbeperking in kaart te brengen. De schriftelijke vragenlijsten over de werkkenmerken (bijvoorbeeld werkdruk) werden ingevuld door 193 van de 306 verzorgende personeelsleden. De gegevens over de afdelingskenmerken (bijvoorbeeld FTE ratio) zijn verzameld met behulp van het registratie systeem van de afdelingen. De resultaten van het onderzoek laten zien dat een hoge werkdruk, een laag ervaren sociale steun (door het verzorgend personeel), een laag percentage verpleegkundigen en een hoog ziekteverzuim op de afdeling, geen van alle leiden tot een toename in de toepassing van vrijheidsbeperking. Anderzijds lijken een hogere mate van autonomie in het werk en een hogere FTE ratio op de afdelingen juist wel te leiden tot meer vrijheidsbeperking. Bewonerskenmerken, waarbii beperkingen in de mobiliteit als meest belangrijke determinant naar voren kwam, zijn sterk bepalend voor vrijheidsbeperking.

Hoofdstuk 4, Hoofdstuk 5 en Hoofdstuk 6 rapporteren over de effectevaluatie van de educatieve interventie. In een cluster gerandomiseerd experiment, uitgevoerd op 15 psychogeriatrische verpleeghuisafdelingen, is de effectiviteit geëvalueerd van de educatieve interventie op het reduceren en voorkómen van vrijheidsbeperking. De educatieve interventie werd hiervoor vergeleken met de gebruikelijke zorg. Data zijn verzameld tijdens de nulmeting en één, vier en acht maanden na afloop van de interventie. Tijdens elke 
meetperiode is de toepassing van vrijheidsbeperking in kaart gebracht aan de hand van observaties uitgevoerd door 'geblindeerde', getrainde observatoren tijdens vier verschillende momenten gedurende een 24-uurs periode.

Hoofdstuk 4 beschrijft een onderzoek naar de korte termijn effecten van de educatieve interventie op het toepassen van vrijheidsbeperking bij psychogeriatrische verpleeghuisbewoners. Data van 5 psychogeriatrische verpleeghuisafdelingen zijn gebruikt om de effecten op het verminderen van het gebruik van vrijheidsbeperkende maatregelen in kaart te brengen één maand na afloop van de interventie. Het belangrijkste resultaat van dit onderzoek was dat de educatieve interventie op korte termijn niet leidde tot een afname in de toepassing van vrijheidsbeperking. Echter, het onderzoek liet ook zien dat vrijheidsbeperking gedurende de onderzoeksperiode meer werd toegepast bij bewoners in de controle groep dan bij bewoners in de experimentele groep. Voor de kortere termijn lijkt de educatieve interventie psychogeriatrische verpleeghuisbewoners dus te beschermen tegen een toename in de vrijheidsbeperking

Hoofdstuk 5 rapporteert over een onderzoek naar de effectiviteit van de educatieve interventie in het reduceren van vrijheidsbeperking na één, vier en acht maanden na afloop van de interventie. Data zijn verkregen uit een cluster gerandomiseerd experiment vitgevoerd op 15 Nederlandse psychogeriatrische verpleeghuisafdelingen, met in total 432 psychogeriatrische verpleeghuisbewoners. In totaal 241 bewoners, die deelnamen aan alle vier de meetperiodes, werden meegenomen in de analyses. Logistische en lineaire regressie analyses lieten tijdens geen van de drie nametingen een interventie effect zien op het wel/niet toepassen van vrijheidsbeperking, op de intensiteit ervan en op het gebruik van meerdere vrijheidsbeperkende maatregelen tegelijkertijd. Er vonden alleen kleine veranderingen plaats in soorten van vrijheidsbeperkende maatregelen die werden toegepast in de experimentele groep. De resultaten van dit onderzoek laten zien dat een scholingsprogramma voor het verzorgend personeel, gecombineerd met consultatie uitgevoerd door een gespecialiseerde verpleegkundige, niet effectief is in het reduceren van vrijheidsbeperking bii psychogeriatrische verpleeghuisbewoners. Het is van groot belang dat nieuwe interventies worden ontwikkeld, in aanvulling op scholing en consultatie, om vrijheidsbeperking bij psychogeriatrische verpleeghuisbewoners te verminderen.

Hoofdstuk 6 beschrijft de effectiviteit van de educatieve interventie op het voorkómen van vrijheidsbeperking bij bewoners die nieuw zijn opgenomen op de psychogeriatrische verpleeghuisafdelingen. In totaal werden 138 bewoners geselecteerd die na de nulmeting van het experiment zijn opgenomen op 14 psychogeriatrische verpleeghuisafdelingen. Hiervan werden 105 bewoners 
meegenomen in de analyses. De data werden verzameld op één, vier en acht maanden na afloop van de interventie. Het onderzoek toonde aan dat de educatieve interventie niet effectief was in het voorkómen van vrijheidsbeperking bij bewoners die nieuw opgenomen zijn op de psychogeriatrische verpleeghuisafdelingen. Tijdens de onderzoeksperiode werden geen significante verschillen gevonden tussen de experimentele en de controle groep met betrekking tot het wel/niet toepassen van vrijheidsbeperking, de intensiteit ervan, het gebruik van meerdere vrijheidsbeperkende maatregelen tegelijkertijd en de soorten van vrijheidsbeperkende maatregelen. Deze resultaten versterken de noodzaak nieuwe of aanvullende interventies te ontwikkelen om het gebruik van vrijheidsbeperking tegen te gaan.

Hoofdstuk 7 betreft de algemene discussie over de onderzoeken die zijn gepresenteerd in dit proefschrift. Een samenvatting van de belangrijkste conclusies van deze onderzoeken zijn ook weergegeven in dit hoofdstuk. Daarnaast zijn een aantal theoretische en methodologische reflecties beschreven. Het hoofdstuk eindigt met de implicaties van dit proefschrift voor de praktijk en voor toekomstig onderzoek. 
144 


\section{Dankwoord}

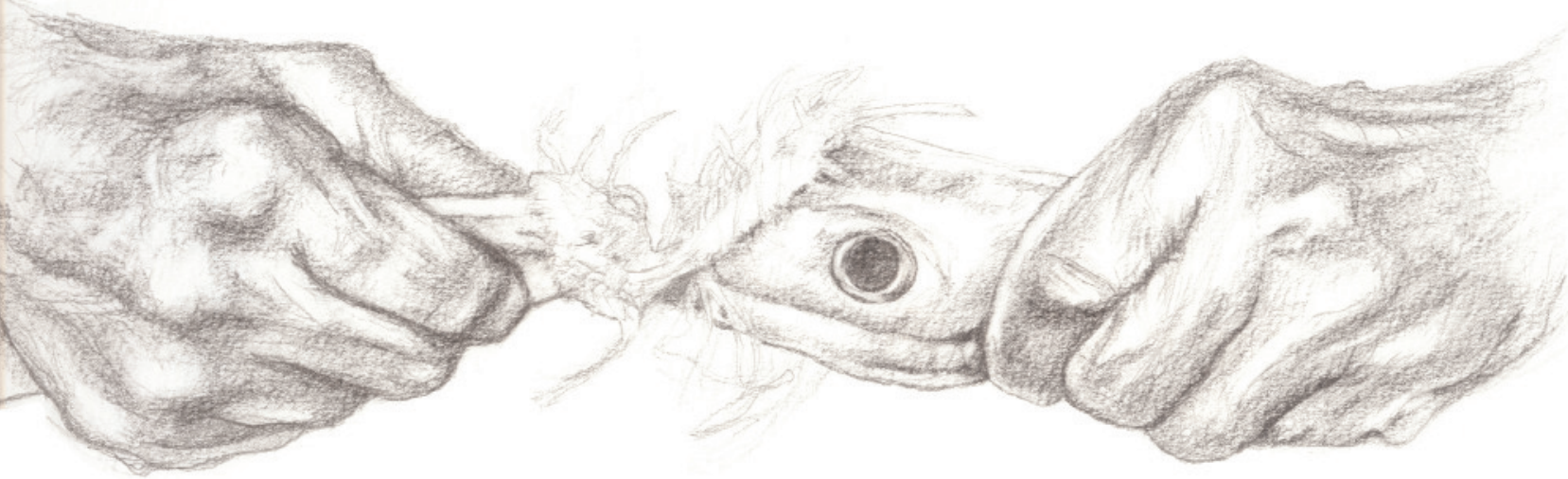


Dankwoord

146 
Dit proefschrift was nooit tot stand gekomen zonder de inzet, betrokkenheid en ondersteuning van vele mensen. Ik wil daarom graag iedereen die hieraan heeft bijgedragen hartelijk bedanken! Een aantal mensen wil ik in het bijzonder noemen.

Allereerst wil ik de bewoners en hun vertegenwoordigers van de psychogeriatrische verpleegafdelingen van MeanderGroep Zuid-Limburg hartelijk bedanken voor hun medewerking aan het onderzoek. Ik heb het bijzonder gewaardeerd dat zoveel mensen ondanks de situatie van henzelf of hun naasten bereid waren om aan het onderzoek deel te nemen. Ook gaat een speciaal woord van dank uit naar het personeel van de MeanderGroep ZuidLimburg. Ondanks hun drukke werkzaamheden in de zorg, was het personeel te allen tijde bereid om de tijdrovende en intensieve activiteiten rondom het onderzoek vit te voeren. Dit heb ik zeer gewaardeerd. Alleen dankzij deze medewerking en inspanningen is het mogelijk geweest het onderzoek vit te voeren. Ontzettend bedankt!

Mijn promotoren Jan Hamers en Martijn Berger wil ik hartelijk bedanken voor het begeleiden en ondersteunen van het promotietraject. Jan, bedankt voor de mogelijkheid die jii me hebt geboden om dit promotietraject in te gaan en af te ronden. Zonder jouw vertrouwen was dit zeker niet gelukt. Martijn, bedankt voor de begeleiding bij het analyseren van de onderzoeksgegevens en je kritische blik op het onderzoek en het proefschrift. Daarnaast wil ik ook de andere co-auteurs op de artikelen bedanken voor hun bijdragen: Jan de Jonge, Math Candel en Math Gulpers. Bedankt voor de prettige en productieve samenwerking.

De Werkgroep Zorgonderzoek Meander (MeanderGroep Zuid-Limburg) speelt al vanaf het eerste begin een cruciale rol in het onderzoek. Ik wil dan ook alle (oud-) leden van deze werkgroep hartelijk bedanken voor hun inzet en inspanningen in het kader van dit onderzoek. Het congres 'Losbandige zorg' was een hele mooie afsluiting van het onderzoeksproject dat dankzij de werkgroep zeer succesvol is verlopen. In het bijzonder wil ik Ine Smeets (verpleegkundige verpleeghuis Lückerheide) en Math Gulpers (directeur verpleeghuis Lückerheide) bedanken voor alles dat zij voor het onderzoek hebben betekend. Ine, als 'nurse specialist' had iii een centrale rol in het onderzoek. Jouw enthousiasme en organisatievaardigheden hebben een enorme positieve bijdrage aan het onderzoek geleverd. Ik heb het altijd erg gezellig gevonden om met je samen te werken! Ook Math Gulpers wil ik in het bijzonder bedanken voor zijn inspanningen betreffende de organisatie en 
vitvoering van het onderzoek binnen de MeanderGroep Zuid-Limburg. Bedankt voor de fijne samenwerking!

De leden van de beoordelingscommissie wil ik bedanken voor hun bereidheid deel te nemen in de commissie, het concept proefschrift te lezen en van commentaar te voorzien.

Alle collega's van de vakgroep Verplegingswetenschap (Universiteit Maastricht) wil ik hartelijk bedanken voor de ondersteuning, de kritische reflecties en natuurlijk de gezelligheid. Een aantal collega's wil ik hierbij in het bijzonder noemen. Pascalle en Marian, jullie waren de beste kamergenoten die ik me maar had kunnen wensen: veel geduld, veel antwoorden (op 'kleine' en 'stomme' vragen), veel adviezen (op allerlei gebieden) en super gezellig! Pascalle, met veel plezier hebben we altiid alles rondom onze onderzoeken en andere belangrijke zaken in het leven gedeeld. Ik ben erg blij dat we ondanks de verhuizing naar Zweden via de telefoon, mail en skype gewoon kunnen doorpraten. Met jou als paranimf weet ik zeker dat het een hele mooie dag wordt. Marian, al vele jaren maak ik volop gebruik van jouw wijze raad! Door de jaren heen heb ik enorm veel van jou geleerd en dankzij jou heb ik mij wegwijs kunnen maken in de onderzoekswereld. Ook ben ik erg blij dat ik een echte Maaskant aan de muur heb hangen. Sandra en Monique, met veel plezier kijk ik terug op alle (EANS) reizen die we samen hebben gemaakt. Ook jullie wil ik bedanken voor alle morele steun en gezelligheid. Arnold, bedankt voor alle vliegensvlugge computerondersteuning. En daarnaast wil ik natuurlijk ook Hilde, Sandrien en alle andere collega's bedanken voor de gezellige tijd op de afdeling!

Dank ook aan alle studentassistenten en onderzoeksassistenten die hebben bijgedragen aan het onderzoek en het proefschrift. Ook alle studenten die voor hun afstudeeronderzoek bij het project betrokken waren, wil ik hierbij hartelijk bedanken voor hun inzet. In het bijzonder wil ik Titia Rietema, die voor langere tijd als studentassistent bij het project betrokken is geweest, bedanken voor haar werkzaamheden en haar zeer enthousiaste inzet voor het onderzoek.

Tot slot wil ik ook graag mijn familie en vrienden hartelijk bedanken voor hun belangstelling en ondersteuning tijdens het gehele promotietraject. Frederika wil ik bedanken voor het maken van de prachtige tekening voor de kaft van het proefschrift. Lieve pap en mam, ik wil jullie ontzettend bedanken voor alle kansen en mogelijkheden die jullie mij op allerlei gebieden hebben geboden. Jullie onvoorwaardelijke steun in alles is geweldig en een voorbeeld! Lieve 
Olga, ik ben super trots dat iij mijn paranimf wilt zijn. Met jouw snelheid, organisatietalent en doortastendheid ben ik in goede handen! Lieve Remco, ontzettend bedankt voor alle steun die iij mij hebt gegeven gedurende de afgelopen jaren! Jouw rust en vertrouwen zijn van cruciaal belang in alles wat $i k$ doe. Ik vind het heel speciaal om samen met jou onze promotietrajecten af te ronden op 14 maart 2008. En met ons eerste kindje, wonend in Zweden zijn we samen alweer aan een nieuw avontuur begonnen! 


\section{Curriculum Vitae}

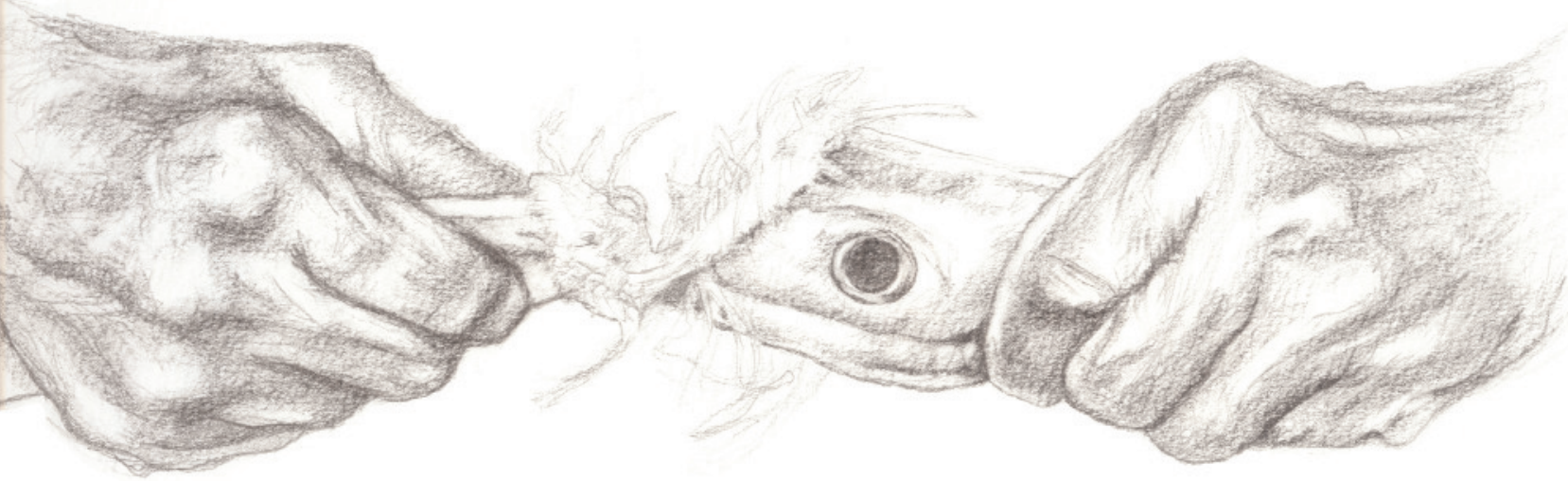


Curriculum Vitae 
Anna Huizing was born on April 25, 1978 in Stadskanaal, the Netherlands. After completing the school of higher secondary education (HAVO) at the Dr. Nassau College in Assen in 1995, she started to study nursing (Hbo-V) at the Hanzehogeschool in Groningen. In 1999 she obtained a bachelor degree in nursing. From 1999 she studied Health Sciences, specialisation Health Care Studies, at Maastricht University, where she obtained a master degree in 2001. In 2001 she started working as a researcher at Maastricht University, Department of Health Care Studies, Section of Nursing Science on the project 'The need for health care from the perspective of people with intellectual disability'. Since 2002 she has been working as a PhD-student at the Section of Nursing Science of Maastricht University on the project 'Physical restraints with psychogeriatric nursing home residents'. 
